\title{
How Inert, Perturbing, or Interacting Are Cryogenic Matrices? A Combined Spectroscopic (Infrared, Electronic, and X-ray Absorption) and DFT Investigation of Matrix-Isolated Iron, Cobalt, Nickel, and Zinc Dibromides
}

\author{
Published as part of The Journal of Physical Chemistry virtual special issue "W. Lester S. Andrews Festschrift".
} Owen M. Wilkin, ${ }^{\dagger}$ Neil Harris, ${ }^{\dagger}$ John F. Rooms, $^{\dagger}$ Emma L. Dixon, ${ }^{\dagger}$ Adam J. Bridgeman, ${ }^{\ddagger}$ and Nigel A. Young ${ }^{*} \dagger \circ$

${ }^{\dagger}$ Department of Chemistry, The University of Hull, Kingston upon Hull HU6 7RX, U.K.

${ }^{\star}$ School of Chemistry, The University of Sydney, Sydney, NSW 2006, Australia

ABSTRACT: The interactions of $\mathrm{FeBr}_{2}, \mathrm{CoBr}_{2}, \mathrm{NiBr}_{2}$, and $\mathrm{ZnBr}_{2}$ with $\mathrm{Ne}, \mathrm{Ar}, \mathrm{Kr}$, $\mathrm{Xe}, \mathrm{CH}_{4}$, and $\mathrm{N}_{2}$ matrices have been investigated using IR, electronic absorption, and X-ray absorption spectroscopies as well as DFT calculations. $\mathrm{ZnBr}_{2}$ is linear in all of the matrices. $\mathrm{NiBr}_{2}$ is linear in all but $\mathrm{N}_{2}$ matrices, where it is severely bent. For $\mathrm{FeBr}_{2}$ and $\mathrm{CoBr}_{2}$ there is a more gradual change, with evidence of nonlinearity in $\mathrm{Xe}$ and $\mathrm{CH}_{4}$ matrices as well as $\mathrm{N}_{2}$. In the $\mathrm{N}_{2}$ matrices, the presence of $\nu_{\mathrm{NN}}$ modes blue-shifted from the "free" $\mathrm{N}_{2}$ values indicates the presence of physisorbed species, and the magnitude of the blue shift correlates with the shift in the $\nu_{3}$ mode

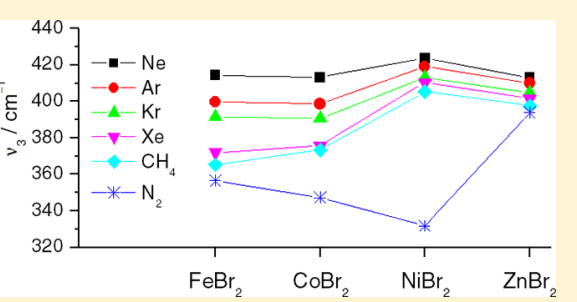
of the metal dibromide. In the case of $\mathrm{NiCl}_{2}$ and $\mathrm{NiBr}_{2}$, chemisorbed species are formed after photolysis, but only if deposition takes place below $10 \mathrm{~K}$. There was no evidence for chemisorbed species for $\mathrm{NiF}_{2}$ and $\mathrm{FeBr}_{2}$, and in the case of CoBr $\mathrm{C}_{2}$ the evidence was not strong.

\section{INTRODUCTION}

While the notion that the spectroscopic data obtained from species trapped in (noble) gas matrices are always directly comparable to those for their vapor-phase counterparts has been acknowledged as naive, the need to identify and understand how matrices can affect the geometric and electronic structures of the trapped species remains. The matrix isolation literature is replete with asides and comments about site effects, matrix splittings, etc., usually invoked to explain some spectral artifact. For example PdCO is found in two sites in $\mathrm{Ar}^{1}{ }^{1}$ as are $\mathrm{CO}_{2}{ }^{2}$ and $\mathrm{SiH}_{4} \cdot{ }^{3-6}$ In the case of PdCO, more recent calculations indicate the possible formation of $\mathrm{Ar}-\mathrm{PdCO}{ }^{7}$ However, in the related $\mathrm{NiCO}$ case, the computational work ${ }^{8,9}$ indicated the possible presence of $\mathrm{Ar}-\mathrm{NiCO}$, but the experimentalists disputed this. ${ }^{10,11}$ The ability of "inert" matrices to affect the structure of the trapped species has been demonstrated by Beattie and co-workers for both actinide tetrahalides and hexafluorometalates. $\mathrm{ThCl}_{4}$ and $\mathrm{UCl}_{4}$ are tetrahedral in neon but have a distorted $C_{2 v}$ geometry in argon. ${ }^{12,13}$ The alkali metal hexafluorouranates are $C_{3 v}$ in solid argon but $C_{2 v}$ in nitrogen matrices. ${ }^{14}$ The alkali metal hexafluoroniobates ${ }^{15}$ have tridentate coordination in neon and argon matrices but a bidentate coordination mode in nitrogen and carbon monoxide matrices. Using $\mathrm{CsClO}_{4}$ as a probe molecule, they showed that the order of host-guest interaction with the matrix was $\mathrm{Ne}<\mathrm{Ar}<\mathrm{O}_{2} \approx \mathrm{F}_{2}<$ $\mathrm{Kr}<\mathrm{Xe}<\mathrm{N}_{2}<\mathrm{CO}^{15} \mathrm{NiCl}_{2}$ is bent in nitrogen matrices but linear in argon matrices, ${ }^{16,17}$ as is $\mathrm{CoCl}_{2} \cdot{ }^{17} \mathrm{SiH}_{4}$ adopts a $D_{2 d}$ geometry in argon but is $C_{3 v}$ in $\mathrm{N}_{2},{ }^{4-6}$ and $\mathrm{GeH}_{4}$ is also $C_{3 v}$ in $\mathrm{N}_{2}$,
The absorption and excitation spectra of $\mathrm{Mn}$ atoms have been used to identify the different sites in which the Mn is trapped in $\mathrm{Ar}, \mathrm{Kr}$, and $\mathrm{Xe}$ matrices. ${ }^{18}$ Fausto and co-workers have demonstrated how the choice of argon or xenon matrices can be used to control the photochemistry of 4-methoxybenzaldehyde. $^{19}$ Kofranek et al. ${ }^{20}$ have carried out calculations on 1,3-butadiene embedded in an $\mathrm{Ar}_{254}$ matrix, which confirmed that the argon matrix stabilizes the s-cis structure over the normally more stable gauche conformation.

It has normally been assumed that these matrix effects are due to different interactions between the trapped guest and the host rather than specific bond formation. However, there are a number of reports of noble gas $(\mathrm{Ng})$ compound formation in matrices. Räsänen and co-workers ${ }^{21-24}$ have beautifully demonstrated the formation of HArF when HF is photolyzed in argon. Their work also includes a wide range of other $\mathrm{Kr}$ and $\mathrm{Xe}$ compounds. ${ }^{24}$ Perutz and co-workers showed that photolysis of matrix-isolated metal hexacarbonyls yielded metal pentacarbonyls with IR and UV-vis spectra that were dependent on the matrix material, indicating that the vacant site was occupied by a matrix atom with a weak metal-matrix bond, implying the formation of $\mathrm{M}(\mathrm{CO})_{5} \mathrm{Ng}$ complexes. ${ }^{25-27}$ This work is often overlooked as one of the first reports of metal-noble gas bonding interactions. Later gas-phase measurements on $\mathrm{M}(\mathrm{CO})_{5} \mathrm{Xe}$

Received: October 8, 2017

Revised: December 22, 2017

Published: December 28, 2017 
indicated $\mathrm{M}-\mathrm{Xe}$ binding energies of ca. $38 \mathrm{~kJ} \mathrm{~mol}^{-1}$ for $\mathrm{Cr}$ and ca. $33-34 \mathrm{~kJ} \mathrm{~mol}^{-1}$ for Mo and $\mathrm{W}^{28}$ The work on noble gas complexes in solutions and supercritical fluids has been reviewed. ${ }^{29}$

Thompson and Andrews ${ }^{30}$ showed that Be atoms can interact with argon matrices to form $\mathrm{ArBeO}$, and more recently, Wang and Wang ${ }^{31}$ extended this to include $\mathrm{NgBeS}(\mathrm{Ng}=\mathrm{Ne}$, $\mathrm{Ar}, \mathrm{Kr}, \mathrm{Xe}$ ) complexes. Andrews and co-workers also carried out detailed studies of the interactions of noble gases with $\mathrm{CUO},{ }^{32-39} \mathrm{UO}_{2},{ }^{40,41} \mathrm{UO}_{2}{ }^{+42}$ and $\mathrm{H}_{2} \mathrm{UO}_{2}{ }^{43}$ On the basis of IR spectra showing stepwise addition of the noble gases and detailed calculations, there is evidence for the formation of $\mathrm{CUO}(\mathrm{Ng})_{4}$ and $\mathrm{UO}_{2}(\mathrm{Ng})_{4}$ complexes with $\mathrm{U}-\mathrm{Ar}$ distances of ca. $3.2 \AA$ and weak binding energies of ca. $17 \mathrm{~kJ} \mathrm{~mol}^{-1}$ per $\mathrm{U}-\mathrm{Ar}$ bond. In contrast, $\mathrm{UO}_{2}^{+}$binds to five argon atoms with about twice the binding energy as for $\mathrm{CUO}(\mathrm{Ng})_{4}$ and $\mathrm{UO}_{2}(\mathrm{Ng})_{4}$. There is also evidence for an $(\mathrm{Ar})_{n}\left(\mathrm{Th}\left(\mathrm{C}_{2} \mathrm{H}_{2}\right)\right)$ complex. ${ }^{44}$ More recently, Andrews and Riedel observed $\mathrm{Ar}-\mathrm{AuF}$ and $\mathrm{Ne}-\mathrm{AuF}$ compounds, but the interactions were much weaker with $\mathrm{CuF}$ and AgF. $^{45,46}$

A series of experiments by Zhou and co-workers using a combination of IR experimental data and density functional theory (DFT) calculations has indicated the formation of transition metal oxide-noble gas complexes. The IR spectrum of $\mathrm{ScO}^{+}$had five new absorptions when $\mathrm{Kr}$ was doped into the argon matrix, and this was taken to imply the presence of $\left[\mathrm{ScO}(\mathrm{Ng})_{5}\right]^{+}(\mathrm{Ng}=\mathrm{Ne}, \mathrm{Ar}, \mathrm{Kr}) .{ }^{47}$ This was confirmed by DFT calculations, which indicated $\mathrm{Sc}-\mathrm{Ng}$ bond lengths of 2.839 and 3.297 $\AA$ for Ar, 2.979 and $3.433 \AA$ for $\mathrm{Kr}$, and 3.197 and 3.663 $\AA$ for Xe. ${ }^{47,48}$ For the neutral scandium oxide/dioxygen complexes, the experimental evidence for argon complexes was less compelling. ${ }^{49}$ In analogous experiments with $\mathrm{YO}^{+}$, six new bands were observed in mixed $\mathrm{Ar} / \mathrm{Kr}$ matrices but only five in $\mathrm{Ar} / \mathrm{Xe}$ matrices, implying the presence of $\left[\mathrm{YO}(\mathrm{Kr})_{6}\right]^{+}$and $\left[\mathrm{YO}(\mathrm{Xe})_{5}\right]^{+} .^{48}$ For neutral monoxides, it was shown that ArMO species were formed for $\mathrm{Cr}$ to $\mathrm{Ni}$ but not for $\mathrm{Sc}, \mathrm{Ti}$, and $\mathrm{V} .{ }^{50}$ The calculated $\mathrm{Ng}-\mathrm{M}$ distances were as follows: $\mathrm{ArCrO}, 3.300 \AA$; $\mathrm{KrCrO}$, $3.164 \AA$ 我 $\mathrm{XeCrO}, 3.257$; ArMnO, $2.973 \AA \AA$; KrMnO, $2.987 \AA$; $\mathrm{XeMnO}, 3.089 \AA$ A $\mathrm{ArFeO}, 2.691 \AA$; $\mathrm{KrFeO}, 2.779 \AA$; $\mathrm{XeFeO}$, $2.910 \AA$; $\mathrm{ArCoO}, 2.561$ A; $\mathrm{KrCoO}, 2.623 \AA$; $\mathrm{XeCoO}, 2.784 \AA$; ArNiO, $2.421 \AA ; \mathrm{KrNiO}, 2.527 \AA$ 品 $\mathrm{XeNiO}, 2.695 \AA .{ }^{50} \mathrm{VO}_{2}$ coordinated two argon or xenon atoms to form $\mathrm{VO}_{2}(\mathrm{Ng})_{2}$ with DFT-calculated V-Ar distances of $2.694 \AA$ and $\mathrm{V}-\mathrm{Xe}$ distances of $2.939 \AA .^{51} \mathrm{VO}_{4}$ only coordinated one argon or xenon, resulting in $\mathrm{VO}_{4}(\mathrm{Ng})$ with calculated $\mathrm{V}-\mathrm{Ar}$ and $\mathrm{V}-\mathrm{Xe}$ distances of 2.730 and $2.951 \AA$, respectively. ${ }^{51}$ While niobium formed $\mathrm{NbO}_{2}(\mathrm{Ng})_{2}$ complexes with calculated $\mathrm{Nb}-\mathrm{Ar}$ distances of $2.925 \AA$, there was no experimental evidence for the analogous tantalum species. ${ }^{52}$ However, for both niobium and tantalum, $\mathrm{MO}_{4}(\mathrm{Ng})$ complexes were observed with calculated $\mathrm{Nb}-\mathrm{Ar}, \mathrm{Nb}-\mathrm{Xe}$, $\mathrm{Ta}-\mathrm{Ar}$, and $\mathrm{Ta}-\mathrm{Xe}$ distances of $2.788,3.089,2.723$, and $3.006 \AA$, respectively. ${ }^{52}$ It has also been shown that as well as forming complexes, noble gas atoms can participate in reactions. For example, xenon induced disproportionation of the side-onbonded disuperoxo complex $\left(\eta^{2}-\mathrm{O}_{2}\right)_{2} \mathrm{CrO}_{2}$ into $\left(\eta^{1}-\mathrm{OO}\right)\left(\eta^{2}\right.$ $\left.\mathrm{O}_{2}\right) \mathrm{CrO}_{2}(\mathrm{Xe})$, which can be regarded as containing a weakly bound dioxygen unit as well as a side-on-bonded peroxo ligand. ${ }^{53}$ Calculations indicated a $\mathrm{Cr}-\mathrm{Xe}$ bond length of $2.892 \AA^{53}$ Work on $4 \mathrm{~d}$ oxides indicated the formation of $\mathrm{Pd}\left(\eta^{2}-\mathrm{O}_{2}\right)(\mathrm{Ng})_{2}$, $\mathrm{Pd}_{2}\left(\eta^{2}-\mathrm{O}_{2}\right)(\mathrm{Ng})_{2}$, and $\mathrm{Pd}_{2}\left(\eta^{2}-\mathrm{O}_{2}\right)_{2}(\mathrm{Ng})_{2}{ }^{54}$ and $\mathrm{Rh}\left(\eta^{2}-\mathrm{O}_{2}\right)(\mathrm{Ng})_{2}$, $\mathrm{Rh}\left(\eta^{2}-\mathrm{O}_{2}\right)_{2}(\mathrm{Ng})_{2}$, and $\mathrm{Rh}\left(\eta^{2}-\mathrm{O}_{2}\right)_{2}\left(\eta^{1}-\mathrm{OO}\right)(\mathrm{Ng}){ }^{55}$ A detailed bonding analysis of these data indicated that the noble gas and transition metal oxides interact by both ion-induced dipole interactions and more formal chemical bonding interactions in which the noble gas atoms act as electron donors into localized metal-based orbitals. ${ }^{56}$ It was suggested that if the transition metal species trapped in the noble gas host has electrophilic character combined with low-lying empty or partially filled orbitals, then it will be able to coordinate with noble gas atoms, resulting in the formation of noble gas-transition metal complexes. An important observation was that while the coordination of the noble gas atom results in vibrational frequency shifts, there was no direct correlation between the matrix shifts and the strength of the noble gas coordination. ${ }^{56}$

In the proceeding work, the evidence for interactions between the noble gas and the matrix-isolated species came from a combination of experimental (usually IR) data and calculations, as there are very few techniques that are able to directly yield bond distances from noble gas matrices. X-ray absorption spectroscopy is one of the few techniques that can yield direct structural information about both the matrix-isolated species and its interaction with the matrix host. The application of X-ray absorption spectroscopy to matrix-isolated species has recently been reviewed. ${ }^{57}$

Gerry carried out extensive microwave studies of the gas-phase complexes between group 11 halides and noble gases (see ref 58 and references therein), and the complexes with xenon as a ligand are also important examples. ${ }^{59-62}$

Therefore, there is considerable evidence that the noble gases, while providing an excellent medium for trapping reactive and unstable species, may actually exert a benign and often poorly characterized effect on the trapped species. While $\mathrm{N}_{2}$ is often a very good matrix material, it is well-known that it can also have a considerable impact on the trapped species. For example, it can lift the degeneracy of degenerate modes, ${ }^{63-65}$ and some $5 \mathrm{~d}$ transition metal pentachlorides adopt a square-pyramidal geometry in $\mathrm{N}_{2}$ but a variety of conformers in $\mathrm{Ar}^{66} \mathrm{~N}_{2}$ matrices are also capable of exerting considerable influence on the structures of coordinatively unsaturated metal halides ${ }^{16,17,67,68}$ and the formation of more formal complexes. ${ }^{69-72}$

Therefore, it may be possible to identify two distinct aspects of interaction between the matrix and the trapped species, one that gives rise to compounds/complexes with significant bonding interactions and a second one that results in perturbation of the guest by the matrix. These could be compared to chemisorption and physisorption for surface species, especially for dinitrogen.

\section{EXPERIMENTAL SECTION}

The anhydrous metal salts were prepared by heating the relevant metal foil (Goodfellow, 99.9+\%) in a flowing atmosphere of $\mathrm{HBr}$, except for $\mathrm{ZnBr}_{2}$, where a commercial (Fluka) anhydrous sample was used. The samples were sublimed under vacuum and stored in sealed silica ampules prior to use. The metal salts were loaded into silica holders in a glovebox and placed within a tantalum-wound silica furnace mounted within a watercooled vacuum jacket mounted on the stainless steel or aluminum vacuum chamber. The furnace was heated resistively, and the temperature was monitored with a type-K thermocouple. The matrix gases Ar (Energas 99.999\%, Distillers MG 99.999\%), $\mathrm{N}_{2}$ (Energas 99.999\%, Distillers MG 99.999\%), ${ }^{15} \mathrm{~N}_{2}$ (EuroisoTop 99\%), Ne (Distillers MG 99.99\%), Kr (Distillers MG 99.99\%), Xe (Distillers MG 99.99\%), $\mathrm{CH}_{4}$ (Distillers MG 99.995\%), $\mathrm{O}_{2}$ (Distillers MG 99.998\%) were used as supplied and admitted via a needle valve at a rate of ca. $3-5 \mathrm{mmol} / \mathrm{h} . \mathrm{Kr}$ matrices were deposited at 25 or $30 \mathrm{~K}$ and $\mathrm{Xe}$ matrices at $50 \mathrm{~K}$, and both were then cooled to ca. $10 \mathrm{~K}$ for spectroscopy. 
Photolysis was carried out with a LOT-Oriel $200 \mathrm{~W} \mathrm{Hg}-\mathrm{Xe}$ lamp equipped with a liquid light guide and appropriate filters.

The IR spectra were recorded using a Bruker IFS66 FTIR spectrometer equipped with a $\mathrm{KBr}$ beamsplitter for the mid-IR (MIR) and a $6 \mu \mathrm{m}$ Mylar beamsplitter for the far-IR (FIR) along with DTGS detectors. The vacuum shroud used CsI windows and had a base pressure of ca. $2 \times 10^{-7}$ mbar before the APD DE204SL Displex closed-cycle helium cryostat (base temperature of ca. $9 \mathrm{~K}$ ) was turned on. Temperature measurement and control were achieved via $\mathrm{Si}$ diodes and a Scientific Instruments 9650 controller. Depending on the experimental requirements, the deposition substrate was either a CsI polished window for transmission experiments (vacuum chamber within the spectrometer sample compartment) or a polished copper plate for reflectance experiments (vacuum chamber mounted externally).

Synchrotron radiation FIR (SR-FIR) spectra were collected using a Nicolet vacuum FIR bench on station $13.3^{73}$ of the Daresbury Laboratory Synchrotron Radiation Source (SRS) operating in gapped beam mode at $2 \mathrm{GeV}$ with circulating currents of ca. $180 \mathrm{~mA}$. The deposition substrate was a polished copper block held at ca. $13 \mathrm{~K}$ with the incident and reflected beams at $135^{\circ}$ to allow for in situ monitoring of the sample during both deposition and photolysis. The vacuum chamber was mounted between the optical bench and the He-cooled Ge bolometer, and the whole optical path was evacuated.

The UV-vis-NIR spectra were recorded using a Varian Cary $5 \mathrm{E}$ spectrometer with a similar vacuum and pumping regime as in the lab-based FTIR experiments, except that $\mathrm{CaF}_{2}$ was used for the deposition substrate and the external windows on the vacuum chamber, which was mounted in the spectrometer sample compartment.

The X-ray absorption experiments utilized station 9.2 of the Daresbury Laboratory SRS, operating in either multibunch or gapped beam mode at $2 \mathrm{GeV}$ with circulating currents of ca. $180 \mathrm{~mA}$. A combined FTIR/XAFS facility ${ }^{68,74}$ was used to collect simultaneous in situ IR and XAFS data from the same sample, which allowed for monitoring of the deposition as well as any subsequent annealing or photolysis. The metal and bromine K-edge XAFS spectra were collected in fluorescence mode (Tl/NaI scintillator) using a $\mathrm{Si}(220)$ double-crystal monochromator detuned by ca. $50 \%$ to remove harmonic contamination. Eight to 12 spectra were collected at each edge and then averaged. The $3 \mathrm{~d}$ metal K-edges were calibrated using the first derivatives in the spectra of 5 or $10 \mu \mathrm{m}$ metal foils (Fe, $7112.0 \mathrm{eV}$; Co, $7709.0 \mathrm{eV}$; Ni, $8333.0 \mathrm{eV}$; Zn, $9659.0 \mathrm{eV}$ ), and the Br K-edge was calibrated using the first derivative of the $\mathrm{L}_{2}$ edge of a $5 \mu \mathrm{m}$ $\mathrm{Au}$ foil $(13734.0 \mathrm{eV}) .^{75}$ Background subtraction was carried out using PAXAS ${ }^{76}$ by fitting the pre-edge region to a quadratic polynomial, subtracting this from the data, and approximating the atomic component of the postedge region with a high (typically sixth)-order polynomial. This approximation was optimized in order to minimize the low- $r$ features in the Fourier transforms (FTs) by an iterative process, although it should be noted that atomic XAFS features may be expected in this part of the FT. ${ }^{77,78}$ Fitting of the experimental data was carried out with EXCURV98, ${ }^{79-81}$ making use of multiple-scattering curvedwave theory, a von Barth ground state, and a Hedin-Lundqvist exchange potential. For some samples, the metal K-edge and the $\mathrm{Br}$ K-edge were refined simultaneously. Although experiments utilizing Ne matrices are attractive, these were not conducted because complete isolation of the metal dibromide could not be guaranteed using the cryostat with a base temperature of $9 \mathrm{~K}$ under optimum conditions and data acquisition times of up to $24 \mathrm{~h}$. The production of aggregates in these experiments would make the analysis of the data at best difficult and at worst meaningless. Experiments involving Ar are also intrinsically difficult for the $3 \mathrm{~d}$ transition metals because of the short penetration depth of the matrix due to the high X-ray absorption cross-section of argon. For example, the attenuation length (1/e) for Ar at $8000 \mathrm{eV}$ is ca. $50 \mu \mathrm{m} .{ }^{82}$ The length of time for deposition is severely limited, as the increased thickness of the matrix soon cancels out any additional fluorescence due to the increase in deposited metal dihalide. For this reason, $\mathrm{Kr}$ and Xe experiments were also not possible, as these matrices have even higher X-ray absorption cross sections, with attenuation lengths of 40 and $10 \mu \mathrm{m}$, respectively, at $8 \mathrm{keV}$. In many ways $\mathrm{CH}_{4}$ is an ideal matrix for XAFS work, as its X-ray absorption cross section is even lower than that of Ne. Therefore, in this work XAFS studies were conducted using $\mathrm{CH}_{4}$ and $\mathrm{N}_{2}$ matrices for $\mathrm{FeBr}_{2}, \mathrm{CoBr}_{2}$, and $\mathrm{NiBr}_{2}$ and $\mathrm{Ar}$ matrices for $\mathrm{FeBr}_{2}$ and $\mathrm{CoBr}$.

Force field calculations using the SVFF approach were carried out using the Wilson GF method within SOTONVIB. ${ }^{83}$ DFT calculations were performed using the ADF program ${ }^{84-86}$ at the BP86 level with triple- $\zeta$ (TZ2P) Slater-type orbital basis sets and relativistic effects at the ZORA level. ${ }^{87}$ The excited states were calculated by changing the orbital configuration. Calculations were started from bent and linear starting points, and the vibrational frequencies were calculated to check that a minimum had been reached for that state. Time-dependent DFT (TD-DFT) calculations of the XANES spectra were carried out with ORCA 2.9.1 using the BP86 def2-TZVP(-f) def2TZVP/J ZORA TightSCF methodology. ${ }^{88-94}$

\section{SETTING THE SCENE}

Transition metal dihalides $\left(\mathrm{MX}_{2}\right)$ are ideal probes of matrix interactions, as they allow for variation in both hardness of the metal center as the halogen is changed and in the d-electron count as one goes across the series. While many matrix studies of the difluorides and dichlorides have been carried out, no complete sets of data are available for the related dibromides and diiodides. While data are available for $\mathrm{CaBr}_{2}$ and $\mathrm{CaI}_{2}$ in $\mathrm{Ar}$ and $\mathrm{Kr}^{95}$ and $\mathrm{ZnBr}_{2}$ and $\mathrm{ZnI}_{2}$ in $\mathrm{Ar}$ and $\mathrm{Kr}{ }^{96,97}$ there is much less data on the dibromides and diodes of the transition metals, with the only reports appearing to be on $\mathrm{CrBr}_{2}$ in $\mathrm{Ar}$ and $\mathrm{N}_{2}$ matrices ${ }^{98}$ and $\mathrm{NiBr}_{2}$ in $\mathrm{Ar}^{68,99}$ and $\mathrm{N}_{2}{ }^{68}$ matrices.

Infrared Spectroscopy. Linear $\mathrm{MX}_{2}$ molecules have four vibrational degrees of freedom, whereas bent $\mathrm{MX}_{2}$ molecules have three vibrational degrees of freedom. For the linear $D_{\infty h}$ molecules, the vibrational modes transform as $\Sigma_{\mathrm{g}}^{+}\left(\nu_{1}\right.$ symmetric stretching mode $), \Pi_{\mathrm{u}}\left(\nu_{2}\right.$ bending mode $)$, and $\Sigma_{\mathrm{u}}^{+}\left(\nu_{3}\right.$ asymmetric stretching mode). Of these, only $\nu_{2}$ and $\nu_{3}$ are infraredactive, but in general the $\nu_{2}$ mode is too low in energy to be observed on most spectrometers $\left(<100 \mathrm{~cm}^{-1}\right)$. The vibrational modes of the bent $C_{2 v}$ molecules span $2 \mathrm{~A}_{1}\left(\nu_{1}\right.$ symmetric stretching mode and $\nu_{2}$ bending mode $)$ and $\mathrm{B}_{2}\left(\nu_{3}\right.$ asymmetric stretching mode), all of which are IR-active. As in the linear case, the low-frequency bending mode is expected to be beyond the range of most commercial spectrometers. Although the observation of the $\nu_{1}$ mode in the IR spectrum is an obvious criterion for unambiguous evidence of a bent geometry in such molecules, its observation has been historically difficult, and assignment of both $\nu_{3}$ and $\nu_{1}$ has produced controversy even with such extensively studied systems as the alkaline-earth metal dihalides. ${ }^{100}$ The intensity of the $\nu_{1}$ mode is critically dependent on the bond angle and is expected to be observed only at fairly acute 
angles. Our DFT calculations indicate that the relative intensities of the $\nu_{3}$ and $\nu_{1}$ modes for bond angles of $155^{\circ}$ and $130^{\circ}$ in metal dibromides (and dichlorides) are 50:1 and 10:1, respectively. Therefore, unless the molecule is severely bent, it will be almost impossible to identify the $\nu_{1}$ mode with any certainty. Therefore, the absence of $\nu_{1}$ is not unambiguous evidence for linearity in $\mathrm{MX}_{2}$ compounds. While the chlorine isotope patterns for the $3 \mathrm{~d}$ transition metal chlorides can be employed relatively routinely to obtain estimates of the bond angles, ${ }^{16,17}$ the isotope splitting arising from bromine is much smaller and is often an experimental challenge to observe. Therefore, unless it is possible to identify the $\nu_{1}$ mode unambiguously, the linearity or lack thereof cannot be determined from IR data alone unless either metal or bromine isotopic data are available. Although we have access to FT-Raman matrix facilities, which in principle allow for the identification of $\nu_{1}$ directly, this is currently limited (because of the incident laser power) to chromophore:matrix ratios of about 1:200, which are too high for these type of experiments. As a result of these limitations, other spectroscopic techniques were employed in addition to IR spectroscopy.

Electronic Absorption Spectroscopy. UV-vis-NIR data on matrix-isolated transition metal dihalides in the literature are limited to the chlorides, although some vapor-phase data are available for the dibromides. For linear $\mathrm{MX}_{2}$ species, the intensity of any $d-d$ bands is expected to be very low because of the orbital and Laporte selection rules, but in the case of the nonlinear molecules, the Laporte selection rule is relaxed. Therefore, as noted previously, ${ }^{101-103}$ the electronic absorption spectra will be dominated by charge transfer bands, with weak $d-d$ bands observed only in some cases. As a result of this, the discussion of the spectra will be mainly based on assigning bands as either charge transfer or $\mathrm{d}-\mathrm{d}$ bands and using the spectra as "fingerprints" indicative of a linear and nonlinear structure, rather than a detailed theoretical treatment.

X-ray Absorption Spectroscopy. In the past we have demonstrated that X-ray absorption fine structure spectroscopy (XAFS) is a powerful tool for determining interatomic distances of matrix-isolated species, ${ }^{67,68,74,104-109}$ and this has recently been reviewed. ${ }^{57} \mathrm{X}$-ray absorption spectroscopy is able to provide a detailed picture of both the local electronic and geometric structure of the matrix-isolated species. The electronic structure, which can also yield valuable information about the coordination geometry and oxidation state, is obtained from the X-ray absorption near edge structure (XANES) part of the spectrum located around the absorption edge. In contrast, bond length data are obtained from the oscillations in the absorption cross section after the absorption edge, which are known as extended X-ray absorption fine structure (EXAFS).

XANES. While metal K-edge XANES spectra are well-known to be diagnostic of the metal oxidation state, coordination number, and geometry for iron, ${ }^{110}$ cobalt, ${ }^{111}$ and nickel ${ }^{112}$ complexes, there are very few examples in the literature of XANES data for triatomic first-row transition metal species. The best examples of these are for copper, where Kau et al. ${ }^{113}$ demonstrated that the intensity of the characteristic $1 \mathrm{~s} \rightarrow 4 \mathrm{p}$ edge feature in $\mathrm{Cu}(\mathrm{I})$ complexes is dependent on the copper coordination number. This has been widely used as a diagnostic probe of the electronic and geometric structure of copper metalloproteins. ${ }^{114}$ Of more relevance to this work is that of Fulton et al., who investigated $\left[\mathrm{CuCl}_{2}\right]^{-115}$ and $\left[\mathrm{CuBr}_{2}\right]^{-116}$ formed under hydrothermal conditions. Also, Brugger et al. ${ }^{117}$ carried out calculations on $\mathrm{Cu}(\mathrm{I})$. In both cases a very intense edge feature was observed, at $8984 \mathrm{eV}$ for $\left[\mathrm{CuCl}_{2}\right]^{-115}$ and $8982 \mathrm{eV}$ for $\left[\mathrm{CuBr}_{2}\right]^{-116}$ and on the basis of the work of Kau et al. ${ }^{113}$ these were assigned to $1 \mathrm{~s} \rightarrow 4 \mathrm{p}$ transitions. With the use of TD-DFT calculations, ${ }^{88-94}$ it is now possible to simulate the pre-edge and edge features in XANES spectra. Figure 1 presents the
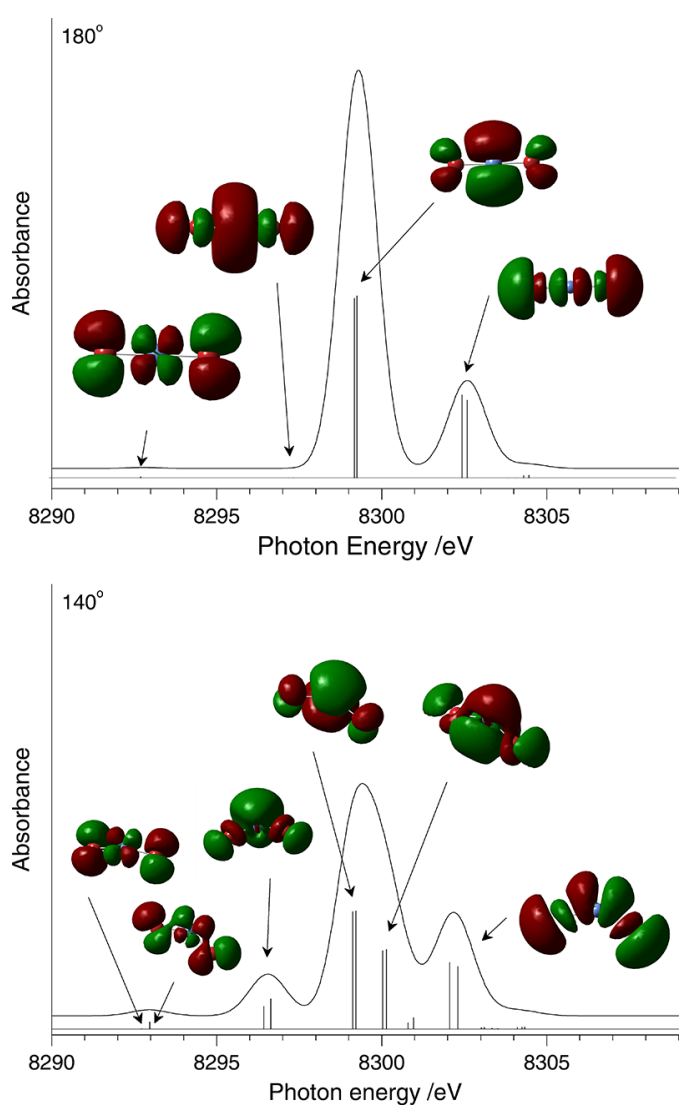

Figure 1. TD-DFT-calculated $\mathrm{Ni}$ K-edge XANES spectra for $\mathrm{NiBr}_{2}$ with bond angles of (top) $180^{\circ}$ and (bottom) $140^{\circ}$.

TD-DFT-calculated XANES spectra of $\mathrm{NiBr}_{2}$ at $180^{\circ}$ and $140^{\circ}$, showing both the individual transitions and also the molecular orbitals involved. The TD-DFT-calculated spectra do not look like conventional experimental XANES spectra, as they model only the electric dipole, electric quadrupole, and magnetic dipole transitions, which are superimposed on the $1 \mathrm{~s} \rightarrow$ continuum (edge) transition in the experimental spectra. In addition, there is an energy offset from the experimental values, and while empirical adjustments for this can be made, we have not done so. At $180^{\circ}$ the spectrum is dominated by the dipole-allowed $1 \mathrm{~s} \rightarrow 4 \mathrm{p}$ transitions, in particular the intense transition at $8299.3 \mathrm{eV}$ involving MOs with substantial $\mathrm{Ni} 4 \mathrm{p}_{x, y}$ character and those at $8302.6 \mathrm{eV}$ involving MOs with $\mathrm{Ni} 4 \mathrm{p}_{z}$ character. The transitions at $8292.8 \mathrm{eV}$ to MOs with substantial $3 \mathrm{~d}_{x z, y z}$ character are weak (one 400th of the main peak) and those at $8297.3 \mathrm{eV}$ to MOs with $4 \mathrm{~s}$ character are very, very weak (one 2300th), as they are dipole-forbidden but gain intensity from quadrupole and magnetic dipole transitions. Upon bending of the $\mathrm{NiBr}_{2}$ molecule, the intensity of the transition from the $1 \mathrm{~s}$ orbital to the $4 p_{x, y}$ orbitals is reduced because the two MOs are no longer degenerate, and as the bond angle becomes more acute, they resolve into two separate peaks. The most noticeable increase in intensity is for the $1 \mathrm{~s} \rightarrow 4 \mathrm{~s}$ transition at $8296.5 \mathrm{eV}$, which is dipole-forbidden in the linear geometry but upon bending becomes dipole-allowed with a very small quadrupole 

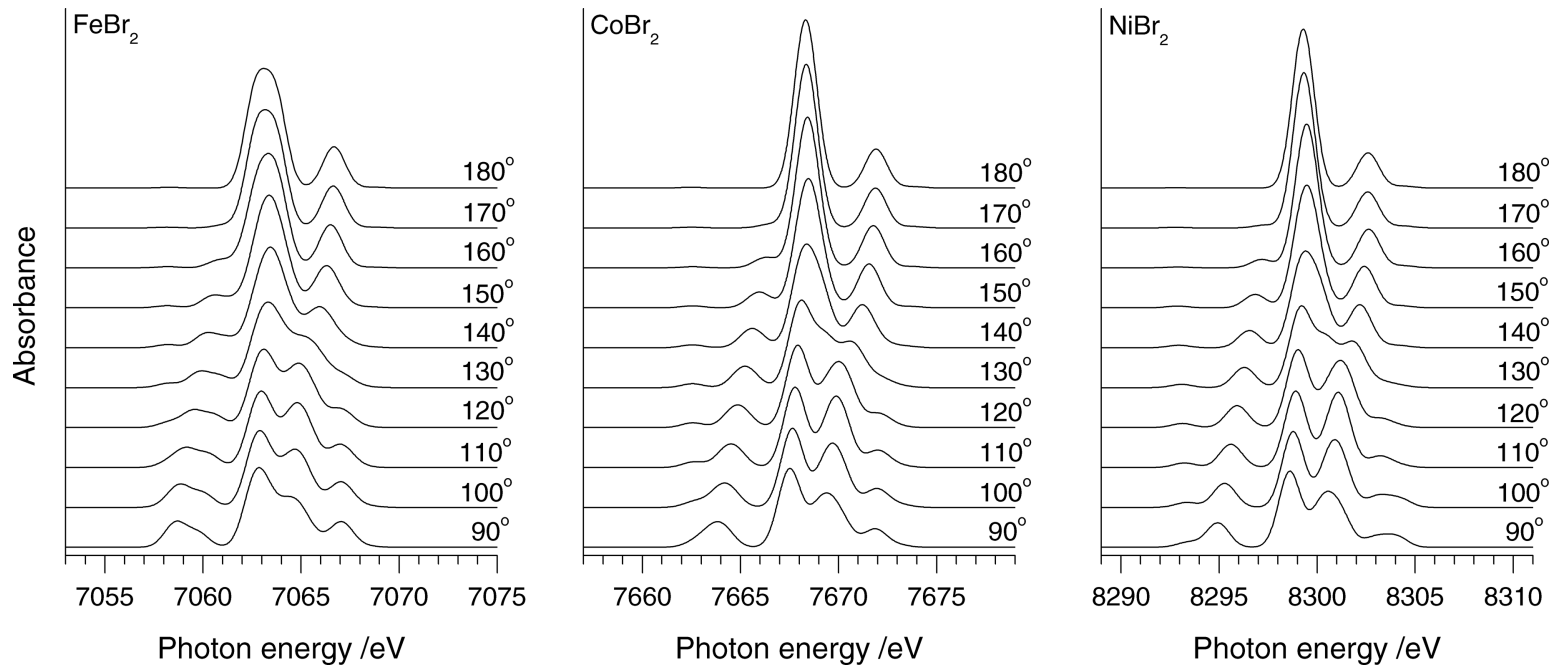

Figure 2. TD-DFT-calculated metal K-edge XANES spectra for (left) $\mathrm{FeBr}_{2}$, (middle) $\mathrm{CoBr}_{2}$, and (right) $\mathrm{NiBr}_{2}$ at different bond angles. The same bond length was used for all bond angles of each metal; the value was set to the ADF-calculated bond length in the ground state (FeBr ${ }_{2}, 2.254 \AA$; $\mathrm{CoBr}_{2}, 2.210 \AA, \mathrm{NiBr}_{2}, 2.180 \AA$ ).

contribution $(\sim 0.3 \%)$. Of the two transitions at $8293 \mathrm{eV}$ involving the $3 \mathrm{~d}$ orbitals within $0.3 \mathrm{eV}$ of each other, one is much more intense than the other by about an order of magnitude, but both are very much weaker than the $1 \mathrm{~s} \rightarrow 4 \mathrm{~s}$ and $1 \mathrm{~s} \rightarrow 4 \mathrm{p}$ transitions. The lower-energy transition is essentially electric-dipole-forbidden and gains its intensity from magnetic dipole (36\%) and electric quadrupole (64\%) transitions, and this is an order of magnitude less intense than the second $1 \mathrm{~s} \rightarrow 3 \mathrm{~d}$ transition, which has now become dipole-allowed (93\%) with small magnetic dipole (2.5\%) and electric quadrupole (4\%) contributions.

Figure 2 shows how the TD-DFT-calculated XANES spectra vary with bond angle for $\mathrm{FeBr}_{2}, \mathrm{CoBr}_{2}$, and $\mathrm{NiBr}_{2}$ (the individual transitions and MOs are very similar to those for $\mathrm{NiBr}_{2}$ shown in Figure 1). Therefore, the metal K-edge XANES spectra are expected to be very sensitive to changes in geometry. In particular, the presence of an intense edge feature in the experimental XANES spectra can be used diagnostically as an indicator of a linear geometry, and any reduction in its intensity can be attributed to nonlinearity. In addition, there is also expected to be an increase in the $1 \mathrm{~s} \rightarrow 3 \mathrm{~d}$ based transitions as well the $1 \mathrm{~s} \rightarrow 4 \mathrm{~s}$ transitions, but the latter may get masked by other changes in the edge structure.

EXAFS. In addition to the bond length information obtainable using EXAFS data, it is also possible to extract bond angle information. While this has been demonstrated previously from triangulation using the $\mathrm{Br} \cdots \mathrm{Br}$ and $\mathrm{Br}-\mathrm{M}$ distances from the $\mathrm{Br}$ K-edge data, ${ }^{68,105,118,119}$ multiple scattering paths through the central metal atom also yield valuable information from both the metal and bromine K-edges. The importance of these pathways as a diagnostic tool in determining the geometry at the metal center has been demonstrated in tetrahedral $\mathrm{NiBr}_{2}\left(\mathrm{PPh}_{3}\right)_{2}$, trans- $\mathrm{NiBr}_{2}\left(\mathrm{PEt}_{3}\right)_{2}$, and cis- $\mathrm{NiBr}_{2}$ (dppe) (dppe $=1,2$-bis(diphenylphosphino)ethane) complexes. ${ }^{120,121}$ The Fourier transforms of the $\mathrm{Ni}$ K-edge data of trans- $\mathrm{NiBr}_{2}\left(\mathrm{PEt}_{3}\right)_{2}$ and cis- $\mathrm{NiBr}_{2}$ (dppe) contained features at approximately twice the first shell distance that were absent in the Fourier transform of the Ni K-edge XAFS data of tetrahedral $\mathrm{NiBr}_{2}\left(\mathrm{PPh}_{3}\right)_{2}$. These features are due to multiple scattering involving pathways through the central absorbing atom (as shown in Figure 3 for $\mathrm{CoBr}_{2}$ ) and can therefore be used as a diagnostic test of linearity for $\mathrm{MBr}_{2}$ units.
Br K-edge

Co K-edge
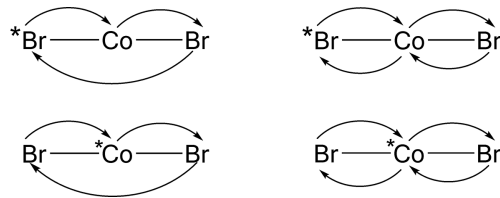

Figure 3. Representative multiple scattering pathways in $\mathrm{CoBr}_{2}$ at the $\mathrm{Br}$ K-edge and the Co K-edge (absorbing atoms are shown with *).

To illustrate the sensitivity of these multiple scattering pathways with respect to the bond angles in the transition metal dihalides studied in this work, theoretical Fourier transforms of $\mathrm{Co}$ and $\mathrm{Br}$ K-edge data for $\mathrm{CoBr}_{2}$ over a range of bond angles $\left(180-90^{\circ}\right)$ are shown in Figure 4. The model for the calculation of the spectra used a constant $\mathrm{Co}-\mathrm{Br}$ bond length of $2.25 \AA$ and constant Debye-Waller $2 \sigma^{2}$ terms of 0.010 and $0.015 \AA^{2}$ for the $\mathrm{Co}-\mathrm{Br}$ and $\mathrm{Br} \cdots \mathrm{Br}$ shells, respectively. The angle of the $\mathrm{Br}-\mathrm{Co}-\mathrm{Br}$ unit was then defined and the theoretical spectrum calculated. The multiple scattering parameters used were also consistent for both K-edges and for every angle calculated. The Co K-edge theoretical Fourier transform for $\mathrm{CoBr}_{2}$ calculated without multiple scattering has just the peak corresponding to the $\mathrm{Co}-\mathrm{Br}$ distance at $2.25 \AA$ for all bond angles.

However, when the multiple scattering contribution is included, a second peak at approximately twice the $\mathrm{Co}-\mathrm{Br}$ bond distance is observed for near-linear geometries (Figure 4a). As the bond angle is reduced, this feature diminishes very rapidly, particularly for bond angles less than $160^{\circ}$, and it completely disappears in the spectra calculated for bond angles of less than $155^{\circ}$, where the FTs are essentially identical to those calculated for no multiple scattering. It can therefore be concluded that in the analysis of good-quality metal K-edge XAFS data for the metal dibromides isolated in inert matrices, the presence of a multiplescattering feature at approximately twice the $\mathrm{M}-\mathrm{Br}$ distance is indicative of a bond angle of $160^{\circ}$ or greater. The effect of multiple scattering on the $\mathrm{Br} \mathrm{K}$-edge data is more complex, as there are no additional peaks solely due to multiple scattering. In this case, the multiple scattering events affect the intensity of the $\mathrm{Br} \cdots \mathrm{Br}$ shell, as the intervening metal atom in a linear arrangement acts as a lens, strongly forward-scattering the photoelectron, thus increasing the intensity of the backscattering $\mathrm{Br}$ shell. This is a much more well-known manifestation of multiple 

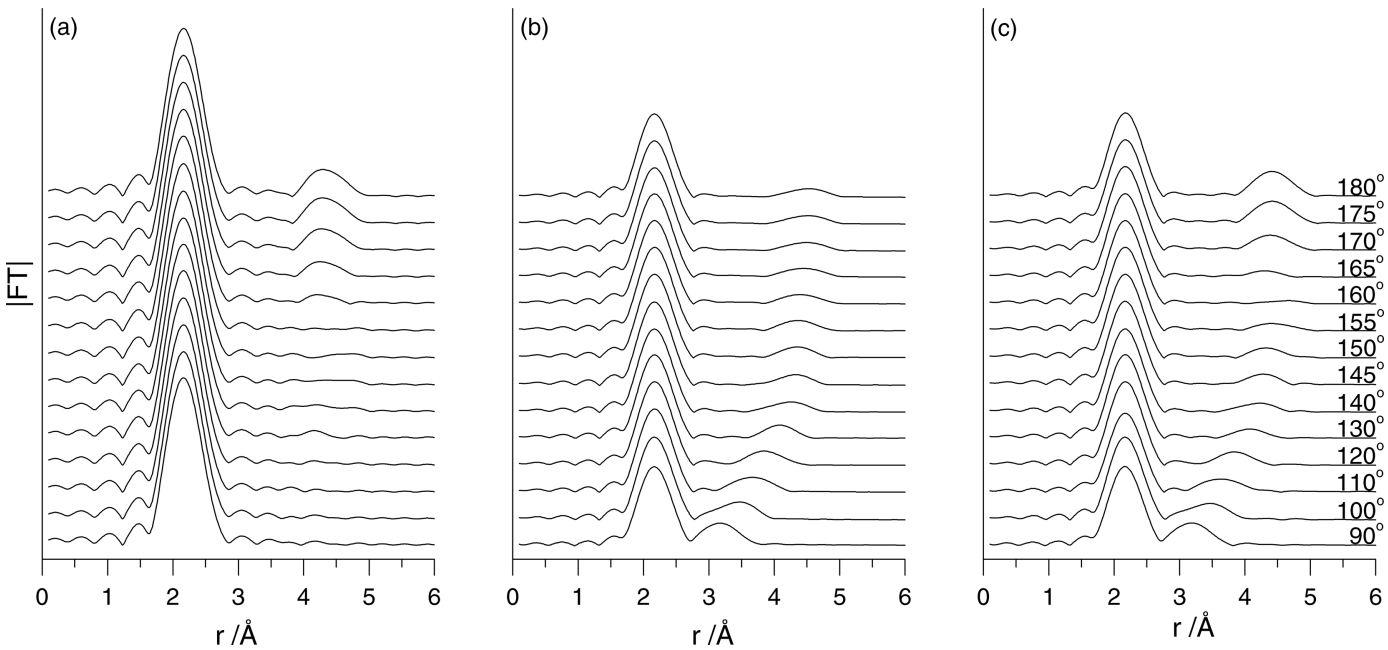

Figure 4. Calculated FTs of EXAFS data for $\mathrm{CoBr}_{2}$ at different bond angles: (a) Co K-edge with multiple scattering; (b) Br K-edge without multiple scattering; (c) Br K-edge with multiple scattering.

scattering than that involving the central absorbing element and is common in complexes containing $\mathrm{CO}, \mathrm{CN}^{-}$, and imidazole ligands. Fourier transforms were calculated without multiple scattering theory, shown in Figure $4 \mathrm{~b}$, as well as with multiple scattering, shown in Figure $4 c$. Figure $4 \mathrm{~b}$ shows a simple and expected increase in the intensity of the $\mathrm{Br} \cdots \mathrm{Br}$ peak as the distance is shortened as a result of the more acute bond angle due to the $1 / r^{2}$ effect. Figure $4 c$ shows an altogether different effect due to multiple scattering. The data for $180^{\circ}$ show an enhanced intensity of the $\mathrm{Br} \cdots \mathrm{Br}$ feature due to the multiple scattering. However, as the bond angle is decreased from $180^{\circ}$, the $\mathrm{Br} \cdots \mathrm{Br}$ peak shows a reduction in intensity, which is particularly evident between $165^{\circ}$ and $155^{\circ}$, to such an extent that the $\mathrm{Br} \cdots \mathrm{Br}$ shell would not be observed above the noise level in the experiment. At smaller angles, the shape and size of the $\mathrm{Br} \cdots \mathrm{Br}$ peak corresponds closely to that of spectra calculated without multiple scattering theory. Thus, multiple scattering at the $\mathrm{Br}$ K-edge increases the intensity of the $\mathrm{Br} \cdots \mathrm{Br}$ peak at near linear geometries, reduces it around $160^{\circ}$, and then has little effect below $150^{\circ}$. Therefore, these calculations suggest that the absence of a $\mathrm{Br} \cdots \mathrm{Br}$ shell in the $\mathrm{Br} \mathrm{K}$-edge spectra is indicative of a bond angle between 155 and $165^{\circ}$ and that peaks with intensities above what was expected when calculated without multiple scattering are indicative of a bond angle between 170 and $180^{\circ}$.

It is to be noted that the sensitivity of the XAFS multiplescattering effects is at a maximum where the trigonometric functions used for bond angle calculations with IR isotopic data are at their least sensitive, i.e., for nearly linear systems. The validity of the model was tested with the other metals employed in this study. As it has been shown previously ${ }^{67}$ that the $\mathrm{M}-\mathrm{Hal}$ bond length increases upon deviation from linearity, the calculations were carried out with slightly different bond lengths, and no appreciable differences in the trends shown in Figure 4 were detected.

DFT Calculations. In addition to the experimental results, DFT calculations on the ground and low-lying excited electronic states of the dibromides and diiodides have been carried out to support the interpretation of the experimental data.

Summary and Outline of Paper. This paper describes the results of the isolation of the $3 \mathrm{~d}$ transition metal dibromides of $\mathrm{Fe}, \mathrm{Co}, \mathrm{Ni}$, and $\mathrm{Zn}$ in matrices of noble gases $(\mathrm{Ne}, \mathrm{Ar}, \mathrm{Kr}, \mathrm{Xe}$ ) as well as $\mathrm{CH}_{4}$ and $\mathrm{N}_{2}$, with $\mathrm{O}_{2}$ also being employed in the $\mathrm{NiBr}_{2}$ studies. While the difluorides and dichlorides of the $3 \mathrm{~d}$ transition metals have been widely studied, the available data in the matrix isolation literature for the dibromides are much more scarce and are limited to $\mathrm{NiBr}_{2}$ in $\mathrm{Ar}^{99} \mathrm{ZnBr}_{2}$ in $\mathrm{Kr},{ }^{96,97,122,123}$ and $\mathrm{CrBr}_{2}$ in $\mathrm{Ar}^{98}$ We have published two preliminary pieces of work on $\mathrm{NiBr}_{2}$ in $\mathrm{N}_{2}$ matrices. ${ }^{68,69}$ The paucity of spectroscopic data for the transition metal dibromides has also been highlighted. ${ }^{124}$ Therefore, the combination of the published data on the difluorides and dichlorides with the data presented herein will make it possible to compare the effect of changing the d-electron count as well as the hardness of the metal in going from the fluorides through the chlorides to the bromides. Previous electron diffraction work ${ }^{124,125}$ on the molecular geometry of gas-phase metal halides has shown that all of the dihalides studied in this work are linear in the gas phase. Mass spectrometry indicates that for $\mathrm{FeBr}_{2}{ }^{126}$ and $\mathrm{CoBr}_{2}{ }^{127}$ the predominant vapor species is the monomer and that the dimer species only become significant close to the melting points. No dimeric species were observed for $\mathrm{NiBr}_{2} .{ }^{127}$ In contrast, the vapor above $\mathrm{ZnBr}_{2}$ can contain a considerable proportion of dimeric species. ${ }^{128}$

\section{RESULTS}

This section is divided into subsections concerning each of the metals, and the metals are presented in the reverse order of their d-electron configurations. However, before the experimental data are considered, the DFT results on the ground and lowlying excited states are discussed.

DFT Calculations on the Ground and Low-Lying Excited States of $\mathrm{MBr}_{2}$ and $\mathrm{Ml}_{2}$. Density functional theory has been employed to calculate the geometries and spectroscopic properties of the ground and lowest-lying excited electronic states for the dibromides and diiodides. Wang and Schwarz ${ }^{129}$ have carried out DFT calculations for the difluorides and dichlorides of the $3 \mathrm{~d}$ transition elements. Although there have been many subsequent papers on chlorides and fluorides, there has not been a systematic study of all of the dibromides and diiodides, although individual reports detailing calculations on the dibromides and diiodides of manganese, ${ }^{130}$ iron, ${ }^{131,132}$ cobalt, ${ }^{133}$ nickel, ${ }^{132}$ and zinc $^{134,135}$ have been published, as well as a comparison of different DFT methods for calculating heats of formation and ionization potentials of third-row transition elements. ${ }^{136}$ Therefore, we have carried out a comprehensive and consistent set of calculations on the ground and lowest-lying excited states for all 
of the $3 \mathrm{~d}$ transition metal dibromides and diiodides as well as those of $\mathrm{Ca}$. The optimized geometries, vibrational frequencies, and IR intensities are given in Tables 1 and 2 and are in good agreement with those of Wang and Schwarz ${ }^{129}$ for the analogous dichlorides and difluorides. The numbers of low-lying excited states, both linear and bent, should be noted.

Zinc Dibromide. Vapor-phase electron diffraction studies on zinc dichloride, dibromide, and diiodide ${ }^{137}$ showed them all to be linear with a $\mathrm{Zn}-\mathrm{Br}$ bond length $\left(r_{\mathrm{g}}\right)$ of 2.204(5) $\AA$ in $\mathrm{ZnBr}_{2}$. XAFS studies ${ }^{67}$ on matrix-isolated $\mathrm{ZnCl}_{2}$ in argon and nitrogen matrices obtained bond distances that are in agreement with those obtained by vapor-phase electron diffraction $\left(r_{\mathrm{g}}\right) .^{137}$ Loewenschuss and co-workers conducted vibrational spectroscopy studies on all of the zinc dihalides isolated in krypton matrices, ${ }^{96,97}$ with particular interest shown in the formation of mixed dihalides. ${ }^{97,123}$

Infrared Spectroscopy. The IR spectra of $\mathrm{ZnBr}_{2}$ isolated in neon, argon, krypton, xenon, methane, ${ }^{14} \mathrm{~N}_{2}$, and ${ }^{15} \mathrm{~N}_{2}$ matrices are shown in Figure 5, and the observed frequencies of the $\nu_{3}$ asymmetric $\mathrm{ZnBr}_{2}$ stretching mode are given in Table 3. These data are in very good agreement with the $\mathrm{Kr}$ matrix data reported by Loewenschuss et al. ${ }^{96,97}$ What is immediately clear is that all of the vibrational frequencies are very close to each other, indicating only a very small effect of the matrix on the vibrational energy levels of the trapped molecules.

At $2 \mathrm{~cm}^{-1}$ resolution, the $\mathrm{Zn}$ isotope pattern is clearly resolved with absorption intensities in line with the isotopic natural abundance $\left({ }^{64} \mathrm{Zn}, 48.6 \%\right.$; ${ }^{66} \mathrm{Zn}, 27.9 \%$; $\left.{ }^{68} \mathrm{Zn}, 18.8 \%\right)$. SVFF calculations (Table 3) using these data clearly indicate the linearity of $\mathrm{ZnBr}_{2}$ in all of the matrices studied. $\mathrm{ZnCl}_{2}$ vapor has been shown to contain a considerable concentration of dimer molecules, ${ }^{128}$ and Loewenschuss and co-workers assigned a band at $326 \mathrm{~cm}^{-1}$ in the spectrum of $\mathrm{ZnBr}_{2}$ isolated in krypton as belonging to the $\mathrm{ZnBr}_{2}$ dimer. ${ }^{96,97}$ None of the spectra recorded in this study showed any significant absorption bands in this region. The broad features at ca. $380 \mathrm{~cm}^{-1}$ in the spectrum of $\mathrm{ZnBr}_{2}$ isolated in neon in Figure 5a are most likely to be associated with the problems of using $\mathrm{Ne}$ as a matrix with an 8-9 $\mathrm{K}$ cryostat. However, the $0.25 \mathrm{~cm}^{-1}$ resolution spectrum of $\mathrm{ZnBr}_{2}$ isolated in neon shown in Figure $5 \mathrm{~b}$ afforded both zinc and bromine isotopic fine structure (Table 3), both indicating a linear geometry and that the $\mathrm{ZnBr}_{2}$ was well-isolated. This spectrum clearly shows the presence of multiple trapping sites in $\mathrm{Ne}$, which are often observed. When $\mathrm{ZnBr}_{2}$ was isolated in an ${ }^{15} \mathrm{~N}_{2}$ matrix (Figure 5h), the shift of the $\nu_{3}$ mode from an ${ }^{14} \mathrm{~N}_{2}$ matrix (Figure $5 \mathrm{~g}$ ) was ca. $0.1 \mathrm{~cm}^{-1}$.

Photolysis studies of $\mathrm{ZnBr}_{2}$ in ${ }^{14} \mathrm{~N}_{2}$ and ${ }^{15} \mathrm{~N}_{2}$ matrices produced no change in the absorption bands in the FIR and MIR. In addition to the usual $\mathrm{H}_{2} \mathrm{O}$ and $\mathrm{CO}_{2}$ bands in the MIR, additional bands were observed in the ${ }^{15} \mathrm{~N}_{2}$ matrix at 2252.2 and $2250.0 \mathrm{~cm}^{-1}$ (Figure 6 and Table 4). The latter of these (marked with *) has been previously assigned as an impurity-induced ${ }^{15} \mathrm{~N}_{2}$ mode. ${ }^{138}$ In the ${ }^{14} \mathrm{~N}_{2}$ matrix, the impurity-induced $\mathrm{N}_{2}$ mode was observed at $2327.8 \mathrm{~cm}^{-1},{ }^{138}$ together with a new band at $2329.9 \mathrm{~cm}^{-1}$.

The bands to high wavenumber of the impurity-induced ones are discussed in more detail in later sections, but their assignment was only possible once they had been clearly identified in the ${ }^{15} \mathrm{~N}_{2}$ matrices because of the problems with masking of this region for ${ }^{14} \mathrm{~N}_{2}$ by gas- and matrix-phase $\mathrm{CO}_{2}$. DFT calculations indicate that the reaction enthalpy for the formation of either a mono- or bis-dinitrogen $\mathrm{ZnBr}_{2}$ complex is about $-1 \mathrm{~kJ} \mathrm{~mol}^{-1}$.
The isolation of a metal dihalide in a matrix can be viewed as being analogous to solvation in many ways. The small consistent matrix shift observed for $\mathrm{ZnBr}_{2}$ is analogous to a solvent shift and indicated that there was no significant change in the geometry of $\mathrm{ZnBr}_{2}$ among all of the matrices studied.

XAFS Spectroscopy. $\mathrm{ZnBr}_{2}$ was isolated in a nitrogen matrix, and both the $\mathrm{Zn}$ and $\mathrm{Br}$ K-edge XAFS spectra were obtained. However, the data for this system were of such poor quality, particularly the $\mathrm{Zn} \mathrm{K}$-edge spectrum because of several large, unnormalized glitches of instrumental origin, that the data were essentially unanalyzable, except for an estimate of 2.19(2) A for the $\mathrm{Zn}-\mathrm{Br}$ bond length, which is in good agreement with the electron diffraction data previously obtained by Hargittai and co-workers (2.204(5) $)$ ). ${ }^{137}$ Therefore, no other matrices were studied using XAFS because of the instrumental origin of the glitches, and hence, no firm conclusions can be drawn from the XAFS data.

Conclusion. From the IR results, the consistent matrix shift observed for $\mathrm{ZnBr}_{2}$ in all of the matrix hosts studied, combined with the bond angle calculations, suggest that $\mathrm{ZnBr}_{2}$ has minimal interaction with the matrix and preserves its linear geometry in all cases. The order of interaction for $\mathrm{ZnBr}_{2}$ is $\mathrm{Ne}<\mathrm{Ar}<$ $\mathrm{Kr}<\mathrm{CH}_{4}<\mathrm{Xe}<\mathrm{N}_{2}$, which is in very good agreement with order proposed by Beattie and Millington. ${ }^{15}$ There is no experimental evidence that $\mathrm{ZnBr}_{2}$ is anything but linear in $\mathrm{Ne}, \mathrm{Ar}, \mathrm{Kr}$, $\mathrm{Xe}, \mathrm{CH}_{4}$, and $\mathrm{N}_{2}$ matrices.

Nickel Dibromide. Nickel dihalides, and in particular $\mathrm{NiCl}_{2}$ with its easily resolved nickel and chlorine isotope patterns, have received the most attention in the matrix isolation literature of all the dihalides investigated in this work. The IR spectra of $\mathrm{NiF}_{2}$ isolated in neon and argon matrices ${ }^{101,139}$ and also in argon matrices doped with $\mathrm{N}_{2}$ and $\mathrm{O}_{2}{ }^{140,141}$ have been studied. A bond angle of $152^{\circ}$ was calculated for $\mathrm{NiF}_{2}$ isolated in $\mathrm{Ne}$ or $\mathrm{Ar}$ matrices by Margrave and co-workers, compared with $157^{\circ}$ for $\mathrm{ZnF}_{2}{ }^{139}$ but as discussed below, these are at the margins of what could be considered as linear.

While $\mathrm{NiF}_{2} \cdot \mathrm{N}_{2}$ and $\mathrm{NiF}_{2} \cdot \mathrm{O}_{2}$ complexes were proposed by DeKock and Van Leirsburg using $\mathrm{N}_{2}$-doped Ar matrices, ${ }^{140,141}$ no $\nu_{\mathrm{NN}}$ modes were observed for $\mathrm{NiF}_{2} \cdot \mathrm{N}_{2}$ other than the impurityinduced mode, even in a pure $\mathrm{N}_{2}$ matrix. $\mathrm{NiCl}_{2}$ has been the subject of numerous studies in an argon matrix, with IR, ${ }^{99,101,140-142}$ electronic absorption, ${ }^{102,103}$ and fluorescence ${ }^{143}$ spectra all indicating a linear or nearly linear structure. $\mathrm{NiCl}_{2}$ has also been the subject of a number of very elegant molecular beam experiments with vibrational and rotational resolution on the 460 and $360 \mathrm{~nm}$ bands, which showed that it is linear in both the ground and excited states, with a ${ }^{3} \Sigma_{\mathrm{g}}^{-}$ground state. ${ }^{144-150}$

Green and co-workers ${ }^{151}$ proposed that $\mathrm{NiCl}_{2}$ isolated in an argon matrix has a nonlinear structure with a calculated bond angle of $161^{\circ}$. However, it has been shown ${ }^{17,148}$ that a difference between the calculated isotope shifts of only ca. $0.1 \mathrm{~cm}^{-1}$ results in a change in bond angle from $180^{\circ}$ to $160^{\circ}$. EXAFS data for $\mathrm{NiCl}_{2}$ isolated in a methane matrix ${ }^{67}$ indicated a linear structure, whereas in a $\mathrm{N}_{2}$ matrix, $\mathrm{NiCl}_{2}{ }^{67}$ and $\mathrm{NiBr}_{2}{ }^{68}$ are strongly bent. $\mathrm{N}_{2}$ and $\mathrm{O}_{2}$ complexes of $\mathrm{NiCl}_{2}$ analogous to those of $\mathrm{NiF}_{2}$ have also been postulated by DeKock and Van Leirsburg. ${ }^{140,141}$ Clearly, the nature of the geometry of nickel dihalides isolated in $\mathrm{Ne}, \mathrm{Ar}$, and $\mathrm{N}_{2}$ matrices has been a contentious issue. The literature reports on matrix $\mathrm{NiBr}_{2}$ concern its isolation in an argon matrix ${ }^{99}$ and our more recent preliminary work. ${ }^{68,69}$ Electron diffraction data indicate linearity in the vapor phase. ${ }^{152}$

Infrared Spectroscopy. The IR spectra of $\mathrm{NiBr}_{2}$ isolated in $\mathrm{Ar}, \mathrm{Kr}, \mathrm{Xe}, \mathrm{O}_{2}$, and $\mathrm{CH}_{4}$ matrices are shown in Figure 7, and 
Table 1. DFT-Calculated Parameters for Ground and Low-Lying Excited States of 3d Transition Metal Dibromides

\begin{tabular}{|c|c|c|c|c|c|}
\hline \multirow[b]{2}{*}{ electronic state } & \multirow[b]{2}{*}{ bond length/Å } & \multicolumn{3}{|c|}{ vibrational data $/ \mathrm{cm}^{-1}$ (intensity) } & \multirow[b]{2}{*}{$E_{\text {rel }} / \mathrm{eV}$} \\
\hline & & $\Sigma_{g}$ & $\overline{\Sigma_{\mathrm{u}}}$ & $\Pi_{\mathrm{u}}$ & \\
\hline \multicolumn{6}{|c|}{$\mathrm{CaBr}_{2}$} \\
\hline${ }^{1} \Sigma_{\mathrm{g}}^{+}\left(\sigma_{\mathrm{g}}^{0} \delta_{\mathrm{g}}{ }^{0} \pi_{\mathrm{g}}^{0}\right)$ & 2.609 & $170(0)$ & $343(186)$ & $27(43)$ & \\
\hline \multicolumn{6}{|c|}{$\mathrm{ScBr}_{2}$} \\
\hline${ }^{2} \mathrm{~A}_{1}\left(\sigma^{1}=\mathrm{a}_{1}^{1}\right)$ & $2.381\left(128^{\circ}\right)$ & $279(18)$ & $384(95)$ & $46(3)$ & 0 \\
\hline${ }^{2} \Sigma_{\mathrm{g}}^{+}\left(\sigma_{\mathrm{g}}{ }^{1} \delta_{\mathrm{g}}^{0} \pi_{\mathrm{g}}^{0}\right)$ & 2.443 & $209(0)$ & $403(157)$ & $-45(6)$ & 0.803 \\
\hline${ }^{2} \Delta_{\mathrm{g}}\left(\sigma_{\mathrm{g}}^{0} \delta_{\mathrm{g}}{ }^{1} \pi_{\mathrm{g}}^{0}\right)$ & 2.500 & & & & 1.320 \\
\hline${ }^{2} \Pi_{\mathrm{g}}\left(\sigma_{\mathrm{g}}^{0} \delta_{\mathrm{g}}^{0} \pi_{\mathrm{g}}{ }^{1}\right)$ & 2.532 & & & & 1.792 \\
\hline \multicolumn{6}{|c|}{$\mathrm{TiBr}_{2}$} \\
\hline${ }^{3} \Delta_{\mathrm{g}}\left(\sigma_{\mathrm{g}}{ }^{1} \delta_{\mathrm{g}}{ }^{1} \pi_{\mathrm{g}}{ }^{0}\right)$ & 2.396 & $196(0)$ & $375(150)$ & $34(6)$ & 0 \\
\hline${ }^{3} \Sigma_{\mathrm{g}}^{+}\left(\sigma_{\mathrm{g}}^{0} \delta_{\mathrm{g}}^{2} \pi_{\mathrm{g}}^{0}\right)$ & 2.399 & & & & 0.402 \\
\hline${ }^{3} \mathrm{II}_{\mathrm{g}}\left(\sigma_{\mathrm{g}}{ }^{1} \delta_{\mathrm{g}}^{0} \pi_{\mathrm{g}}{ }^{1}\right)$ & 2.396 & & & & 1.050 \\
\hline${ }^{1} \Sigma_{\mathrm{g}}^{+}\left(\sigma_{\mathrm{g}}^{2} \delta_{\mathrm{g}}^{0} \pi_{\mathrm{g}}^{0}\right)$ & 2.325 & & & & 1.242 \\
\hline \multicolumn{6}{|c|}{$\mathrm{VBr}_{2}$} \\
\hline${ }^{4} \Sigma_{\mathrm{g}}^{-}\left(\sigma_{\mathrm{g}}{ }^{1} \delta_{\mathrm{g}}^{2} \pi_{\mathrm{g}}^{0}\right)$ & 2.329 & $208(0)$ & $394(134)$ & $31(4)$ & 0 \\
\hline${ }^{4} \mathrm{II}_{\mathrm{g}}\left(\sigma_{\mathrm{g}}^{0} \delta_{\mathrm{g}}^{2} \pi_{\mathrm{g}}^{1}\right)$ & 2.385 & & & & 0.783 \\
\hline${ }^{2} \Delta_{\mathrm{g}}\left(\sigma_{\mathrm{g}}^{2} \delta_{\mathrm{g}}{ }^{1} \pi_{\mathrm{g}}^{0}\right)$ & 2.280 & & & & 1.784 \\
\hline${ }^{2} \mathrm{II}_{\mathrm{g}}\left(\sigma_{\mathrm{g}}^{2} \delta_{\mathrm{g}}^{0} \pi_{\mathrm{g}}^{1}\right)$ & 2.298 & & & & 3.253 \\
\hline \multicolumn{6}{|c|}{$\mathrm{CrBr}_{2}$} \\
\hline${ }^{5} \mathrm{II}_{\mathrm{g}}\left(\delta_{\mathrm{g}}^{2} \sigma_{\mathrm{g}}{ }^{1} \pi_{\mathrm{g}}^{1}\right)$ & 2.319 & $201(0)$ & $386(88)$ & $50(5)$ & 0 \\
\hline${ }^{5} \Sigma_{\mathrm{g}}^{+}\left(\delta_{\mathrm{g}}^{2} \sigma_{\mathrm{g}}^{0} \pi_{\mathrm{g}}^{2}\right)$ & 2.364 & & & & 0.484 \\
\hline${ }^{5} \Delta_{\mathrm{g}}\left(\delta_{\mathrm{g}}{ }^{1} \sigma_{\mathrm{g}}{ }^{1} \pi_{\mathrm{g}}{ }^{2}\right)$ & 2.325 & & & & 1.318 \\
\hline${ }^{3} \Sigma_{\mathrm{g}}^{-}\left(\delta_{\mathrm{g}}^{2} \sigma_{\mathrm{g}}^{2} \pi_{\mathrm{g}}^{0}\right)$ & 2.245 & & & & 1.493 \\
\hline${ }^{1} \Sigma_{\mathrm{g}}^{+}\left(\delta_{\mathrm{g}}{ }^{4} \sigma_{\mathrm{g}}^{0} \pi_{\mathrm{g}}^{0}\right)$ & 2.271 & & & & 4.865 \\
\hline \multicolumn{6}{|c|}{$\mathrm{MnBr}_{2}$} \\
\hline${ }^{6} \Sigma_{\mathrm{g}}^{-}\left(\delta_{\mathrm{g}}^{2} \sigma_{\mathrm{g}}{ }^{1} \pi_{\mathrm{g}}^{2}\right)$ & 2.324 & $199(0)$ & $372(111)$ & $66(9)$ & 0 \\
\hline${ }^{4} \Phi_{\mathrm{g}}\left(\delta_{\mathrm{g}}^{3} \sigma_{\mathrm{g}}{ }^{1} \pi_{\mathrm{g}}{ }^{1}\right)$ & 2.271 & & & & 2.532 \\
\hline${ }^{4} \Delta_{\mathrm{g}}\left(\delta_{\mathrm{g}}^{3} \sigma_{\mathrm{g}}^{0} \pi_{\mathrm{g}}^{2}\right)$ & 2.319 & & & & 3.008 \\
\hline${ }^{2} \Phi_{\mathrm{g}}\left(\delta_{\mathrm{g}}^{3} \sigma_{\mathrm{g}}^{2} \pi_{\mathrm{g}}^{0}\right)$ & 2.207 & & & & 3.345 \\
\hline${ }^{2} \Pi_{\mathrm{g}}\left(\delta_{\mathrm{g}}{ }^{4}{\sigma_{\mathrm{g}}}^{0} \pi_{\mathrm{g}}{ }^{1}\right)$ & 2.255 & & & & 5.272 \\
\hline \multicolumn{6}{|c|}{$\mathrm{FeBr}_{2}$} \\
\hline${ }^{5} \Delta_{\mathrm{g}}\left(\delta_{\mathrm{g}}^{3} \sigma_{\mathrm{g}}^{1} \pi_{\mathrm{g}}^{2}\right)$ & 2.254 & $217(0)$ & $404(104)$ & $53(6)$ & 0 \\
\hline${ }^{5} \Sigma_{\mathrm{g}}^{-}\left(\delta_{\mathrm{g}}^{2} \sigma_{\mathrm{g}}^{2} \pi_{\mathrm{g}}^{2}\right)$ & 2.252 & & & & 0.005 \\
\hline${ }^{5} \Pi_{\mathrm{g}}\left(\delta_{\mathrm{g}}^{2} \sigma_{\mathrm{g}}^{1} \pi_{\mathrm{g}}^{3}\right)$ & 2.284 & & & & 0.284 \\
\hline${ }^{3} \Pi_{\mathrm{g}}\left(\delta_{\mathrm{g}}^{4} \sigma_{\mathrm{g}}{ }^{1} \pi_{\mathrm{g}}{ }^{1}\right)$ & 2.226 & & & & 2.221 \\
\hline${ }^{1} \Sigma_{\mathrm{g}}^{+}\left(\delta_{\mathrm{g}}^{4} \sigma_{\mathrm{g}}^{2} \pi_{\mathrm{g}}^{0}\right)$ & 2.173 & & & & 2.649 \\
\hline \multicolumn{6}{|c|}{$\mathrm{CoBr}_{2}$} \\
\hline${ }^{4} \Delta_{\mathrm{g}}\left(\delta_{\mathrm{g}}^{3} \sigma_{\mathrm{g}}^{2} \pi_{\mathrm{g}}^{2}\right)$ & 2.210 & $216(0)$ & $398(69)$ & $63(2)$ & 0 \\
\hline${ }^{4} \mathrm{~B}_{1}$ & $2.211(155)$ & $229(1)$ & $390(63)$ & & 0.108 \\
\hline${ }^{4} B_{1}$ & $2.212(130)$ & $261(4)$ & $367(49)$ & & 0.296 \\
\hline${ }^{4} \Sigma_{\mathrm{g}}^{-}\left(\delta_{\mathrm{g}}^{4} \sigma_{\mathrm{g}}{ }^{1} \pi_{\mathrm{g}}^{2}\right)$ & 2.212 & & & & 0.331 \\
\hline${ }^{4} \mathrm{~B}_{1}$ & $2.241(105)$ & $291(8)$ & $313(28)$ & & 0.726 \\
\hline${ }^{4} \Phi_{\mathrm{g}}\left(\delta_{\mathrm{g}}^{3} \sigma_{\mathrm{g}}{ }^{1} \pi_{\mathrm{g}}^{3}\right)$ & 2.249 & & & & 0.480 \\
\hline${ }^{2} \Pi_{\mathrm{g}}\left(\delta_{\mathrm{g}}{ }^{4} \sigma_{\mathrm{g}}^{2} \pi_{\mathrm{g}}{ }^{1}\right)$ & 2.179 & & & & 1.148 \\
\hline \multicolumn{6}{|c|}{$\mathrm{NiBr}_{2}$} \\
\hline${ }^{3} \Sigma_{\mathrm{g}}^{-}\left(\delta_{\mathrm{g}}^{4} \sigma_{\mathrm{g}}^{2} \pi_{\mathrm{g}}^{2}\right)$ & 2.180 & $218(0)$ & $405(56)$ & $68(1)$ & 0 \\
\hline${ }^{3} \mathrm{~B}_{1}$ & $2.181(155)$ & $231(1)$ & $397(51)$ & - & 0.070 \\
\hline${ }^{3} \mathrm{~B}_{1}$ & $2.182(130)$ & $266(3)$ & $376(34)$ & - & 0.293 \\
\hline${ }^{3} \Pi_{\mathrm{g}}\left(\delta_{\mathrm{g}}{ }^{4} \sigma_{\mathrm{g}}{ }^{1} \pi_{\mathrm{g}}{ }^{3}\right)$ & 2.218 & & & & 0.643 \\
\hline${ }^{3} \mathrm{~B}_{1}$ & $2.213(105)$ & & & & 0.703 \\
\hline${ }^{3} \Phi_{\mathrm{g}}\left(\delta_{\mathrm{g}}^{3} \sigma_{\mathrm{g}}^{2} \pi_{\mathrm{g}}^{3}\right)$ & 2.214 & & & & 0.984 \\
\hline${ }^{3} \Delta_{\mathrm{g}}\left(\delta_{\mathrm{g}}{ }^{3} \sigma_{\mathrm{g}}{ }^{1} \pi_{\mathrm{g}}{ }^{4}\right)$ & 2.256 & & & & 1.444 \\
\hline \multicolumn{6}{|c|}{$\mathrm{CuBr}_{2}$} \\
\hline${ }^{2} \Pi_{\mathrm{g}}\left(\delta_{\mathrm{g}}^{4} \sigma_{\mathrm{g}}^{2} \pi_{\mathrm{g}}^{3}\right)$ & 2.198 & $206(0)$ & $370(13)$ & $80(1)$ & 0 \\
\hline${ }^{2} \Sigma_{\mathrm{g}}^{+}\left(\delta_{\mathrm{g}}^{4} \sigma_{\mathrm{g}}{ }^{1} \pi_{\mathrm{g}}^{4}\right)$ & 2.233 & & & & 0.902 \\
\hline${ }^{2} \Delta_{\mathrm{g}}\left(\delta_{\mathrm{g}}^{3} \sigma_{\mathrm{g}}^{2} \pi_{\mathrm{g}}^{4}\right)$ & 2.236 & & & & 2.535 \\
\hline \multicolumn{6}{|c|}{$\mathrm{ZnBr}_{2}$} \\
\hline${ }^{2} \Sigma_{\mathrm{g}}^{+}\left(\delta_{\mathrm{g}}^{4} \sigma_{\mathrm{g}}^{2} \pi_{\mathrm{g}}^{4}\right)$ & 2.223 & $212(0)$ & $390(55)$ & $88(4)$ & \\
\hline
\end{tabular}


Table 2. DFT-Calculated Parameters for Ground and Low-Lying Excited States of 3d Transition Metal Diiodides

\begin{tabular}{|c|c|c|c|c|c|}
\hline \multirow[b]{2}{*}{ electronic state } & \multirow[b]{2}{*}{ bond length/Å } & \multicolumn{3}{|c|}{ vibrational data $/ \mathrm{cm}^{-1}$ (intensity) } & \multirow[b]{2}{*}{$E_{\text {rel }} / \mathrm{eV}$} \\
\hline & & $\Sigma_{g}$ & $\Sigma_{\mathrm{u}}$ & $\Pi_{\mathrm{u}}$ & \\
\hline \multicolumn{6}{|c|}{$\mathrm{CaI}_{2}$} \\
\hline${ }^{1} \Sigma_{\mathrm{g}}^{+}\left(\sigma_{\mathrm{g}}^{0} \delta_{\mathrm{g}}^{0} \pi_{\mathrm{g}}^{0}\right)$ & 2.824 & $129(0)$ & $323(160)$ & 30 & \\
\hline \multicolumn{6}{|c|}{$\mathrm{ScI}_{2}$} \\
\hline${ }^{2} \mathrm{~A}_{1}\left(\sigma^{1}=\mathrm{a}_{1}^{1}\right)$ & 2.657 & $177(14)$ & $318(110)$ & $29(4)$ & 0 \\
\hline${ }^{2} \Sigma_{\mathrm{g}}^{+}\left(\sigma_{\mathrm{g}}^{1} \delta_{\mathrm{g}}^{0} \pi_{\mathrm{g}}^{0}\right)$ & 2.659 & $148(0)$ & $351(136)$ & $-30(5)$ & 0.035 \\
\hline${ }^{2} \Delta_{\mathrm{g}}\left(\sigma_{\mathrm{g}}^{0} \delta_{\mathrm{g}}{ }^{1} \pi_{\mathrm{g}}^{0}\right)$ & 2.716 & & & & 0.481 \\
\hline${ }^{2} \Pi_{\mathrm{g}}\left(\sigma_{\mathrm{g}}^{0} \delta_{\mathrm{g}}{ }^{0} \pi_{\mathrm{g}}{ }^{1}\right)$ & 2.733 & & & & 0.824 \\
\hline \multicolumn{6}{|c|}{$\mathrm{TiI}_{2}$} \\
\hline${ }^{3} \Delta_{\mathrm{g}}\left(\sigma_{\mathrm{g}}{ }^{1} \delta_{\mathrm{g}}{ }^{1} \pi_{\mathrm{g}}{ }^{0}\right)$ & 2.592 & $144(0)$ & $336(129)$ & $16(0)$ & 0 \\
\hline${ }^{3} \Sigma_{\mathrm{g}}^{+}\left(\sigma_{\mathrm{g}}^{0} \delta_{\mathrm{g}}^{2} \pi_{\mathrm{g}}^{0}\right)$ & 2.633 & & & & 0.422 \\
\hline${ }^{3} \Pi_{\mathrm{g}}\left(\sigma_{\mathrm{g}}^{1} \delta_{\mathrm{g}}^{0} \pi_{\mathrm{g}}^{1}\right)$ & 2.594 & & & & 0.929 \\
\hline${ }^{1} \Sigma_{\mathrm{g}}^{+}\left(\sigma_{\mathrm{g}}^{2} \delta_{\mathrm{g}}^{0} \pi_{\mathrm{g}}^{0}\right)$ & 2.532 & & & & 1.220 \\
\hline \multicolumn{6}{|c|}{$\mathrm{VI}_{2}$} \\
\hline${ }^{4} \Sigma_{\mathrm{g}}^{-}\left(\sigma_{\mathrm{g}}{ }^{1} \delta_{\mathrm{g}}^{2} \pi_{\mathrm{g}}{ }^{0}\right)$ & 2.543 & $146(0)$ & $336(108)$ & $30(2)$ & 0 \\
\hline${ }^{4} \Pi_{\mathrm{g}}\left(\sigma_{\mathrm{g}}^{0} \delta_{\mathrm{g}}^{2} \pi_{\mathrm{g}}^{1}\right)$ & 2.593 & & & & 0.168 \\
\hline${ }^{2} \Delta_{\mathrm{g}}\left(\sigma_{\mathrm{g}}^{2} \delta_{\mathrm{g}}{ }^{1} \pi_{\mathrm{g}}^{0}\right)$ & 2.486 & & & & 1.753 \\
\hline${ }^{2} \Pi_{\mathrm{g}}\left(\sigma_{\mathrm{g}}^{2} \delta_{\mathrm{g}}^{0} \pi_{\mathrm{g}}{ }^{1}\right)$ & 2.497 & & & & 4.015 \\
\hline \multicolumn{6}{|c|}{$\mathrm{CrI}_{2}$} \\
\hline${ }^{5} \Pi_{\mathrm{g}}\left(\delta_{\mathrm{g}}^{2} \sigma_{\mathrm{g}}{ }^{1} \pi_{\mathrm{g}}^{1}\right)$ & 2.532 & $140(0)$ & $326(56)$ & $44(3)$ & 0 \\
\hline${ }^{5} \Sigma_{\mathrm{g}}^{+}\left(\delta_{\mathrm{g}}^{2} \sigma_{\mathrm{g}}^{0} \pi_{\mathrm{g}}^{2}\right)$ & 2.567 & & & & 0.552 \\
\hline${ }^{5} \Delta_{\mathrm{g}}\left(\delta_{\mathrm{g}}{ }^{1} \sigma_{\mathrm{g}}{ }^{1} \pi_{\mathrm{g}}{ }^{2}\right)$ & 2.534 & & & & 1.317 \\
\hline${ }^{3} \Sigma_{\mathrm{g}}^{-}\left(\delta_{\mathrm{g}}{ }^{2} \sigma_{\mathrm{g}}^{2} \pi_{\mathrm{g}}^{0}\right)$ & 2.451 & & & & 1.574 \\
\hline${ }^{1} \Sigma_{\mathrm{g}}^{+}\left(\delta_{\mathrm{g}}^{4} \sigma_{\mathrm{g}}^{0} \pi_{\mathrm{g}}^{0}\right)$ & 2.483 & & & & 5.116 \\
\hline \multicolumn{6}{|c|}{$\mathrm{MnI}_{2}$} \\
\hline${ }^{6} \Sigma_{\mathrm{g}}^{-}\left(\delta_{\mathrm{g}}^{2} \sigma_{\mathrm{g}}{ }^{1} \pi_{\mathrm{g}}^{2}\right)$ & 2.511 & $145(0)$ & $331(94)$ & $48(5)$ & 0 \\
\hline${ }^{4} \Phi_{\mathrm{g}}\left(\delta_{\mathrm{g}}{ }^{3} \sigma_{\mathrm{g}}{ }^{1} \pi_{\mathrm{g}}{ }^{1}\right)$ & 2.484 & & & & 2.501 \\
\hline${ }^{4} \Delta_{\mathrm{g}}\left(\delta_{\mathrm{g}}{ }^{3} \sigma_{\mathrm{g}}^{0} \pi_{\mathrm{g}}^{2}\right)$ & 2.507 & & & & 3.076 \\
\hline${ }^{2} \Delta_{\mathrm{g}}\left(\delta_{\mathrm{g}}^{3} \sigma_{\mathrm{g}}^{2} \pi_{\mathrm{g}}^{0}\right)$ & 2.408 & & & & 3.547 \\
\hline${ }^{2} \Pi_{\mathrm{g}}\left(\delta_{\mathrm{g}}^{4} \sigma_{\mathrm{g}}^{0} \pi_{\mathrm{g}}{ }^{1}\right)$ & 2.464 & & & & 5.380 \\
\hline \multicolumn{6}{|c|}{$\mathrm{FeI}_{2}$} \\
\hline${ }^{5} \Sigma_{\mathrm{g}}^{-}\left(\delta_{\mathrm{g}}^{2} \sigma_{\mathrm{g}}^{2} \pi_{\mathrm{g}}^{2}\right)$ & 2.448 & $154(0)$ & $347(85)$ & $37(3)$ & 0 \\
\hline${ }^{5} \Delta_{\mathrm{g}}\left(\delta_{\mathrm{g}}^{3} \sigma_{\mathrm{g}}{ }^{1} \pi_{\mathrm{g}}^{2}\right)$ & 2.448 & & & & 0.076 \\
\hline${ }^{5} \Pi_{\mathrm{g}}\left(\delta_{\mathrm{g}}{ }^{2} \sigma_{\mathrm{g}}{ }^{1} \pi_{\mathrm{g}}^{3}\right)$ & 2.478 & & & & 0.220 \\
\hline${ }^{3} \Pi_{\mathrm{g}}\left(\delta_{\mathrm{g}}^{4} \sigma_{\mathrm{g}}{ }^{1} \pi_{\mathrm{g}}{ }^{1}\right)$ & 2.436 & & & & 2.257 \\
\hline${ }^{1} \Sigma_{\mathrm{g}}^{+}\left(\delta_{\mathrm{g}}{ }^{4} \sigma_{\mathrm{g}}^{2} \pi_{\mathrm{g}}^{0}\right)$ & 2.371 & & & & 2.726 \\
\hline \multicolumn{6}{|c|}{$\mathrm{CoI}_{2}$} \\
\hline${ }^{4} \Delta_{\mathrm{g}}\left(\delta_{\mathrm{g}}^{3} \sigma_{\mathrm{g}}^{2} \pi_{\mathrm{g}}^{2}\right)$ & 2.397 & $155(0)$ & $340(54)$ & $49(1)$ & 0 \\
\hline${ }^{4} \Sigma_{\mathrm{g}}^{-}\left(\delta_{\mathrm{g}}^{4} \sigma_{\mathrm{g}}{ }^{1} \pi_{\mathrm{g}}{ }^{2}\right)$ & 2.416 & & & & 0.432 \\
\hline${ }^{4} \Phi_{\mathrm{g}}\left(\delta_{\mathrm{g}}{ }^{3} \sigma_{\mathrm{g}}{ }^{1} \pi_{\mathrm{g}}{ }^{3}\right)$ & 2.443 & & & & 0.450 \\
\hline${ }^{2} \Pi_{\mathrm{g}}\left(\delta_{\mathrm{g}}^{4} \sigma_{\mathrm{g}}^{2} \pi_{\mathrm{g}}{ }^{1}\right)$ & 2.379 & & & & 1.110 \\
\hline \multicolumn{6}{|c|}{$\mathrm{NiI}_{2}$} \\
\hline${ }^{3} \Sigma_{\mathrm{g}}^{-}\left(\delta_{\mathrm{g}}^{4} \sigma_{\mathrm{g}}^{2} \pi_{\mathrm{g}}^{2}\right)$ & 2.368 & $155(0)$ & $341(42)$ & $52(0)$ & 0 \\
\hline${ }^{3} \Pi_{\mathrm{g}}\left(\delta_{\mathrm{g}}^{4} \sigma_{\mathrm{g}}{ }^{1} \pi_{\mathrm{g}}^{3}\right)$ & 2.413 & & & & 0.634 \\
\hline${ }^{3} \Phi_{\mathrm{g}}\left(\delta_{\mathrm{g}}^{3} \sigma_{\mathrm{g}}^{2} \pi_{\mathrm{g}}^{3}\right)$ & 2.401 & & & & 0.860 \\
\hline${ }^{3} \Delta_{\mathrm{g}}\left(\delta_{\mathrm{g}}^{3} \sigma_{\mathrm{g}}{ }^{1} \pi_{\mathrm{g}}^{4}\right)$ & 2.453 & & & & 1.495 \\
\hline \multicolumn{6}{|c|}{$\mathrm{CuI}_{2}$} \\
\hline${ }^{2} \Pi_{\mathrm{g}}\left(\delta_{\mathrm{g}}^{4} \sigma_{\mathrm{g}}^{2} \pi_{\mathrm{g}}^{3}\right)$ & 2.371 & $152(0)$ & $320(6)$ & $60(1)$ & 0 \\
\hline${ }^{2} \Sigma_{\mathrm{g}}^{+}\left(\delta_{\mathrm{g}}^{4} \sigma_{\mathrm{g}}^{1} \pi_{\mathrm{g}}^{4}\right)$ & 2.434 & & & & 1.105 \\
\hline${ }^{2} \Delta_{\mathrm{g}}\left(\delta_{\mathrm{g}}^{3} \sigma_{\mathrm{g}}^{2} \pi_{\mathrm{g}}^{4}\right)$ & 2.432 & & & & 2.735 \\
\hline \multicolumn{6}{|c|}{$\mathrm{ZnI}_{2}$} \\
\hline${ }^{2} \Sigma_{\mathrm{g}}^{+}\left(\delta_{\mathrm{g}}^{4} \sigma_{\mathrm{g}}^{2} \pi_{\mathrm{g}}^{4}\right)$ & 2.418 & $150(0)$ & $330(50)$ & $72(2)$ & \\
\hline
\end{tabular}

the observed frequencies of the $\nu_{3}$ asymmetric $\mathrm{Ni}-\mathrm{Br}$ stretching vibration are given in Table 5. There is reasonable agreement with the previous argon data. ${ }^{99}$ The spectra obtained at $2 \mathrm{~cm}^{-1}$ resolution, shown in Figure 7, produced clear bands due to the ${ }^{58} \mathrm{Ni}$ and ${ }^{60} \mathrm{Ni}$ isotopes (natural abundances of $68.3 \%$ and
$26.1 \%$, respectively), with the ${ }^{62} \mathrm{Ni}$ isotope (natural abundance $3.6 \%$ ) also observed after prolonged deposition. It is clear from the relative positions of the $\nu_{3}$ modes in the spectra that a simple matrix shift is observed for $\mathrm{NiBr}_{2}$, analogous to the $\mathrm{ZnBr}_{2}$ case. Bond angle determination from the ${ }^{58} \mathrm{Ni}$ and ${ }^{60} \mathrm{Ni}$ isotope 


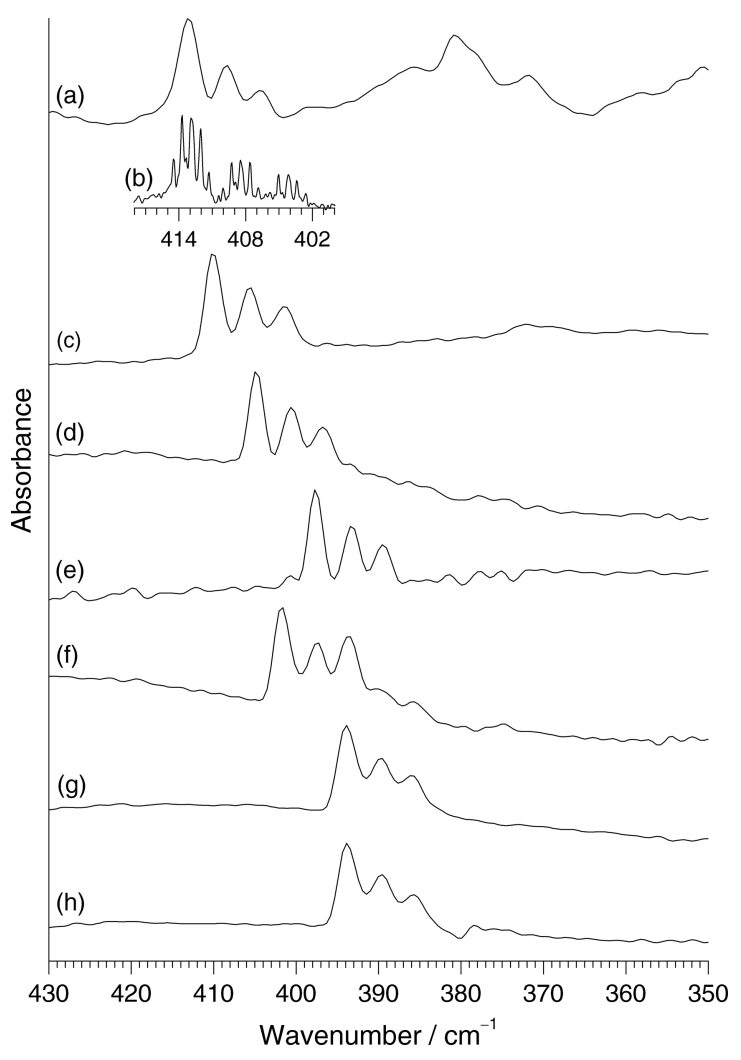

Figure 5. IR spectra of $\mathrm{ZnBr}_{2}$ isolated in (a) $\mathrm{Ne}$, (b) Ne at high resolution, (c) $\mathrm{Ar}$, (d) $\mathrm{Kr}$, (e) $\mathrm{Xe}$, (f) $\mathrm{CH}_{4},(\mathrm{~g}){ }^{14} \mathrm{~N}_{2}$, and (h) ${ }^{15} \mathrm{~N}_{2}$ matrices.

pattern and also from the ${ }^{58} \mathrm{Ni}^{79} \mathrm{Br}_{2}$ and ${ }^{58} \mathrm{Ni}^{81} \mathrm{Br}_{2}$ absorption bands resolved in $\mathrm{Ar}$ (Figure 7a), $\mathrm{O}_{2}$ (Figure 7b), $\mathrm{Kr}$ (Figure 7c), and $\mathrm{Xe}$ (Figure $7 \mathrm{e}$ ) matrices all indicated a linear structure (Table 5). In line with the previous report on $\mathrm{NiCl}_{2}$ isolated in an $\mathrm{Ar} / \mathrm{O}_{2}$ matrix, ${ }^{140,141}$ no $\mathrm{O}-\mathrm{O}$ stretches were seen for $\mathrm{NiBr}_{2}$ isolated in an $\mathrm{O}_{2}$ matrix or after broadband photolysis. This was perhaps not surprising, as the interaction between the guest molecule and the matrix seems to be weak since the gas-phase molecular geometry was preserved. Indeed, the broad absorption band observed for $\mathrm{NiCl}_{2}$ in mixed $\mathrm{Ar} / \mathrm{O}_{2}$ matrices at $480.2 \mathrm{~cm}^{-1}$ (compared with $520.7 \mathrm{~cm}^{-1}$ for a pure Ar matrix) and assigned $^{140,141}$ as the asymmetric stretch of $\mathrm{NiCl}_{2} \mathrm{O}_{2}$ may be simply due to the perturbed asymmetric stretch of $\mathrm{NiCl}_{2}$ in a predominantly $\mathrm{O}_{2}$ environment or mixed $\mathrm{Ar} / \mathrm{O}_{2}$ environment.

The $\nu_{\mathrm{Ni}-\mathrm{Br}}$ modes for $\mathrm{NiBr}_{2}$ in nitrogen matrices are shifted by ca. $90 \mathrm{~cm}^{-1}$ (419.1 $\mathrm{cm}^{-1}$ in Ar to $331.8 \mathrm{~cm}^{-1}$ in $\mathrm{N}_{2}$ ) (Figure $7 \mathrm{f}, \mathrm{g}$ ). As identified in our preliminary IR data, this indicates a very bent geometry for $\mathrm{NiBr}_{2}$ in a nitrogen matrix, with a bond angle of ca. $125^{\circ} .^{68}$ IR studies by Beattie et al. ${ }^{16,17}$ also found that $\mathrm{NiCl}_{2}$ isolated in a $\mathrm{N}_{2}$ matrix was also strongly bent, with a bond angle of ca. $130^{\circ}$. These observations are in contrast to what is seen for the other matrices described above, where bond angle calculations indicated linear geometries. When ${ }^{15} \mathrm{~N}_{2}$ was used instead of ${ }^{14} \mathrm{~N}_{2}$ (Figure $7 \mathrm{~g}$ ), the $\nu_{3}$ mode shifted by $0.3 \mathrm{~cm}^{-1}$ to $331.5 \mathrm{~cm}^{-1}$, indicating an enhanced interaction between the $\mathrm{NiBr}_{2}$ guest and $\mathrm{N}_{2}$ host compared with the $0.1 \mathrm{~cm}^{-1}$ shift observed for $\mathrm{ZnBr}_{2}$. The separation of the features due to the $\mathrm{Ni}$ isotopes was less defined in the $\mathrm{N}_{2}$ matrices than previously seen for the other matrices and is a direct consequence of the change in bond angle, as the central-element isotope splitting decreases on bending, whereas the terminal-atom isotope splitting increases. The $\mathrm{Br}$ isotope splitting pattern could not be resolved in nitrogen matrices. The nature of the very weak bands centered around $315 \mathrm{~cm}^{-1}$ is uncertain, but they are probably not due to dimers, as these would be expected to be at lower energy ${ }^{99}$ and their shape and intensity are also not consistent with dimer modes. These bands are more likely to be some sort of matrix site effect that is dependent on the experimental conditions. It is conceivable that they are the $\nu_{1}$ modes, but our calculations show that for bond angles of ca. $130^{\circ}$ the $\nu_{3}-\nu_{1}$ separation is expected to be in excess of $100 \mathrm{~cm}^{-1}$.

The low-energy bending mode of $\mathrm{NiBr}_{2}$ in argon matrices has been reported previously to be $69 \mathrm{~cm}^{-1}$. 99 This is below the range of most commercial spectrometers, so in order to determine how the bending mode was affected by varying the matrix gas, synchrotron radiation far-IR experiments were carried out. The SR-FIR spectra of $\mathrm{NiBr}_{2}$ trapped in $\mathrm{Ar}, \mathrm{N}_{2}$, and $\mathrm{CH}_{4}$ matrices are shown in Figure 8. These experiments utilized heavy deposits because the DFT calculations indicated that the intensity of the $\nu_{2}$ bending mode would be about $1-2 \%$ of that of the $\nu_{3}$ mode. Unfortunately, it is clear from the SR-FIR argon matrix spectrum (Figure 8a) that the low-energy part of the spectrum $\left(<100 \mathrm{~cm}^{-1}\right)$, where the bending modes are expected to appear, is dominated by the Ar phonon bands (32.4 and $\left.70.8 \mathrm{~cm}^{-1}\right)$ and bands due to nearly freely rotating water molecules $\left(<40 \mathrm{~cm}^{-1}\right)$ and argon hydrates $\left(40-100 \mathrm{~cm}^{-1}\right) .{ }^{153,154}$ While the water bands could be reduced by prolonged pumping and baking of the vacuum system, this was not feasible in the limited amount of SR-FIR time available, and water bands are essentially impossible to remove completely. In nitrogen matrices (Figure $8 \mathrm{~b}$ ) the spectrum is also badly affected by the $\mathrm{N}_{2}$ lattice modes at 49 and $71 \mathrm{~cm}^{-1}$ and the water libration bands at 147 and $225 \mathrm{~cm}^{-1} \cdot 153,154$ The $225 \mathrm{~cm}^{-1}$ bands are usually obscured when CsI optics are used down to $200 \mathrm{~cm}^{-1}$. Therefore, it is not possible to identify the $\nu_{2}$ mode with any certainty in $\mathrm{Ar}$ or $\mathrm{N}_{2}$ matrices. However, in the spectrum of $\mathrm{NiBr}_{2}$ isolated in $\mathrm{CH}_{4}$ (Figure 8c) there is a band at $55 \mathrm{~cm}^{-1}$, which is in reasonable agreement with the earlier Ar matrix value of $69 \mathrm{~cm}^{-1}$.99

If the molecule is severely bent in nitrogen, the $\nu_{1}$ mode would be expected to gain some intensity, but there is no convincing evidence of this in any of the IR spectra. The DFT calculations indicate that the intensity of the $\nu_{1}$ mode relative to the $\nu_{3}$ mode is ca. $10 \%$ at $130^{\circ}$ and ca. $2 \%$ at $155^{\circ}$. One explanation for the apparent absence of $\nu_{1}$ is that it is masked by the broad libration modes of $\mathrm{H}_{2} \mathrm{O}$ in $\mathrm{N}_{2}$ around $225 \mathrm{~cm}^{-1}$, or it could possibly be the weak features at $315 \mathrm{~cm}^{-1}$. The DFT calculations indicate that the separation of $\nu_{1}$ and $\nu_{3}$ decreases upon bending, and the separation is expected to be around $100 \mathrm{~cm}^{-1}$ for bond angles around $130^{\circ}$. Therefore, the most likely explanation is that the $\nu_{1}$ mode is masked by the broad modes around $250-200 \mathrm{~cm}^{-1}$ in nitrogen matrices.

Experiments were also carried out on $\mathrm{NiF}_{2}$ in nitrogen matrices (Table 6) to provide a comparison with the $\mathrm{NiCl}_{2}$ and $\mathrm{NiBr}_{2}$ data. The $\mathrm{Ni}$ isotope pattern on $\nu_{3}$ for ${ }^{58} \mathrm{NiF}_{2}$ and ${ }^{60} \mathrm{NiF}_{2}$ in ${ }^{14} \mathrm{~N}_{2}$ at 705.8 and $701.3 \mathrm{~cm}^{-1}$ gave a bond angle of $152^{\circ}$, and for ${ }^{15} \mathrm{~N}_{2}$ matrices the bands at 705.3 and $700.7 \mathrm{~cm}^{-1}$ yielded $162^{\circ}$ (but these values reflect a difference of only 0.2 and $0.1 \mathrm{~cm}^{-1}$ from linearity, respectively). Previous work had calculated a bond angle of $152^{\circ}$ for the $\nu_{3}$ modes of $\mathrm{NiF}_{2}$ in solid $\mathrm{Ne}\left({ }^{58} \mathrm{NiF}_{2}, 800.7 \mathrm{~cm}^{-1}\right.$; $\left.{ }^{60} \mathrm{NiF}_{2}, 795.5_{5} \mathrm{~cm}^{-1}\right)$ and solid $\mathrm{Ar}\left({ }^{58} \mathrm{NiF}_{2}, 780.0 \mathrm{~cm}^{-1} ;{ }^{60} \mathrm{NiF}_{2}\right.$, $\left.775.0_{4} \mathrm{~cm}^{-1}\right) .{ }^{139,141}$ These values indicate a $10 \%$ reduction in wavenumber and an $18 \%$ drop in force constant (assuming linearity) between $\mathrm{NiF}_{2}$ in $\mathrm{Ar}$ and $\mathrm{NiF}_{2}$ in $\mathrm{N}_{2}$. The corresponding shifts in wavenumber for $\mathrm{NiCl}_{2}$ and $\mathrm{NiBr}_{2}$ between $\mathrm{Ar}$ and $\mathrm{N}_{2}$ matrices are $17 \%$ and $21 \%$, respectively, with a drop in force 
Table 3. IR Data for $\mathrm{ZnBr}_{2}$ Isolated in Different Matrices

\begin{tabular}{|c|c|c|c|c|}
\hline matrix & $\begin{array}{l}\text { wavenumber } / \mathrm{cm}^{-1} \text { and assignment at } \\
\text { medium resolution }\left(2 \mathrm{~cm}^{-1}\right)\end{array}$ & $\begin{array}{l}\text { calculated wavenumber } / \mathrm{cm}^{-1} \\
\text { for } 180^{\circ} \text { bond angle }\end{array}$ & $\begin{array}{l}\text { wavenumber } / \mathrm{cm}^{-1} \text { and assignment at high } \\
\text { resolution }\left(0.25 \mathrm{~cm}^{-1}\right)\end{array}$ & $\begin{array}{l}\text { calculated wavenumber } / \mathrm{cm}^{-1} \\
\text { for } 180^{\circ} \text { bond angle }\end{array}$ \\
\hline \multirow[t]{17}{*}{$\mathrm{Ne}$} & $413.1-{ }^{64} \mathrm{Zn}$ & $413.1^{a}$ & $414.49-{ }^{64} \mathrm{Zn}^{79} \mathrm{Br}_{2}$ & $414.49^{a}$ \\
\hline & $408.4-{ }^{66} \mathrm{Zn}$ & 408.6 & $413.73-{ }^{64} \mathrm{Zn}^{79} \mathrm{Br}^{81} \mathrm{Br}$ & \\
\hline & $404.3-{ }^{68} \mathrm{Zn}$ & 404.3 & $412.90-{ }^{64} \mathrm{Zn}^{81} \mathrm{Br}_{2}$ & 413.01 \\
\hline & & & $\begin{array}{l}412.90-{ }^{64} \mathrm{Zn}^{79} \mathrm{Br}_{2} \text { 2nd site } \\
412.07-{ }^{64} \mathrm{Zn}^{79} \mathrm{Br}^{81} \mathrm{Br} \text { 2nd site }\end{array}$ & $412.90^{a}$ \\
\hline & & & $411.31-{ }^{64} \mathrm{Zn}^{81} \mathrm{Br}_{2}$ 2nd site & 411.43 \\
\hline & & & $410.01-{ }^{66} \mathrm{Zn}^{79} \mathrm{Br}_{2}$ & 410.00 \\
\hline & & & $409.29-{ }^{66} \mathrm{Zn}^{79} \mathrm{Br}^{81} \mathrm{Br}$ & \\
\hline & & & $408.46-{ }^{66} \mathrm{Zn}^{81} \mathrm{Br}_{2}$ & 408.50 \\
\hline & & & $408.46-{ }^{66} \mathrm{Zn}^{79} \mathrm{Br}_{2}$ 2nd site & 408.43 \\
\hline & & & $407.60-{ }^{66} \mathrm{Zn}^{79} \mathrm{Br}^{81} \mathrm{Br} 2^{\text {nd }}$ site & \\
\hline & & & $406.87-{ }^{66} \mathrm{Zn}^{81} \mathrm{Br}_{2} 2^{\text {nd }}$ site & 406.94 \\
\hline & & & $405.83-{ }^{68} \mathrm{Zn}^{79} \mathrm{Br}_{2}$ & 405.72 \\
\hline & & & $405.03-{ }^{68} \mathrm{Zn}^{79} \mathrm{Br}^{81} \mathrm{Br}$ & \\
\hline & & & $404.17-{ }^{68} \mathrm{Zn}^{81} \mathrm{Br}_{2}$ & 404.21 \\
\hline & & & $404.17-{ }^{68} \mathrm{Zn}^{79} \mathrm{Br}_{2}$ 2nd site & 404.16 \\
\hline & & & $403.41-{ }^{68} \mathrm{Zn}^{79} \mathrm{Br}^{81} \mathrm{Br}$ 2nd site & \\
\hline & & & $402.61-{ }^{68} \mathrm{Zn}^{81} \mathrm{Br}_{2}$ 2nd site & 402.66 \\
\hline \multirow[t]{3}{*}{$\mathrm{Ar}$} & $410.1-{ }^{64} \mathrm{Zn}$ & $410.1^{a}$ & & \\
\hline & $405.6-{ }^{66} \mathrm{Zn}$ & 405.6 & & \\
\hline & $401.4-{ }^{68} \mathrm{Zn}$ & 401.4 & & \\
\hline \multirow[t]{3}{*}{$\mathrm{Kr}$} & $404.9-{ }^{64} \mathrm{Zn}$ & $404.9^{a}$ & & \\
\hline & $400.6-{ }^{66} \mathrm{Zn}$ & 400.5 & & \\
\hline & $396.8-{ }^{68} \mathrm{Zn}$ & 396.3 & & \\
\hline \multirow[t]{6}{*}{$\mathrm{CH}_{4}$} & $401.7-{ }^{64} \mathrm{Zn}$ & $401.7^{a}$ & & \\
\hline & $397.5-{ }^{66} \mathrm{Zn}$ & 397.3 & & \\
\hline & $393.7-{ }^{68} \mathrm{Zn}$ & 393.2 & & \\
\hline & $393.7-{ }^{64} \mathrm{Zn}$ site & $393.7^{a}$ & & \\
\hline & $389.8-{ }^{66} \mathrm{Zn}$ site & 389.4 & & \\
\hline & $385.8-{ }^{68} \mathrm{Zn}$ site & 385.3 & & \\
\hline \multirow[t]{3}{*}{$\mathrm{Xe}$} & $397.7-{ }^{64} \mathrm{Zn}$ & $397.7^{a}$ & & \\
\hline & $393.3-{ }^{66} \mathrm{Zn}$ & 393.4 & & \\
\hline & $389.5-{ }^{68} \mathrm{Zn}$ & 389.3 & & \\
\hline \multirow[t]{3}{*}{${ }^{14} \mathrm{~N}_{2}$} & $393.9-{ }^{64} \mathrm{Zn}$ & $393.9^{a}$ & & \\
\hline & $389.8-{ }^{66} \mathrm{Zn}$ & 389.5 & & \\
\hline & $386.0-{ }^{68} \mathrm{Zn}$ & 385.5 & & \\
\hline \multirow[t]{3}{*}{${ }^{15} \mathrm{~N}_{2}$} & $393.8-{ }^{64} \mathrm{Zn}$ & $393.8^{a}$ & & \\
\hline & $389.6-{ }^{66} \mathrm{Zn}$ & 389.5 & & \\
\hline & $385.8-{ }^{68} \mathrm{Zn}$ & 385.4 & & \\
\hline
\end{tabular}

constant of $32 \%$ for $\mathrm{NiCl}_{2}$ and $37 \%$ for $\mathrm{NiBr}_{2}$. This is a clear indication that the level of interaction between the nickel dihalide and the dinitrogen matrix decreases in the order $\mathrm{Br}>$ $\mathrm{Cl}>\mathrm{F}$. $\mathrm{NiI}_{2}$ would be of obvious interest, as it would possibly coordinate to dinitrogen the most readily. Performing successful experiments with bulk $\mathrm{NiI}_{2}$ was a challenge, as it decomposed upon heating to liberate $\mathrm{I}_{2}$, resulting in very poor throughput of the IR radiation, and no meaningful data were obtained.

Having identified that there is some form of interaction between the $\mathrm{N}_{2}$ matrix and the trapped $\mathrm{NiBr}_{2}$ and that the $\mathrm{NiBr}_{2}$ unit is bent, the $\nu_{\mathrm{NN}}$ region was studied in some detail. A preliminary report of this has been published previously, ${ }^{69}$ but the main findings are summarized below to put the rest of the data in context.

The $\nu_{\mathrm{NN}}$ region of $\mathrm{NiBr}_{2}$ in an ${ }^{15} \mathrm{~N}_{2}$ matrix contained two bands at 2263.8 and $2259.4 \mathrm{~cm}^{-1}$ after deposition (Figures $6 \mathrm{~b}$ and $9 \mathrm{a}$ and Table 4) in addition to the perturbed $\nu_{\mathrm{NN}}$ mode of ${ }^{15} \mathrm{~N}_{2}$ at $2250.0 \mathrm{~cm}^{-1} \cdot{ }^{138}$ In contrast, in the $\mathrm{ZnBr}_{2}$ data (Figure 6a) the only additional bands were shoulders on the impurity-induced modes. The position of $\nu_{\mathrm{NN}}$ modes in the $\mathrm{NiBr}_{2}$ spectra to high frequency of the "free" $\mathrm{N}_{2}$ modes is unusual, and in comparison with the isoelectronic carbonyl species may be indicative of "nonclassical" bonding with very limited $\pi$ back-bonding. ${ }^{155}$ When this sample was photolyzed with broad-band $\mathrm{Hg}-\mathrm{Xe}$ radiation, a radical change was observed (Figure 9b) compared with the spectrum recorded after initial deposition (Figure 9a), with the appearance of two new bands at 2205.7 and $2186.4 \mathrm{~cm}^{-1}$ (these have low intensity, about $1-2 \%$ of the absorbance of the $\mathrm{NiBr}_{2} \nu_{3}$ mode) together with a slight reduction in the intensity of the $2259.4 \mathrm{~cm}^{-1}$ band shown in the difference spectrum (Figure 9c). When $\mathrm{NiBr}_{2}$ was isolated in an ${ }^{14} \mathrm{~N}_{2}$ matrix, there were features at 2336.9 and $2342.8 \mathrm{~cm}^{-1}$ as well as the perturbed $\nu_{\mathrm{NN}}$ mode at $2327.8 \mathrm{~cm}^{-1}$ on deposition (Figure $6 \mathrm{a}$ ), but because of the ubiquitous presence of matrix-isolated $\mathrm{CO}_{2}$ features, these were only identifiable once the corresponding ${ }^{15} \mathrm{~N}_{2}$ features had been identified. After photolysis (Figure 9d), 


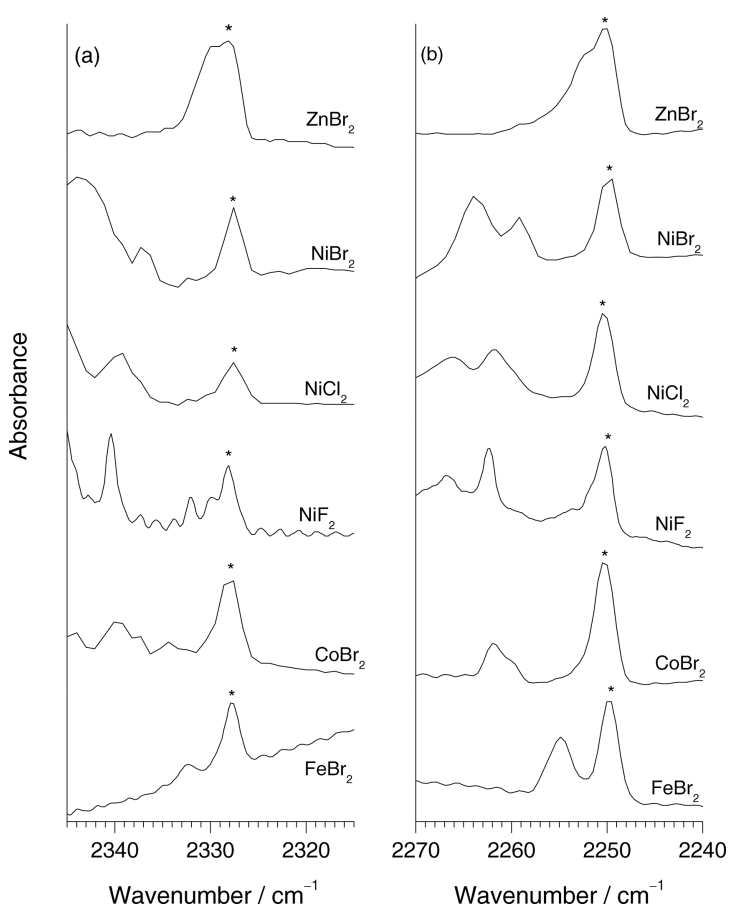

Figure 6. IR spectra of $\mathrm{MX}_{2}$ species trapped in solid (a) ${ }^{14} \mathrm{~N}_{2}$ and (b) ${ }^{15} \mathrm{~N}_{2}$ matrices. Each spectrum has an absorbance of ca. 0.01 . The * labels indicate impurity-induced ${ }^{14} \mathrm{~N}_{2}$ and ${ }^{15} \mathrm{~N}_{2}$ modes.

new bands appeared at 2281.4 and $2261.4 \mathrm{~cm}^{-1}$. When an ${ }^{14} \mathrm{~N}_{2} /{ }^{15} \mathrm{~N}_{2}$ matrix was used (Figure 9e), bands after photolysis were observed at 2273.3 and $2195.3 \mathrm{~cm}^{-1}$ in addition to those present in the pure ${ }^{14} \mathrm{~N}_{2}$ or ${ }^{15} \mathrm{~N}_{2}$ matrices, giving rise to a pair of triplets indicating the presence of two $\mathrm{N}_{2}$ units. Attempts to use ${ }^{14} \mathrm{~N}^{15} \mathrm{~N}$ matrices to identify the $\mathrm{N}_{2}$ bonding mode (end-on vs side-on $)^{156,157}$ were unsuccessful because of the very weak nature of the features. Failure to observe ${ }^{14,15} \mathrm{~N}_{2}$ species with weak $\nu_{\mathrm{NN}}$ modes was previously noted by Andrews and co-workers in their study of beryllium dinitrogen complexes. ${ }^{138}$ No changes were observed in the $\mathrm{NiBr}_{2} \nu_{3}$ region after photolysis. In all cases the intensity of the $\nu_{\mathrm{NN}}$ bands observed after photolysis was markedly reduced after annealing to $15 \mathrm{~K}$, and the bands disappeared completely after the matrix was warmed to ca. $20 \mathrm{~K}$ but could be regenerated (with lower intensity) after further photolysis at ca. $8 \mathrm{~K}$, but only three or four times. The intensity of the photoactive bands was greater when UV rather than visible irradiation was used and was also slightly enhanced if photolysis was carried out during deposition. The new bands after photolysis were only observed if the deposition (rather than photolysis) was carried out below $10 \mathrm{~K}$.

To confirm that the $\nu_{\mathrm{NN}}$ bands observed in the $\mathrm{NiBr}_{2}$ experiments were due to interaction of $\mathrm{NiBr}_{2}$ with dinitrogen,

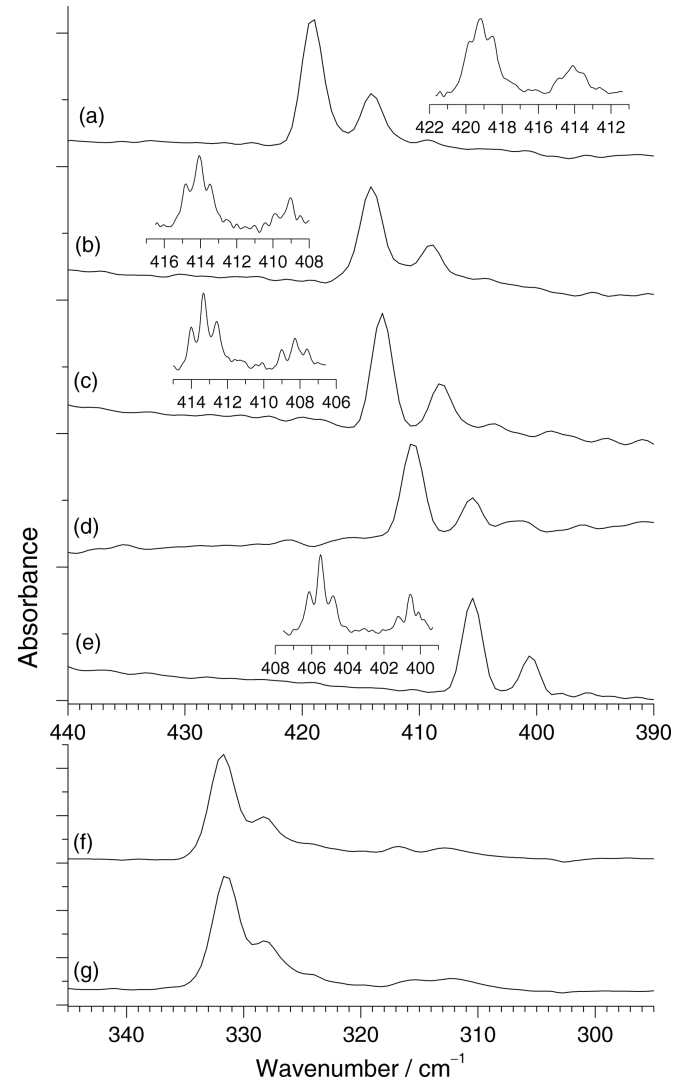

Figure 7. IR spectra of $\mathrm{NiBr}_{2}$ isolated in (a) Ar, (b) $\mathrm{O}_{2}$, (c) $\mathrm{Kr}$, (d) $\mathrm{CH}_{4}$, (e) Xe, (f) ${ }^{14} \mathrm{~N}_{2}$, and (g) ${ }^{15} \mathrm{~N}_{2}$ matrices. The insets show higher-resolution $\left(0.25 \mathrm{~cm}^{-1}\right)$ spectra.

a series of experiments involving $\mathrm{NiCl}_{2}$ and $\mathrm{NiF}_{2}$ were also carried out (Table 4 and 6 ). When $\mathrm{NiCl}_{2}$ was isolated in nitrogen matrices, bands to high frequency of the impurity-induced modes $\left({ }^{14} \mathrm{~N}_{2}, 2327.8 \mathrm{~cm}^{-1} ;{ }^{15} \mathrm{~N}_{2}, 2250.0 \mathrm{~cm}^{-1}\right)$ were observed (Figure 6 and Table 4) at 2342.8 and $2339.3 \mathrm{~cm}^{-1}\left({ }^{14} \mathrm{~N}_{2}\right)$ and 2266.3 and $2261.8 \mathrm{~cm}^{-1}\left({ }^{15} \mathrm{~N}_{2}\right)$, which are shifted slightly from the $\mathrm{NiBr}_{2}$ values. After photolysis, new bands were observed at 2280.9 and $2260.3 \mathrm{~cm}^{-1}$ in ${ }^{14} \mathrm{~N}_{2}$ (Figure 9f) and at 2205.2 and $2184.8 \mathrm{~cm}^{-1}$ in ${ }^{15} \mathrm{~N}_{2}$ (Figure $9 \mathrm{~g}$ ), with a slight decrease in the bands at $2339.3 \mathrm{~cm}^{-1}\left({ }^{14} \mathrm{~N}_{2}\right)$ and $2261.8 \mathrm{~cm}^{-1}\left({ }^{15} \mathrm{~N}_{2}\right)$. These features were weaker and also slightly shifted from those observed for $\mathrm{NiBr}_{2}$. For $\mathrm{NiF}_{2}$, no new bands were detectable after photolysis, but bands close to, and blue-shifted from, the perturbed $\nu_{\mathrm{NN}}$ mode were observed upon deposition at 2266.7 and $2262.5 \mathrm{~cm}^{-1}$ in an ${ }^{15} \mathrm{~N}_{2}$ matrix and at 2337.5 and $2340.5 \mathrm{~cm}^{-1}$ in an ${ }^{14} \mathrm{~N}_{2}$ matrix (Figure 6).

From these experiments, it is clear that the bands observed between 2350 and $2150 \mathrm{~cm}^{-1}$ can be readily assigned to $\nu_{\mathrm{NN}}$

Table 4. $\nu_{\mathrm{NN}}$ Data for $M X_{2}$ Molecules in ${ }^{14} \mathrm{~N}_{2}$ and ${ }^{15} \mathrm{~N}_{2}$ Matrices

\begin{tabular}{|c|c|c|c|c|c|c|}
\hline \multirow[b]{2}{*}{ molecule } & \multicolumn{2}{|c|}{${ }^{14} \mathrm{~N}_{2}$ matrix } & \multicolumn{2}{|c|}{${ }^{15} \mathrm{~N}_{2}$ matrix } & \multicolumn{2}{|c|}{${ }^{14} \mathrm{~N}_{2} /{ }^{15} \mathrm{~N}_{2}$ matrix, after photolysis } \\
\hline & deposition & after photolysis & deposition & after photolysis & triplet 1 & triplet 2 \\
\hline $\mathrm{N}_{2}$ & 2327.8 & & 2250.0 & & & \\
\hline $\mathrm{ZnBr}_{2}$ & 2329.9 & & 2252.2 & & & \\
\hline $\mathrm{NiBr}_{2}$ & $2336.9,2342.8$ & $2281.4,2261.4$ & $2263.8,2259.4$ & $2205.7,2186.4$ & $2281.4,2273.3,2261.4$ & $2205.7,2195.3,2186.4$ \\
\hline $\mathrm{NiCl}_{2}$ & $2342.8,2339.3$ & $2280.9,2260.3$ & $2266.3,2261.8$ & $2205.2,2184.8$ & & \\
\hline $\mathrm{NiF}_{2}$ & $2337.5,2340.5$ & & $2267.7,2262.5$ & & & \\
\hline $\mathrm{CoBr}_{2}$ & $2340.0,2336.8$ & & $2261.9,2260.2$ & $2235.1,2229.7$ & & \\
\hline $\mathrm{FeBr}_{2}$ & 2332.3 & & 2254.9 & & & \\
\hline
\end{tabular}


Table 5. IR Data for $\mathrm{NiBr}_{2}$ Isolated in Different Matrices

\begin{tabular}{|c|c|c|c|c|}
\hline matrix & $\begin{array}{c}\text { wavenumber } / \mathrm{cm}^{-1} \text { and assignment at } \\
\text { medium resolution }\left(2 \mathrm{~cm}^{-1}\right)\end{array}$ & $\begin{array}{l}\text { calculated wavenumber } / \mathrm{cm}^{-1} \\
\text { for } 180^{\circ} \text { bond angle }\end{array}$ & $\begin{array}{c}\text { wavenumber } / \mathrm{cm}^{-1} \text { and assignment at } \\
\text { high resolution }\left(0.25 \mathrm{~cm}^{-1}\right)\end{array}$ & $\begin{array}{l}\text { calculated wavenumber } / \mathrm{cm}^{-1} \\
\text { for } 180^{\circ} \text { bond angle }\end{array}$ \\
\hline \multirow[t]{3}{*}{$\mathrm{Ne}$} & $423.5-{ }^{58} \mathrm{Ni}$ & $423.5^{a}$ & & \\
\hline & $418.2-{ }^{60} \mathrm{Ni}$ & 418.3 & & \\
\hline & $414.1-{ }^{62} \mathrm{Ni}$ & 413.4 & & \\
\hline \multirow[t]{3}{*}{$\mathrm{Ar}$} & $419.1-{ }^{58} \mathrm{Ni}$ & $419.1^{a}$ & $419.78-{ }^{58} \mathrm{Ni}^{79} \mathrm{Br}_{2}$ & 419.78 \\
\hline & $414.1-{ }^{60} \mathrm{Ni}$ & 413.9 & $419.29-{ }^{58} \mathrm{Ni}^{79} \mathrm{Br}^{81} \mathrm{Br}$ & \\
\hline & $409.3-{ }^{62} \mathrm{Ni}$ & 409.1 & $418.57-{ }^{58} \mathrm{Ni}^{81} \mathrm{Br}_{2}$ & 418.39 \\
\hline \multirow[t]{3}{*}{$\mathrm{O}_{2}$} & $414.1-{ }^{58} \mathrm{Ni}$ & $414.1^{a}$ & $414.83-{ }^{58} \mathrm{Ni}^{79} \mathrm{Br}_{2}$ & $414.83^{a}$ \\
\hline & $409.1-{ }^{60} \mathrm{Ni}$ & 409.0 & $414.06-{ }^{58} \mathrm{Ni}^{79} \mathrm{Br}^{81} \mathrm{Br}$ & \\
\hline & $-\quad-{ }^{62} \mathrm{Ni}$ & 404.2 & $413.49-{ }^{58} \mathrm{Ni}^{81} \mathrm{Br}_{2}$ & 413.45 \\
\hline \multirow[t]{6}{*}{$\mathrm{Kr}$} & $413.2-{ }^{58} \mathrm{Ni}$ & $413.2^{a}$ & $414.02-{ }^{58} \mathrm{Ni}^{79} \mathrm{Br}_{2}$ & $414.02^{a}$ \\
\hline & $408.2-{ }^{60} \mathrm{Ni}$ & 408.1 & $413.33-{ }^{58} \mathrm{Ni}^{79} \mathrm{Br}^{81} \mathrm{Br}$ & \\
\hline & $403.7-{ }^{62} \mathrm{Ni}$ & 403.3 & $412.60-{ }^{58} \mathrm{Ni}^{81} \mathrm{Br}_{2}$ & 412.64 \\
\hline & & & $409.03-{ }^{60} \mathrm{Ni}^{79} \mathrm{Br}_{2}$ & 408.95 \\
\hline & & & $408.30-{ }^{60} \mathrm{Ni}^{79} \mathrm{Br}^{81} \mathrm{Br}$ & \\
\hline & & & $407.61-{ }^{60} \mathrm{Ni}^{81} \mathrm{Br}_{2}$ & 407.55 \\
\hline \multirow[t]{3}{*}{$\mathrm{CH}_{4}$} & $410.6-{ }^{58} \mathrm{Ni}$ & $410.6^{a}$ & & \\
\hline & $405.0-{ }^{60} \mathrm{Ni}$ & 405.5 & & \\
\hline & $401.4-{ }^{62} \mathrm{Ni}$ & 400.7 & & \\
\hline \multirow[t]{6}{*}{$\mathrm{Xe}$} & $405.5-{ }^{58} \mathrm{Ni}$ & $405.5^{a}$ & $406.14-{ }^{58} \mathrm{Ni}^{79} \mathrm{Br}_{2}$ & $406.14^{a}$ \\
\hline & $400.6-{ }^{60} \mathrm{Ni}$ & 400.5 & $405.49-{ }^{58} \mathrm{Ni}^{79} \mathrm{Br}^{81} \mathrm{Br}$ & \\
\hline & $395.7-{ }^{62} \mathrm{Ni}$ & 395.8 & $404.80-{ }^{58} \mathrm{Ni}^{81} \mathrm{Br}_{2}$ & 404.79 \\
\hline & & & $401.23-{ }^{60} \mathrm{Ni}^{79} \mathrm{Br}_{2}$ & 401.16 \\
\hline & & & $400.54-{ }^{60} \mathrm{Ni}^{79} \mathrm{Br}^{81} \mathrm{Br}$ & \\
\hline & & & $400.09-{ }^{60} \mathrm{Ni}^{81} \mathrm{Br}_{2}$ & 399.80 \\
\hline \multirow[t]{5}{*}{${ }^{14} \mathrm{~N}_{2}$} & $331.8-{ }^{58} \mathrm{Ni}$ & $331.8^{a}$ & & \\
\hline & $328.3-{ }^{60} \mathrm{Ni}$ & 327.7 & & \\
\hline & $324.7-{ }^{62} \mathrm{Ni}$ & 323.8 & & \\
\hline & 316.7 - matrix effect & & & \\
\hline & 312.7 - matrix effect & & & \\
\hline \multirow[t]{5}{*}{${ }^{15} \mathrm{~N}_{2}$} & $331.5-{ }^{58} \mathrm{Ni}$ & $331.5^{a}$ & & \\
\hline & $328.2-{ }^{60} \mathrm{Ni}$ & 327.4 & & \\
\hline & $324.4-{ }^{62} \mathrm{Ni}$ & 323.6 & & \\
\hline & 315.4 - matrix effect & & & \\
\hline & 312.2 - matrix effect & & & \\
\hline
\end{tabular}

modes on the basis of their ${ }^{14} \mathrm{~N} /{ }^{15} \mathrm{~N}$ isotopic shifts and that there are a variety of different $\mathrm{X}_{2} \mathrm{Ni} \cdots\left(\mathrm{N}_{2}\right)_{n}$ and $\mathrm{X}_{2} \mathrm{Ni}-\left(\mathrm{N}_{2}\right)_{n}$ interactions occurring in nitrogen matrices. The fact that the position and intensity of the $\nu_{\mathrm{NN}}$ modes are halogen-dependent clearly indicates that they arise from interactions between the nitrogen matrix and the trapped metal dihalide rather than from $\mathrm{N}_{2} \cdots \mathrm{H}_{2} \mathrm{O}$ or $\mathrm{N}_{2} \cdots \mathrm{HX}$ complexes. ${ }^{158,159}$

The isotopic behavior of the $\nu_{\mathrm{NN}}$ bands observed after photolysis is clearly indicative of the formation of a species containing two geminal $\mathrm{N}_{2}$ units. They are at relatively high values compared with those for low-oxidation-state dinitrogen complexes but are similar to those observed for other complexes containing cationic metal centers such as $\left[\mathrm{Ru}^{\mathrm{II}}\left(\mathrm{N}_{2}\right)_{2}\right]^{2+}$ $\left(2207 \text { and } 2173 \mathrm{~cm}^{-1}\right)^{160,161}$ and $\left[\mathrm{Rh}^{\mathrm{I}}\left(\mathrm{N}_{2}\right)_{2}\right]^{+}(2244$ and $\left.2218 \mathrm{~cm}^{-1}\right) .{ }^{162}$ Most significantly they are very similar to those observed for matrix-isolated $\mathrm{Ni}\left(\mathrm{N}_{2}\right)_{2}\left(\mathrm{O}_{2}\right)$, which was shown via isotopic substitution to have a pseudotetrahedral geometry with two end-on-bonded dinitrogen ligands $\left(\eta^{1}-\mathrm{N}_{2}\right)$ in a cis configuration and one side-on bonded dioxygen ligand $\left(\eta^{2}-\mathrm{O}_{2}\right)$, with the dioxygen unit believed to be between peroxo and superoxo in character. ${ }^{163,164}$

Our original DFT calculations ${ }^{69}$ indicated that all of the sideon-bonded $\left(\eta^{2}-\mathrm{N}_{2}\right)$ complexes were unbound with respect to
$\mathrm{NiX}_{2}(\mathrm{X}=\mathrm{Cl}, \mathrm{Br})$ and dinitrogen. Of the end-on-bonded species, pseudotetrahedral $\mathrm{NiX}_{2}\left(\eta^{1}-\mathrm{N}_{2}\right)_{2}$ were the most stable. The relatively small complexation enthalpies $\left(\Delta_{\mathrm{r}} H\right)$ of $-43 \mathrm{~kJ} \mathrm{~mol}^{-1}$ $\left(\mathrm{NiBr}_{2}\right)$ and $-37 \mathrm{~kJ} \mathrm{~mol}^{-1}\left(\mathrm{NiCl}_{2}\right)$ for the reaction $\mathrm{NiX}_{2}+2 \mathrm{~N}_{2}$ $\rightarrow \mathrm{NiX}_{2}\left(\eta^{1}-\mathrm{N}_{2}\right)_{2}$ indicated rather weak chemical bonding, consistent with complexes that are stable only at low temperatures. These calculations have been repeated for $\mathrm{NiX}_{2}\left(\eta^{1}-\mathrm{N}_{2}\right)_{2}$ using $\mathrm{ADF}$, and the reaction enthalpies are very similar for $\mathrm{NiBr}_{2}$ $\left(-45 \mathrm{~kJ} \mathrm{~mol}^{-1}\right)$ and slightly lower for $\mathrm{NiCl}_{2}\left(-28 \mathrm{~kJ} \mathrm{~mol}^{-1}\right)$, indicating that in the case of $\mathrm{NiF}_{2}$ only one $\mathrm{N}_{2}$ will bind end-on, but with a very low reaction enthalpy of ca. $-11 \mathrm{~kJ} \mathrm{~mol}^{-1}$. The original DFT-calculated values ${ }^{69}$ for the $\nu_{\mathrm{NN}}$ modes of $\mathrm{NiX}_{2}\left(\eta^{1}-\mathrm{N}_{2}\right)_{2}$ were in excellent agreement with the experimental values, confirming the assignments. The relative intensities of the absorption bands observed after photolysis were used to determine a $\mathrm{N}-\mathrm{Ni}-\mathrm{N}$ bond angle of $98^{\circ} \pm 5$ for the $\left(\mathrm{N}_{2}\right) \mathrm{Ni}\left(\mathrm{N}_{2}\right)$ fragment, with the principal $\mathrm{NN}$ force constant, $k_{\mathrm{NN}}$, and the interaction force constant, $k_{\mathrm{NN} \cdot \mathrm{NN}}$, having values of 21.268 and 0.192 mdyne $\AA^{-1}$, respectively.

The $\mathrm{NiX}_{2}\left(\eta^{1}-\mathrm{N}_{2}\right)_{2}$ complexes reported in this work are very unstable, even under matrix isolation conditions, and provide an indication of the (in)stability of $\mathrm{Ni}$ (II) dinitrogen complexes as well as being an example of reversible binding of $\mathrm{N}_{2}$ to $\mathrm{Ni}$ (II) 


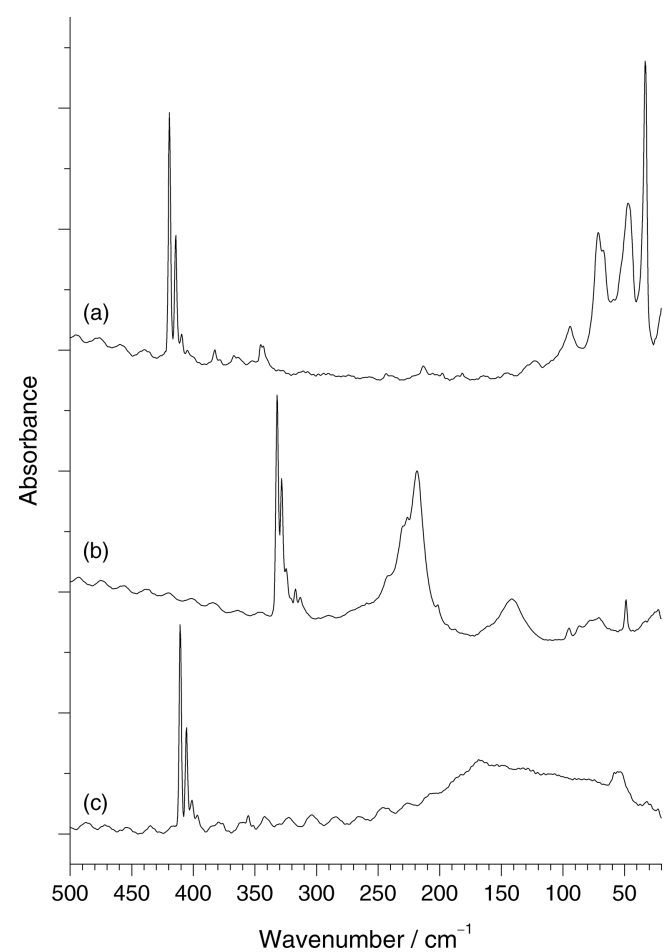

Figure 8. SR-FIR spectra of $\mathrm{NiBr}_{2}$ isolated in (a) $\mathrm{Ar}$, (b) $\mathrm{N}_{2}$, and (c) $\mathrm{CH}_{4}$ matrices.

centers. This work has also yielded a calibration value for $\nu_{\mathrm{NN}}$ attached to a $\mathrm{Ni}$ (II) center, thus confirming that the previous $\mathrm{Ni}\left(\mathrm{N}_{2}\right)_{2}\left(\mathrm{O}_{2}\right)$ complexes $^{163,164}$ are best considered to contain $\mathrm{Ni}(\mathrm{II})$ and a peroxo ligand. The proportion of $\mathrm{NiX}_{2}\left(\eta^{1}-\mathrm{N}_{2}\right)_{2}$ formed upon photolysis is dependent on the deposition temperature and the photolysis wavelength but in all cases appears to remain fairly low. Upon warming to $20 \mathrm{~K}$ these chemisorbed species dissociate, as also found for $\mathrm{Pd}\left(\mathrm{N}_{2}\right)_{2}\left(\mathrm{O}_{2}\right)^{164}$ and $\operatorname{Mo}\left(\mathrm{N}_{2}\right)_{x},{ }^{165}$ indicating their extremely reactive nature. The very low deposition temperatures required to observe the photoproducts may be related to the need for some preorganization of the nitrogen lattice that is only achieved by very rapid quenching of the $\mathrm{NiX}_{2}$ in solid nitrogen below $10 \mathrm{~K}$.

Electronic Absorption Spectroscopy. The electronic absorption spectra of gaseous $\mathrm{NiCl}_{2}, \mathrm{NiBr}_{2}$, and $\mathrm{NiI}_{2}$ were studied previously in the range of $4000-20000 \mathrm{~cm}^{-1}$, and assignments were made on the basis of axial ligand field calculations. ${ }^{166}$ Gasphase spectra are often complicated by population of many rotational and vibrational levels as a consequence of the high temperatures required to obtain sufficient vapor pressure. The electronic absorption ${ }^{101-103}$ and emission ${ }^{101,143}$ spectra of $\mathrm{NiCl}_{2}$ isolated in an argon matrix were also studied previously and found to be simpler. The most intense absorption for $\mathrm{NiCl}_{2}$ in $\mathrm{Ar}$ at 28 $400 \mathrm{~cm}^{-1}$ was found to have extensive vibrational structure. This progression with a spacing of ca. $260 \mathrm{~cm}^{-1}$ was believed to correspond to the symmetric $\nu_{1}$ stretching mode in the excited state. ${ }^{103}$ A splitting of approximately $80 \mathrm{~cm}^{-1}$ was also observed for some of the most prominent levels, possibly corresponding to the bending frequency, $\nu_{2}$, of the excited state or simply due to multiple sites in the matrix. The ligand field model applied to the gas-phase spectra by DeKock and Gruen ${ }^{166}$ predicted a ${ }^{3} \mathrm{II}_{\mathrm{g}}$ ground state, which gave rise to four charge transfer transitions, and these were also observed for matrix-isolated $\mathrm{NiCl}_{2} .{ }^{102}$ This approach predicted that the $\mathrm{d}$ orbitals would split into three levels with the relative energies $\mathrm{d}_{\delta}<\mathrm{d}_{\pi}<\mathrm{d}_{\sigma}$, leading to a

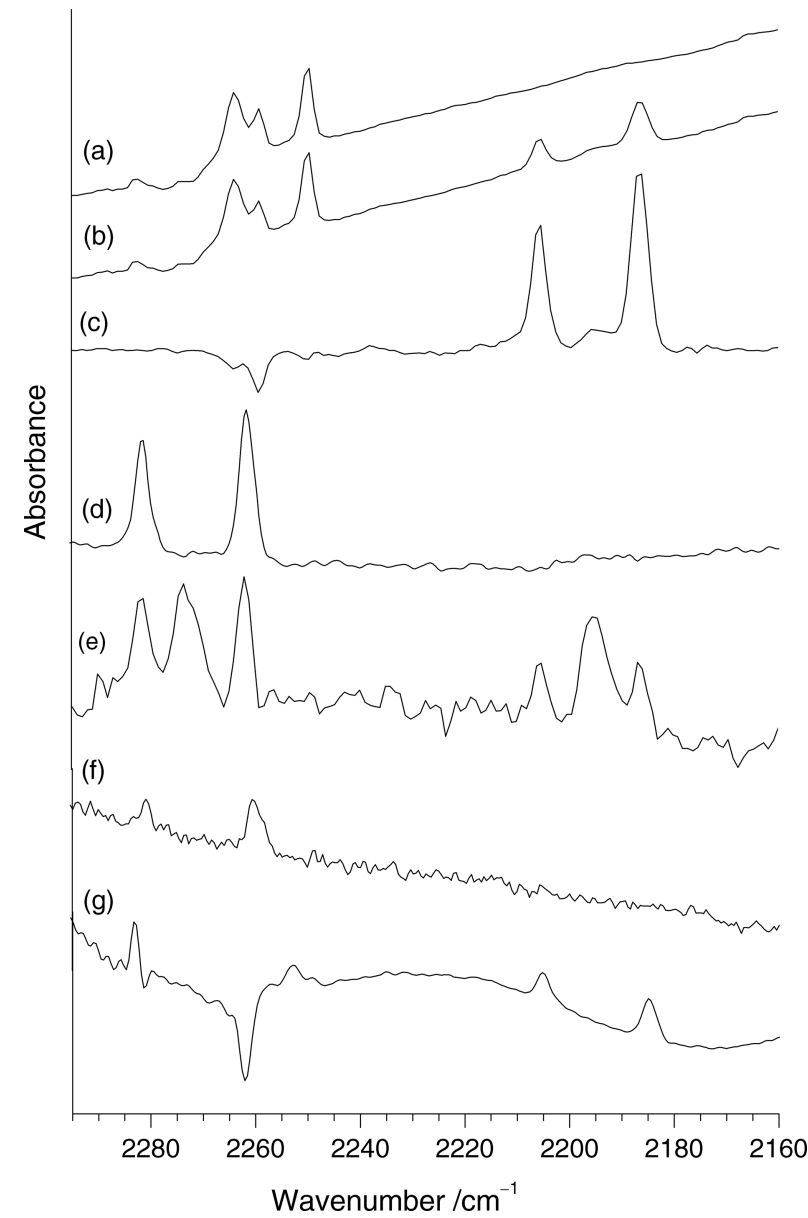

Figure 9. $(\mathrm{a}-\mathrm{c})$ IR spectra of $\mathrm{NiBr}_{2}$ isolated in ${ }^{15} \mathrm{~N}_{2}$ (a) after deposition and (b) after broadband photolysis and (c) their difference spectrum (photolysis - deposition). ( $\mathrm{d}-\mathrm{g})$ Difference IR spectra of (d) $\mathrm{NiBr}_{2}$ isolated in ${ }^{14} \mathrm{~N}_{2}$ after broadband photolysis, (e) $\mathrm{NiBr}_{2}$ isolated in $1: 1{ }^{14} \mathrm{~N}_{2} /{ }^{15} \mathrm{~N}_{2}$ after broadband photolysis, (f) $\mathrm{NiCl}_{2}$ isolated in ${ }^{14} \mathrm{~N}_{2}$ after broadband photolysis, and $(\mathrm{g}) \mathrm{NiCl}_{2}$ isolated in ${ }^{15} \mathrm{~N}_{2}$ after broadband photolysis.

Table 6. IR Data for $\mathrm{NiCl}_{2}$ and $\mathrm{NiF}_{2}$ in $\mathrm{N}_{2}$ Matrices

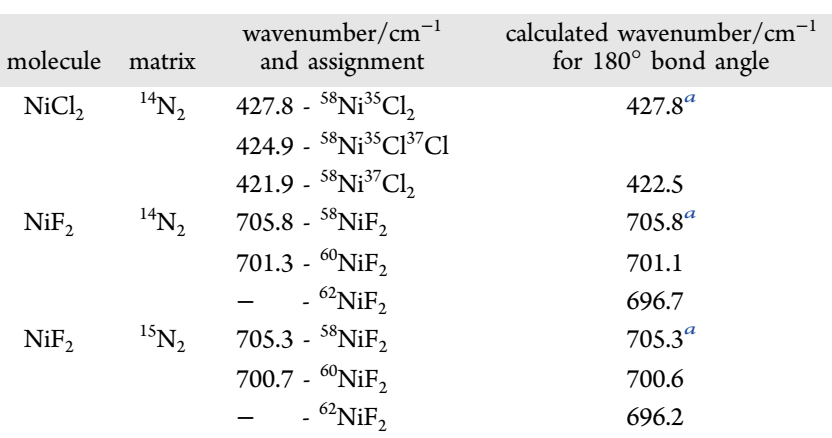

${ }^{a}$ Band used in bond angle calculation.

$\delta_{\mathrm{g}}{ }^{4} \pi_{\mathrm{g}}{ }^{3} \sigma_{\mathrm{g}}{ }^{1}$ configuration. Brown and co-workers studied gasphase $\mathrm{NiCl}_{2}$ in a "cold" molecular beam using laser-induced fluorescence spectroscopy of the 360 and $460 \mathrm{~nm}$ bands. ${ }^{144-150}$ They showed that $\mathrm{NiCl}_{2}$ is linear in both the ground and excited states with a ${ }^{3} \Sigma_{\mathrm{g}}^{-}$ground state, in contrast to ${ }^{3} \Pi_{\mathrm{g}}$ as proposed by DeKock and Gruen. ${ }^{102}$ This assignment has been debated further by computational chemists ${ }^{129,167,168}$ and underlines the challenge that molecules of this type present. Local DFT calculations by Bridgeman ${ }^{168}$ found $\mathrm{NiCl}_{2}$ to be linear and 
agreed with Brown's assignment of the ground state as ${ }^{3} \Sigma_{\mathrm{g}}^{-}$. This ground state could only arise from a $\delta_{\mathrm{g}}{ }^{4} \sigma_{\mathrm{g}}{ }^{2} \pi_{\mathrm{g}}{ }^{2}$ or $\pi_{\mathrm{g}}{ }^{4} \sigma_{\mathrm{g}}{ }^{2} \delta_{\mathrm{g}}^{2}$ configuration. Cellular ligand field calculations, which explored the parameter values that would be required to generate such configurations, produced negative values for the $\pi_{\mathrm{g}}{ }^{4} \sigma_{\mathrm{g}}{ }^{2} \delta_{\mathrm{g}}{ }^{2}$ configuration, and this was therefore discounted. This led to the orbital occupation of $\delta_{\mathrm{g}}{ }^{4} \sigma_{\mathrm{g}}{ }^{2} \pi_{\mathrm{g}}{ }^{2}$ for the ${ }^{3} \Sigma_{\mathrm{g}}^{-}$ground state with a reversal in the relative energy of the $\mathrm{d}_{\sigma}$ and $\mathrm{d}_{\pi}$ orbitals. While the $\mathrm{d}_{\delta}$ orbitals are nonbonding because of the lack of ligand orbitals of matching symmetry, both the $\mathrm{d}_{\sigma}$ and $\mathrm{d}_{\pi}$ orbitals are antibonding. As discussed in detail by Bridgeman for $\mathrm{NiCl}_{2}$, ${ }^{168}$ the relative energy $d_{\sigma}<d_{\pi}$ does not indicate that $\pi$ bonding is stronger than $\sigma$ bonding. Rather, the mixing between $3 \mathrm{~d}$ and $4 \mathrm{~s}$ is sufficient to lower the energy of the $\mathrm{d}_{\sigma}$ orbital. Indeed, this interaction is enough to make the energy of $\mathrm{d}_{\delta}$ and $\mathrm{d}_{\sigma}$ quite similar. These calculations were also found to concur with the experimentally observed bond length and vibrational frequency values from the molecular beam experiments. Our DFT calculations (see Table 1) indicate that the ground state of $\mathrm{NiBr}_{2}$ also has a ${ }^{3} \Sigma_{\mathrm{g}}^{-}$ground state with a $\delta_{\mathrm{g}}{ }^{4} \sigma_{\mathrm{g}}{ }^{2} \pi_{\mathrm{g}}{ }^{2}$ configuration. Between this and the first linear excited state, ${ }^{3} \Pi_{\mathrm{g}}$ with a $\delta_{\mathrm{g}}{ }^{4} \sigma_{\mathrm{g}}{ }^{1} \pi_{\mathrm{g}}{ }^{3}$ configuration, there are two bent triplet states with bond angles of $155^{\circ}$ and $130^{\circ}$.

The UV-vis-NIR spectrum of $\mathrm{NiBr}_{2}$ isolated in an $\mathrm{Ar}$ matrix is shown in Figure 10a, together with a spectrum of $\mathrm{NiCl}_{2}$ in an

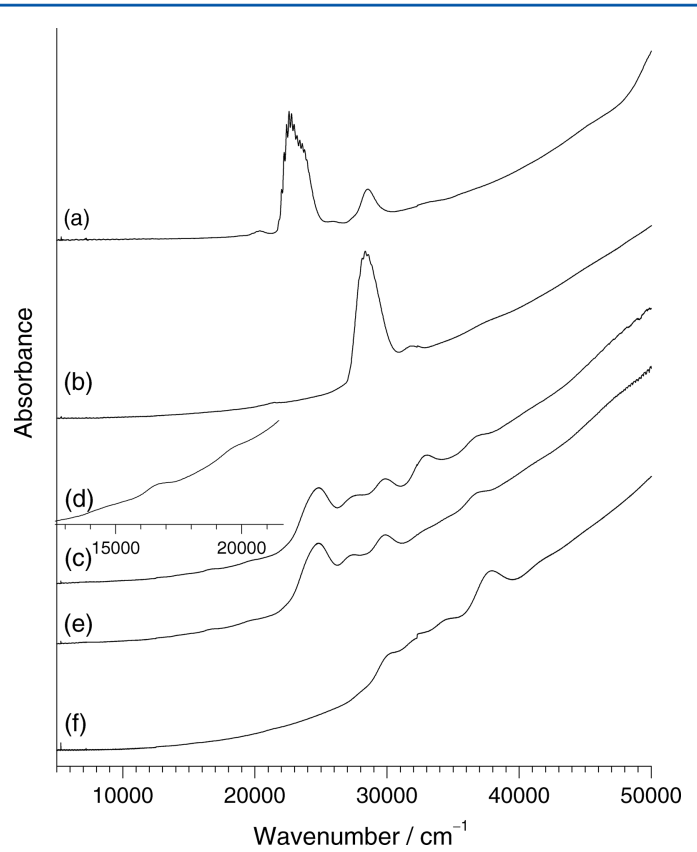

Figure 10. Electronic absorption spectra of (a) $\mathrm{NiBr}_{2}$ in an Ar matrix, (b) $\mathrm{NiCl}_{2}$ in an Ar matrix, (c, d) $\mathrm{NiBr}_{2}$ in an ${ }^{14} \mathrm{~N}_{2}$ matrix, (e) $\mathrm{NiBr}_{2}$ in an ${ }^{14} \mathrm{~N}_{2}$ matrix after broadband photolysis, and (f) $\mathrm{NiCl}_{2}$ in an ${ }^{14} \mathrm{~N}_{2}$ matrix.

argon matrix (Figure 10b), and the values are given in Table 7. The latter spectrum is in very good agreement with those previously reported for $\mathrm{NiCl}_{2},{ }^{101-103}$ where the bands at $28500 \mathrm{~cm}^{-1}$ were assigned as ligand-to-metal charge-transfer bands. The intensities of any $d-d$ bands are expected to be very low because of the linearity of the molecule and the low temperatures of the experiment. As expected, the features in the $\mathrm{NiBr}_{2}$ spectrum are shifted by about $5500 \mathrm{~cm}^{-1}$ to lower energy compared with the $\mathrm{NiCl}_{2}$ spectrum. The spectra for $\mathrm{NiBr}_{2}$ isolated in $\mathrm{Kr}, \mathrm{Xe}$, and $\mathrm{CH}_{4}$ matrices are very similar to those in $\mathrm{Ar}$, and in all cases the most intense absorption displayed vibrational structure, as shown in Figure 11, with the values tabulated in Table 8. Although the vibrational fine structure is less well resolved for the $\mathrm{CH}_{4}$ matrix data, it does highlight the fact that there are two absorption bands between 21000 and $25000 \mathrm{~cm}^{-1}$. In the case of $\mathrm{NiBr}_{2}$, the vibrational progression on the first band has a separation of $188 \mathrm{~cm}^{-1}$ in $\mathrm{Ar}, \mathrm{Kr}$, and $\mathrm{Xe}$ and ca. $180 \mathrm{~cm}^{-1}$ in $\mathrm{CH}_{4}$. The progression separation for the second band in the $\mathrm{Ar}, \mathrm{Kr}$, and $\mathrm{Xe}$ data is also very similar to $188 \mathrm{~cm}^{-1}$ but suffers from overlap of the first progression. Therefore, it is possible to estimate a symmetric stretching frequency of $188 \mathrm{~cm}^{-1}$ for $\mathrm{NiBr}_{2}$ in the excited state. In the case of $\mathrm{NiCl}_{2}$ (Figure $10 \mathrm{~b}$ ), the poorly resolved vibrational fine structure (ca. $230 \mathrm{~cm}^{-1}$ ) was in good agreement with the previous values of $260 \mathrm{~cm}^{-1}$. 102,103

The striking similarity between the spectra, with a simple matrix shift being observed, further underlines a consistent linear geometry for $\mathrm{NiBr}_{2}$ isolated in argon, krypton, xenon, and methane matrices. The band system studied by Brown and coworkers ${ }^{144-150}$ at ca. $22000 \mathrm{~cm}^{-1}$ for $\mathrm{NiCl}_{2}$ was not observed by DeKock and Gruen ${ }^{102}$ and was seen only by Jacox and Milligan ${ }^{103}$ after extensive deposition, and there is only the faintest hint of it in our spectra (Figure 10b). The only bands observed for $\mathrm{NiBr}_{2}$ in this work at lower energy relative to the intense structured absorption band at ca. $23000 \mathrm{~cm}^{-1}$ were very weak bands at $20300 \mathrm{~cm}^{-1}$ in $\mathrm{Ar}, 20030 \mathrm{~cm}^{-1}$ in $\mathrm{Kr}, 19820 \mathrm{~cm}^{-1}$ in $\mathrm{Xe}$, and $18840 \mathrm{~cm}^{-1}$ in $\mathrm{CH}_{4}$.

The UV-vis-NIR spectrum of $\mathrm{NiBr}_{2}$ isolated in an ${ }^{14} \mathrm{~N}_{2}$ matrix is shown in Figure 10c, with the observed absorption bands appearing at 24800, $27650,29870,33000$, and $37100 \mathrm{~cm}^{-1}$. The inset (Figure 10d) shows the presence of weak features at 16890 and $19710 \mathrm{~cm}^{-1}$ and a very, very weak peak at $14570 \mathrm{~cm}^{-1}$ that could be assigned as $\mathrm{d}-\mathrm{d}$ transitions. The spectrum of $\mathrm{NiCl}_{2}$ in a nitrogen matrix is given in Figure $10 \mathrm{f}$ and is similar to that of $\mathrm{NiBr}_{2}$ but with all of the charge transfer bands (27 900, $30410,32150,34790$, and $37940 \mathrm{~cm}^{-1}$ ) shifted by about $5000 \mathrm{~cm}^{-1}$ to higher wavenumber. There are some very weak features at 15400 and $21150 \mathrm{~cm}^{-1}$. These spectra are both radically different compared with those obtained from argon matrices (Figure 10a,b). The most significant difference, aside from the extra transitions at high frequency, is the absence of the band centered around $22600 \mathrm{~cm}^{-1}$ for $\mathrm{NiBr}_{2}$ and $28350 \mathrm{~cm}^{-1}$ for $\mathrm{NiCl}_{2}$, which provides further confirmation that a fundamental change in the geometric and electronic structures of both $\mathrm{NiBr}_{2}$ and $\mathrm{NiCl}_{2}$ occurs in going to a $\mathrm{N}_{2}$ matrix. Broadband photolysis of $\mathrm{NiBr}_{2}$ in solid $\mathrm{N}_{2}$ also produced a subtle but significant change compared with the electronic absorption spectrum obtained after deposition. In the spectrum of the photolyzed sample, shown in Figure 10e, the absorption band at $33000 \mathrm{~cm}^{-1}$ observed for the unphotolyzed sample disappeared. Annealing to $20 \mathrm{~K}$ brought about the return of this feature, with the rest the spectrum remaining unchanged. Further photolysis diminished this peak again, and the cycle of photolysis and annealing could be repeated two or three times before enhanced spectral noise and scattering intervened. A difference spectrum of before and after photolysis revealed that in addition to the reduction in intensity of the $33000 \mathrm{~cm}^{-1}$ band after photolysis there were some more subtle changes after photolysis, including a reduction in intensity in the tail of the $27650 \mathrm{~cm}^{-1}$ band and an enhancement in intensity of the band at $24800 \mathrm{~cm}^{-1}$. These changes mirror the formation of the dinitrogen complex observed in the IR spectra. However, they clearly indicate that only a small proportion of the trapped $\mathrm{NiBr}_{2}$ molecules participate in the photochemistry, and it is intriguing 
Table 7. Electronic Absorption Data $\left(\right.$ in $\mathrm{cm}^{-1}$ ) for $\mathrm{NiBr}_{2}, \mathrm{CoBr}_{2}$, and $\mathrm{FeBr}_{2}$ Isolated in Different Matrices

\begin{tabular}{|c|c|c|c|c|c|c|c|c|}
\hline \multirow[b]{2}{*}{ molecule } & \multirow{2}{*}{$\frac{\mathrm{Ar}}{\text { charge transfer }}$} & \multirow{2}{*}{$\frac{\mathrm{Kr}}{\text { charge transfer }}$} & \multicolumn{2}{|c|}{$\mathrm{Xe}$} & \multicolumn{2}{|c|}{$\mathrm{CH}_{4}$} & \multicolumn{2}{|c|}{$\mathrm{N}_{2}$} \\
\hline & & & $d-d$ & charge transfer & $d-d$ & charge transfer & $d-d$ & charge transfer \\
\hline \multirow[t]{6}{*}{$\mathrm{NiBr}_{2}$} & 20300 & 20030 & & 19820 & & 18840 & 14570 & 24800 \\
\hline & 22600 & 22190 & & 21670 & & 20000 & 16890 & 27650 \\
\hline & 23500 & 23560 & & 22650 & & 22380 & 19710 & 29870 \\
\hline & 25900 & 28400 & & 27900 & & 23580 & & 33000 \\
\hline & 28540 & & & & & 25750 & & 37100 \\
\hline & & & & & & 28360 & & \\
\hline \multirow{5}{*}{$\mathrm{NiCl}_{2}$} & 21400 & & & & & & 15400 & 27900 \\
\hline & 28350 & & & & & & 21150 & 30410 \\
\hline & 31900 & & & & & & & 32150 \\
\hline & & & & & & & & 34790 \\
\hline & & & & & & & & 37940 \\
\hline \multirow[t]{14}{*}{$\mathrm{CoBr}_{2}$} & 25030 & 24940 & 11780 & 26800 & 12475 & 23390 & 12235 & 26470 \\
\hline & 25840 & 27380 & 11845 & 29300 & 12675 & 27325 & 12290 & $28260(\mathrm{sh})$ \\
\hline & 27720 & 29860 & 11920 & 34950 & & 30050 & 12385 & 31250 \\
\hline & 30100 & 31000 & 12045 & 37520 & & 33070 & 12435 & 35070 \\
\hline & 30970 & 40170 & 12280 & 40450 & & 39760 & 12475 & 37750 \\
\hline & 31960 & & 12345 & & & 41750 & 12535 & 41100 \\
\hline & 33280 & & 12670 & & & & 12660 & \\
\hline & 36540 & & 12800 & & & & 12990 & \\
\hline & & & 12970 & & & & 13055 & \\
\hline & & & 13140 & & & & 13150 & \\
\hline & & & 13950 & & & & 15910 & \\
\hline & & & 14440 & & & & 16820 & \\
\hline & & & 15690 & & & & 17610 & \\
\hline & & & 17040 & & & & & \\
\hline \multirow[t]{6}{*}{$\mathrm{CoCl}_{2}$} & & & & & & & 12310 & 33210 \\
\hline & & & & & & & 12405 & 37770 \\
\hline & & & & & & & 12955 & 40030 \\
\hline & & & & & & & 13035 & 42820 \\
\hline & & & & & & & 13445 & 46340 \\
\hline & & & & & & & 13605 & \\
\hline \multirow[t]{8}{*}{$\mathrm{FeBr}_{2}$} & 31260 & & & & & $33870(\mathrm{sh})$ & & 35300 \\
\hline & $32950(\mathrm{sh})$ & & & & & 35550 & & 45190 \\
\hline & 33650 & & & & & 39780 & & \\
\hline & 35570 & & & & & 41930 & & \\
\hline & 37060 & & & & & 44130 & & \\
\hline & 39615 & & & & & & & \\
\hline & 41180 & & & & & & & \\
\hline & 43850 & & & & & & & \\
\hline
\end{tabular}

that it is easier to identify the bands that disappear rather than those that appear upon photolysis. Therefore, it appears from the electronic absorption spectra that there may be at least two $\mathrm{NiBr}_{2}$ species trapped in nitrogen and that only one of these (a minor component) is involved in the photochemistry.

XAFS Spectroscopy. As shown in Figures 1 and 2, features close to the edge in $\mathrm{Ni}(\mathrm{II}) \mathrm{K}$-edge XANES spectra can be assigned to specific electronic transitions characteristic of different geometries. ${ }^{112}$ The $1 \mathrm{~s} \rightarrow 3 \mathrm{~d}$ transitions several electron volts below the edge are forbidden for centrosymmetric environments but are expected to gain intensity due to $\mathrm{p}-\mathrm{d}$ mixing in noncentrosymmetric geometries. Therefore, relatively weak $1 \mathrm{~s} \rightarrow 3 \mathrm{~d}$ peaks are expected for octahedral, square-planar, and linear geometries, with greater intensity expected for trigonalbipyramidal, square-pyramidal, and tetrahedral geometries as well as nonlinear triatomics. ${ }^{57,112} \mathrm{~A}$ second pre-edge feature (peak or shoulder) about $1-3 \mathrm{eV}$ below the edge that is found in the spectra of tetragonal complexes missing one or more axial ligands and in linear complexes has been assigned to
$1 \mathrm{~s} \rightarrow 4 \mathrm{p}_{z}$ transitions with shakedown contributions, ${ }^{112}$ and this is confirmed by our calculations shown in Figures 1 and 2. Therefore, a sharp intense feature on the edge of the metal K-edge XANES spectrum can be used diagnostically to indicate linearity, and a reduction in the intensity of this feature and the appearance of weak pre-edge features are indicators of the onset of nonlinearity.

The Ni K-edge XANES spectra of $\mathrm{NiBr}_{2}$ isolated in $\mathrm{CH}_{4}$ and $\mathrm{N}_{2}$ matrices are shown in Figure 12, and it is clear that the spectra of $\mathrm{NiBr}_{2}$ in methane and nitrogen are very different, again confirming the significant change in geometry already indicated by the IR and UV-vis data. In the $\mathrm{CH}_{4}$ matrix spectrum there is a very weak pre-edge $1 \mathrm{~s} \rightarrow 3 \mathrm{~d}$ transition at $8334.0 \mathrm{eV}$, while in the $\mathrm{N}_{2}$ matrix spectrum it is more defined and appears at $8329.5 \mathrm{eV}$. Analogous peaks are observed at $8332.9 \mathrm{eV}$ for (solid) $\mathrm{NiBr}_{2}$ and $\left[(\mathrm{en})_{2} \mathrm{NiBr}_{2} \mathrm{Ni}(\mathrm{en})_{2}\right] \mathrm{Br}_{2},{ }^{57}$ both of which have octahedral coordination, and at $8331.7 \mathrm{eV}$ for tetrahedral $\mathrm{NiBr}_{2}\left(\mathrm{PPh}_{3}\right)_{2} \cdot{ }^{57}$ Although the intensity of the pre-edge feature in the Ni K-edge XANES spectrum of $\mathrm{NiBr}_{2}$ in $\mathrm{N}_{2}$ is more characteristic of a relatively high symmetry environment such as 


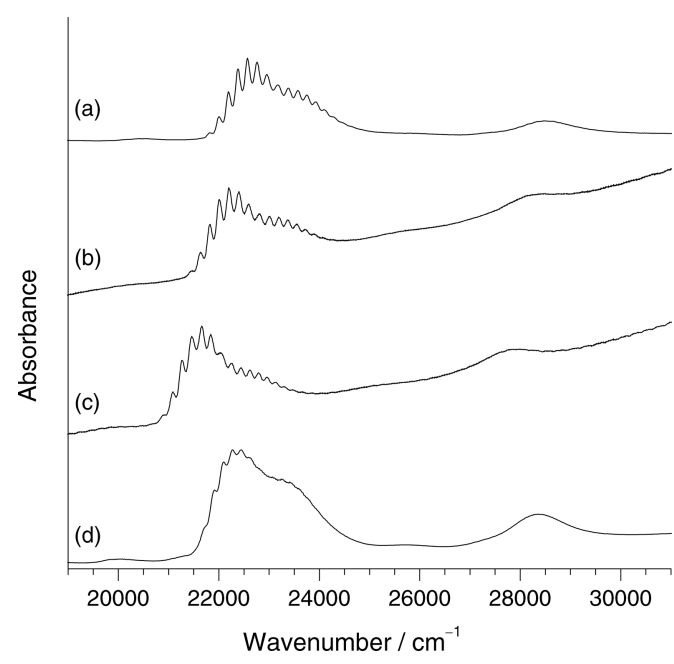

Figure 11. Expansion of electronic absorption spectra of $\mathrm{NiBr}_{2}$ isolated in (a) $\mathrm{Ar}$, (b) $\mathrm{Kr}$, (c) $\mathrm{Xe}$, and (d) $\mathrm{CH}_{4}$ matrices.

Table 8. Electronic Absorption Data (in $\mathrm{cm}^{-1}$ ) for the Vibrationally Resolved Structure of $\mathrm{NiBr}_{2}$ in $\mathrm{Ar}, \mathrm{Kr}, \mathrm{Xe}$, and $\mathrm{CH}_{4}$ Matrices

$\begin{array}{cccc}\mathrm{Ar} & \mathrm{Kr} & \mathrm{Xe} & \mathrm{CH}_{4} \\ 19836 & & & \\ 20123 & & & \\ 20356 & & & \\ 20584 & & 20881 & 21700 \\ 21810 & 21439 & 21075 & 21890 \\ 21999 & 21628 & 21262 & 22078 \\ 22190 & 21817 & 21459 & 22260 \\ 22380 & 22008 & 21658 & 22443 \\ 22569 & 22202 & 21842 & 22628 \\ 22761 & 22397 & 21985 & 22833 \\ 22960 & 22596 & 22077 & 23066 \\ 23178 & 22809 & 22259 & 23272 \\ 23388 & 23011 & 22444 & 23442 \\ 23575 & 23196 & 22622 & 23610 \\ 23757 & 23377 & 22794 & 23794 \\ 23936 & 23553 & 22964 & 24001 \\ 24113 & 23728 & 23134 & \\ 24281 & 23915 & 23309 & \\ & 24076 & 23479 & \\ & & 23649 & \\ & & & \end{array}$

octahedral, its position and that of the edge itself are ca. $2 \mathrm{eV}$ lower than in tetrahedral examples and ca. $3 \mathrm{eV}$ lower than in octahedral examples. ${ }^{57}$ In contrast, the intense edge feature at $8341.0 \mathrm{eV}$ in the Ni K-edge XANES spectrum of $\mathrm{NiBr}_{2}$ in solid $\mathrm{CH}_{4}$ is associated with transitions from the 1s orbital to orbitals with significant $\mathrm{p}$ character, and as shown earlier this, is diagnostic of linearity. In the case of square-planar $\left[\mathrm{Ni}(\mathrm{CN})_{4}\right]^{2-}$ complexes these intense transitions involve the $\mathrm{p}_{\pi}$ orbitals. ${ }^{169-172}$ In the case of square-planar $\mathrm{Ni}(\mathrm{II})$ phosphine halide complexes, similar transitions were observed at $8334.7 \mathrm{eV}$ for cis$\left[\mathrm{NiBr}_{2}(\mathrm{dppe})\right]$ and $8335.4 \mathrm{eV}$ for trans- $\left[\mathrm{NiBr}_{2}\left(\mathrm{PEt}_{3}\right)_{2}\right]{ }^{57}$ Therefore, as expected from both the IR and UV-vis-NIR data, the Ni K-edge XANES confirms that a significant change in electronic and geometric structure occurs in going from the methane matrix to the nitrogen matrix, consistent with a change from a linear to bent geometry. There was no significant difference between the $\mathrm{Br}$ K-edge XANES spectra of $\mathrm{NiBr}_{2}$ in $\mathrm{CH}_{4}$ and $\mathrm{N}_{2}$ matrices.

The Ni K-edge and $\mathrm{Br}$ K-edge EXAFS and FTs for $\mathrm{NiBr}_{2}$ isolated in $\mathrm{CH}_{4}$ and $\mathrm{N}_{2}$ matrices are shown in Figure 13. It is clear that there are significant differences between the $\mathrm{CH}_{4}$ and $\mathrm{N}_{2}$ data. Analysis of these data have been discussed in a preliminary report previously, ${ }^{68}$ but full analysis was not possible at the time because of limitations in the analysis program (EXCURV92). As the implications of these experiments are significant and we now have substantial additional experimental data that have afforded considerable insight, the data have been reanalyzed using EXCURV98.

The Br K-edge data (Figure 13) are straightforward to interpret and analyze with a $\mathrm{Br}-\mathrm{Ni}$ shell and a $\mathrm{Br} \cdots \mathrm{Br}$ shell, and by simple triangulation the $\mathrm{Br}-\mathrm{Ni}-\mathrm{Br}$ bond angle can be determined. The greater intensity of the second shell in the FT of the $\mathrm{NiBr} 2 / \mathrm{CH}_{4}$ data compared with the $\mathrm{NiBr}_{2} / \mathrm{N}_{2}$ data is due to the multiple scattering in the linear $\mathrm{Br}-\mathrm{Ni}-\mathrm{Br}$ unit (see Figure 4). With light matrix scatterers such as $\mathrm{C}$ and $\mathrm{N}$ there is, as expected, very little contribution from the matrix. The $\mathrm{Ni}$ $\mathrm{K}$-edge data (Figure 13) are not so straightforward. There is a feature at ca. 2 times the $\mathrm{Ni}-\mathrm{Br}$ distance in the $\mathrm{FT}$ for the $\mathrm{CH}_{4}$ matrix data that is absent in the $\mathrm{N}_{2}$ data, but there is evidence of light scatterers in the low- $k$ region of the $\mathrm{N}_{2}$ matrix data. The first of these is due to multiple scattering through the central $\mathrm{Ni}$ atom, but this could not be modeled with the analysis programs available at the time of the initial publication ${ }^{68}$ (EXCURV92). Subsequently these features were shown to be due to multiple scattering through the central atom, which is very diagnostic of linearity. ${ }^{57,120,121}$ Therefore, the theoretical fits shown in Figure 13 for $\mathrm{NiBr}_{2}$ in a $\mathrm{CH}_{4}$ matrix are those derived using this approach with the more recent analysis suite (EXCURV98), and for consistency the other data in Figure 13 have also been reanalyzed.

The original $\mathrm{Br}$ K-edge EXAFS data for $\mathrm{NiBr}_{2}$ in a $\mathrm{CH}_{4}$ matrix gave $r_{\mathrm{Br}-\mathrm{Ni}}=2.19(3) \AA$ and $r_{\mathrm{Br} \cdots \mathrm{Br}}=4.36(6) \AA{ }^{68}$ and reanalysis gave essentially the same values (2.20(2) and 4.38(4) $\AA$, respectively). Both of these sets of data imply a bond angle of $170^{\circ}$, which in view of the insensitivity of the sine function close to $90^{\circ}$ can be taken as linear in both cases. These values are in good agreement with the $r_{\mathrm{g}}$ value of $2.201 \AA$ A derived from electron diffraction experiments. ${ }^{152}$ The reanalysis of the $\mathrm{Ni}$ K-edge data using the full multiple scattering (FMS) approach for $\mathrm{NiBr}_{2}$ in a $\mathrm{CH}_{4}$ matrix gave a $\mathrm{Ni}-\mathrm{Br}$ bond length of $2.20(2) \AA$ (compared to the original value of $2.19(2) \AA$ ) and a good fit to the feature at ca. $4.35 \AA$, indicating a linear geometry. This is in excellent agreement with the $r_{\mathrm{g}}$ electron diffraction value of $2.201 \AA .{ }^{152}$ While the reanalysis of these data made no significant difference to the overall picture, the reanalysis of the $\mathrm{NiBr}_{2} / \mathrm{N}_{2}$ data does have more significant implications.

At the time of the original and very careful data analysis, the best model to fit both the XAFS and IR data was thought to be a bent $\mathrm{NiBr}_{2}$ unit with a $\mathrm{Br}-\mathrm{Ni}-\mathrm{Br}$ bond angle of ca. $145^{\circ}$ together with two nitrogen atoms ca. $2.6 \AA$ from the Ni together with a second nitrogen shell at $3.4 \AA \AA^{68}$ This model gave a fit as good or better than that involving short $\mathrm{Ni}-\mathrm{N}$ distances. In addition, the $\mathrm{Ni}-\mathrm{Br}$ distance from the data including the short $\mathrm{Ni}-\mathrm{N}$ interactions (2.30(3) $\AA$ ) was in poorer agreement with the $\mathrm{Br}$ K-edge $\mathrm{Br}-\mathrm{N}$ distance of 2.27(3) $\AA$ than that for the longer $\mathrm{Ni} \cdots \mathrm{N}$ distances $(2.27(3) \AA)$. The use of $k^{2}$ and $k^{1}$ weighting factors to enhance the low- $z$ contribution also indicated against the inclusion of short $\mathrm{Ni}-\mathrm{N}$ distances. Therefore, in conjunction with the absence of conventional $\nu_{\mathrm{NN}}$ modes in the IR spec- 

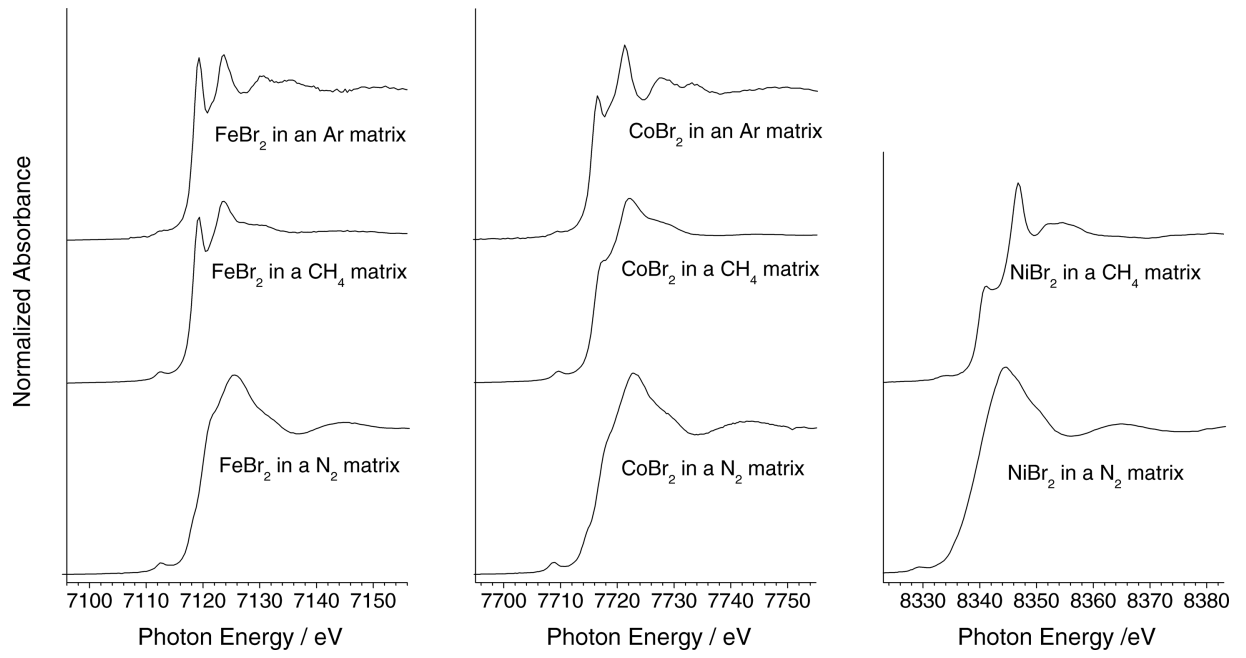

Figure 12. Metal K-edge XANES spectra of metal dibromides isolated in different matrices.

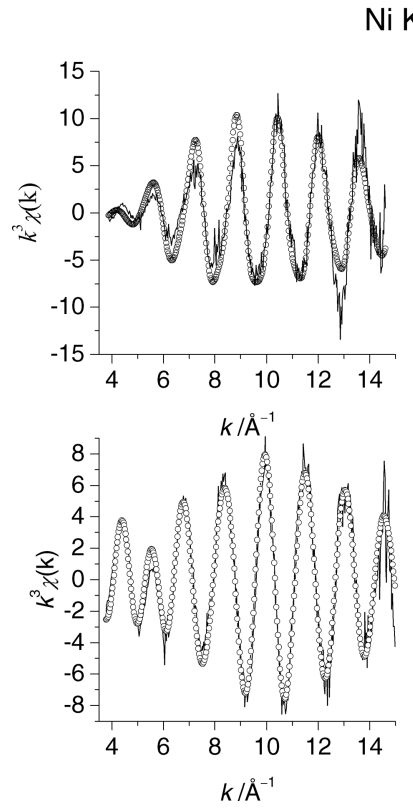

Ni K-edge

Br K-edge
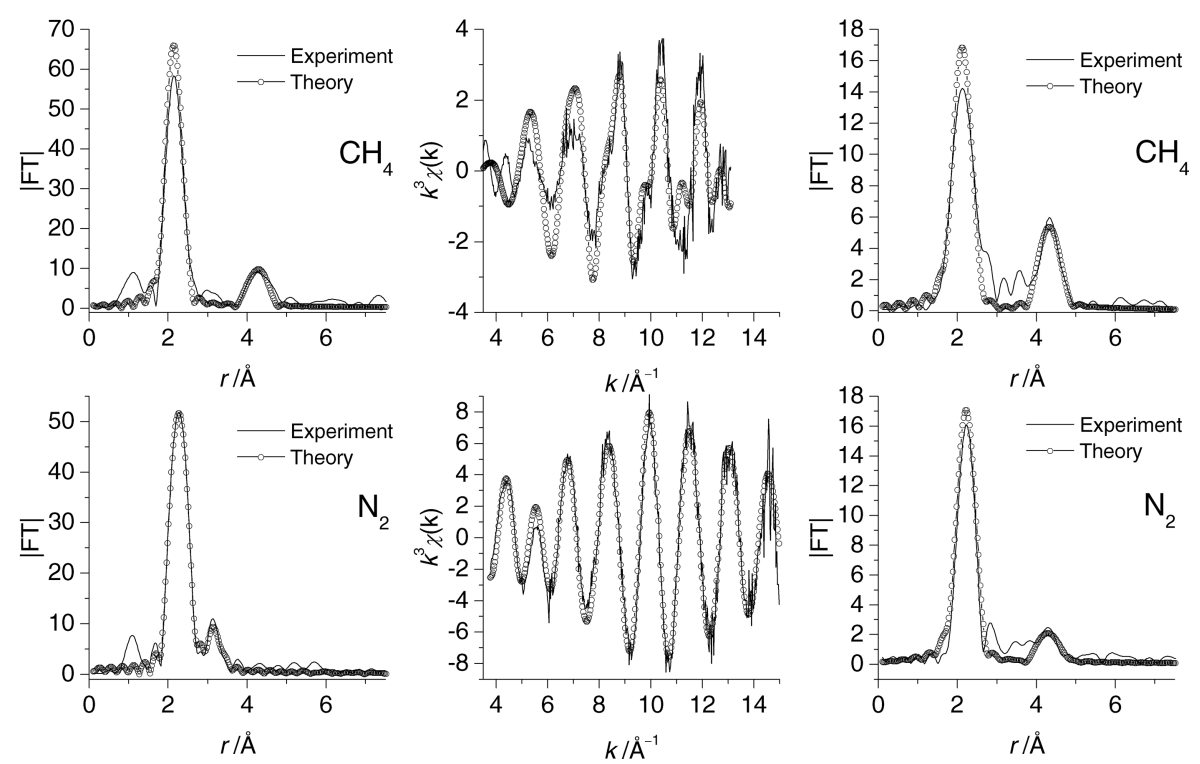

Figure 13. (left) Ni K-edge EXAFS and FTs and (right) Br K-edge EXAFS and FTs for $\mathrm{NiBr}_{2}$ isolated in (top) $\mathrm{CH}_{4}$ and (bottom) $\mathrm{N}_{2}$ matrices.

tra (the ${ }^{15} \mathrm{~N}_{2}$ experiments had not been carried out at that time), we concluded that "there appears to be no convincing evidence for a short $\mathrm{Ni}-\mathrm{N}$ interaction." ${ }^{68}$ Having re-examined this original EXCURV92 data analysis in detail, we would almost certainly have come to the same conclusion, i.e., that there was no convincing evidence for $\mathrm{Ni}-\mathrm{N}_{2}$ formation when using EXCURV92 for analysis.

For $\mathrm{NiBr}_{2}$ in a $\mathrm{N}_{2}$ matrix, the original analysis of the $\mathrm{Br}$ K-edge data gave $r_{\mathrm{Br}-\mathrm{Ni}}=2.27(3) \AA$ and $r_{\mathrm{Br} \cdots \mathrm{Br}}=4.34(6) \AA$, and the absence of a second relatively intense feature in the FT indicated a nonlinear geometry with a bond angle of $145^{\circ} .{ }^{68}$ Reanalysis using the cluster multiple scattering (CMS) approach yielded similar values of $\mathrm{r}_{\mathrm{Br}-\mathrm{Ni}}(2.29(3) \AA)$ and $r_{\mathrm{Br} \cdots \mathrm{Br}}(4.33(5) \AA)$, indicating a bond angle of $142^{\circ}$. Although the change in the $\mathrm{Br}-\mathrm{Ni}$ distance is small, it does have a considerable impact. The Br K-edge data are presented in Figure 13, and the refinement details are given in Table 9.

The analysis of the $\mathrm{Ni} \mathrm{K}$-edge data of $\mathrm{NiBr}_{2}$ in solid nitrogen (Figure 13) was less straightforward. From the relatively intense oscillations at low $k$ in the Ni K-edge EXAFS, it is clear that there are low- $z$ backscatterers in addition to bromine in the nickel coordination environment. The difficulty in analyzing these $\mathrm{Ni}$ K-edge data is in determining whether these oscillations are due to $\mathrm{Ni}-\mathrm{N}$ or $\mathrm{Ni} \cdots \mathrm{N}$ type interactions. As in the previous EXCURV92 analysis, there are at least two different types of nickel-nitrogen interactions: one is at a similar distance to the $\mathrm{Ni}-\mathrm{Br}$ interaction, with the other at ca. $3.2 \AA$. It was not possible to fit the data to just $\mathrm{Ni}-\mathrm{Br}$ at ca. $2.3 \AA$ and a $\mathrm{Ni} \cdots \mathrm{N}$ interaction at $3.2 \AA$. The $3.2 \AA$ shell does not fit to a $\mathrm{Ni} \cdots \mathrm{Ni}$ interaction, as might be expected for a dimeric structure. The question therefore is whether the additional nickel-nitrogen interaction is at a short distance of ca. 2.1 $\AA$, indicative of $\mathrm{Ni}-\mathrm{N}$, or at a longer distance of $2.6 \AA$, characteristic of $\mathrm{Ni} \cdots \mathrm{N}$. The data can be modeled reasonably well by either a short $\mathrm{Ni}-\mathrm{N}$ distance of ca. $2.12 \AA$ together with a $\mathrm{Ni} \cdots \mathrm{N}$ distance of ca. $3.19 \AA$ or a longer $\mathrm{Ni} \cdots \mathrm{N}$ distance of ca. $2.6 \AA$ together with another $\mathrm{Ni} \cdots \mathrm{N}$ distance at ca. $3.2 \AA$. The $\mathrm{Ni}-\mathrm{Br}$ bond length varies between the two different models, as does the $E_{\mathrm{f}}$ parameter, 
Table 9. EXAFS-Derived Structural Data for $\mathrm{NiBr}_{2}, \mathrm{CoBr}_{2}$, and $\mathrm{FeBr}_{2}$ in Different Matrices and Vapor-Phase Electron Diffraction (ED) Data

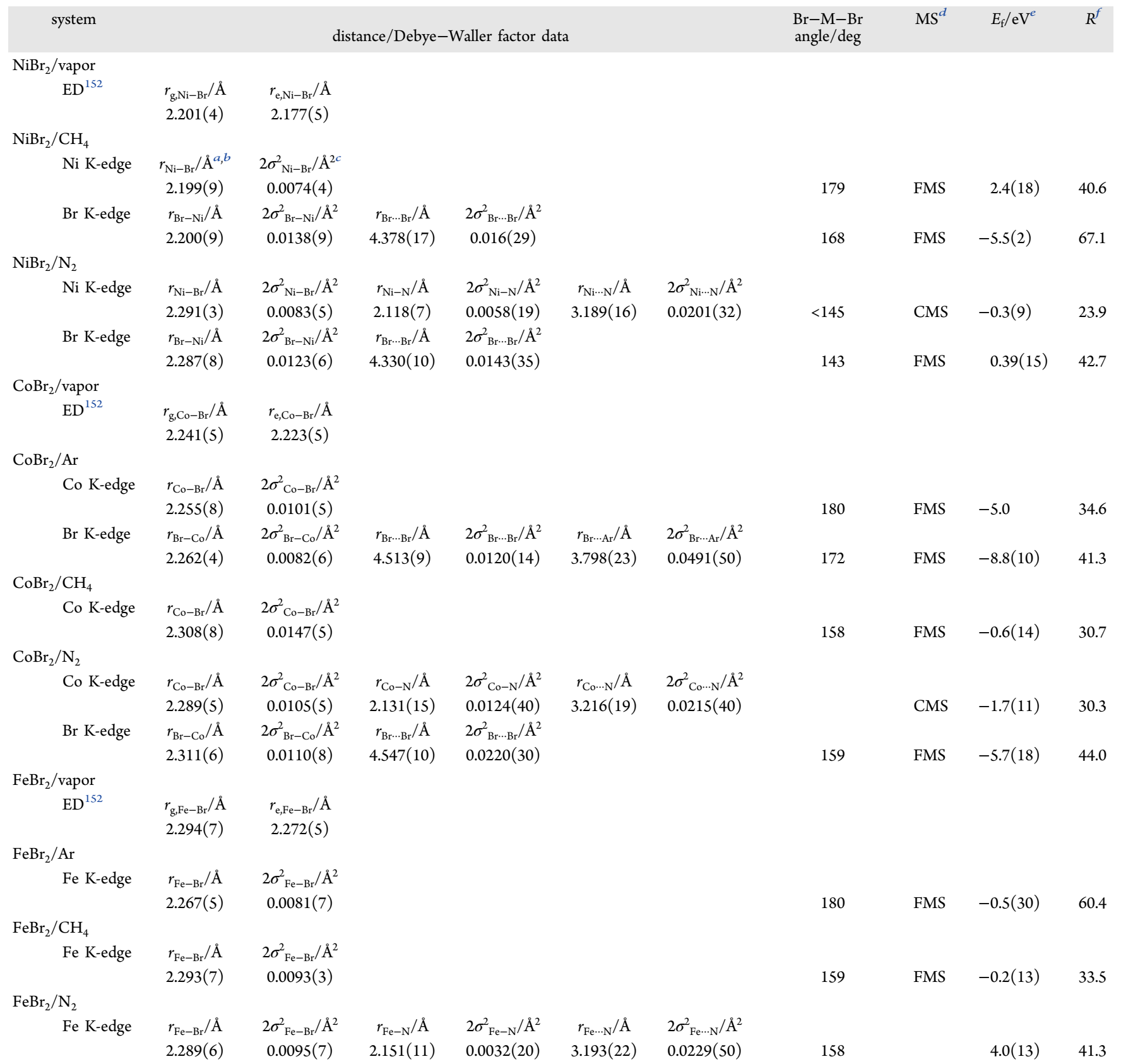

${ }^{a}$ The refinement standard deviation is given in parentheses. ${ }^{b}$ The estimated systematic errors in EXAFS bond lengths are $\pm 1.5 \%$ for well-defined coordination shells. ${ }^{c} 2 \sigma^{2}$ is twice the mean square displacement term used in the Debye-Waller factor. ${ }^{d} \mathrm{MS}$ is multiple scattering approach used; FMS is full multiple scattering, CMS is cluster multiple scattering. ${ }^{e} E_{\mathrm{f}}$ is a single refined parameter to reflect differences in the theoretical and experimental Fermi levels. ${ }^{f} R=\left[\int\left|\chi^{\mathrm{T}}-\chi^{\mathrm{E}}\right| k^{3} \mathrm{~d} k / \int\left|\chi^{\mathrm{E}}\right| k^{3} \mathrm{~d} k\right] \times 100 \%$.

which reflects the difference between the experimental and calculated Fermi energies. For the model with a $2.1 \AA \mathrm{Ni}-\mathrm{N}$ distance the $\mathrm{Ni}-\mathrm{Br}$ bond length refines to 2.29(3) $\AA$, in excellent agreement with the $\mathrm{Br}$ K-edge data (2.29(3) $\AA$ ), and the $E_{\mathrm{f}}$ value remains essentially the same as for just a $\mathrm{Ni}-\mathrm{Br}$ refinement. In contrast, when a $2.6 \AA \mathrm{Ni}-\mathrm{N}$ shell is included in the fit, the $\mathrm{Ni}-\mathrm{Br}$ bond length decreases to $2.26 \AA$, and the $E_{\mathrm{f}}$ parameter lies very close to its accepted boundaries $(15$ or $-15 \mathrm{eV})$. The combination of a relatively large discrepancy between the $\mathrm{Br}$ and $\mathrm{Ni}$ K-edge data and the behavior of the $E_{\mathrm{f}}$ parameter indicates that the model involving the longer $\mathrm{Ni}-\mathrm{N}$ interaction at $2.6 \AA$ is less physically reasonable than the model including the shorter Ni-N interaction at $2.1 \AA$. The goodness of fit $(R)$ between the two models is small, but the model incorporating the shorter Ni-N distance has the best fit. For both of these models, the Ni-N occupation number was small, and the preferred number was 2 in each case, both in terms of $R$ factor and also reasonableness of the Debye-Waller $2 \sigma^{2}$ terms. Therefore, we are forced to the conclusion that with more modern data analysis techniques, the only realistic interpretation of the $\mathrm{Ni}$ K-edge EXAFS data is that there is a $\mathrm{Ni}-\mathrm{N}$ interaction at $2.12(2) \AA$ with an occupation number of 2 . The second $\mathrm{Ni} \cdots \mathrm{N}$ shell in this refinement at 3.19(4) $\AA$ implies the presence of linear $\mathrm{Ni}-\mathrm{N} \equiv \mathrm{N}$ units with a $\mathrm{N} \equiv \mathrm{N}$ bond length of $1.07 \AA$. 
This should be compared to the solid-state value of $1.075 \AA$ in $\alpha-\mathrm{N}_{2}{ }^{173}$ Although it is possible to fit the EXAFS data properly only by including multiple scattering for this contribution, the Debye-Waller factor for this shell is a little larger than expected. If the $\mathrm{Ni}-\mathrm{N} \equiv \mathrm{N}$ bond angle is reduced to ca. $160-170^{\circ}$, the Debye-Waller factor becomes more reasonable, which may indicate that the $\mathrm{Ni}-\mathrm{N} \equiv \mathrm{N}$ units are not completely linear. The fit shown in Figure 13 and the data in the Table 9 are for linear $\mathrm{Ni}-\mathrm{N} \equiv \mathrm{N}$ units.

There are relatively few crystallographically characterized nickel dinitrogen complexes, and these are often stabilized by pincer ligands. Of the tetrahedral $\mathrm{Ni}(0)$ complexes with terminal $\mathrm{N}_{2}$ ligands, $\mathrm{Ni}-\mathrm{N}$ and $\mathrm{N} \equiv \mathrm{N}$ distances and $\nu_{\mathrm{NN}}$ modes have been observed at 1.830 and $1.112 \AA$ and $2072 \mathrm{~cm}^{-1}$, respectively, ${ }^{174}$ and 1.848 and $1.104 \AA$ and $2144 \mathrm{~cm}^{-1}$, respectively, ${ }^{175}$ as have $\mathrm{Ni}-\mathrm{N}$ and $\mathrm{N} \equiv \mathrm{N}$ distances of $1.861 \AA$ and $1.101 \AA$, respectively ${ }^{176}$ A square-planar $\mathrm{Ni}(\mathrm{II})$ complex with terminal dinitrogen ligands has a Ni-N distance of $1.872 \AA$ and a $\mathrm{N} \equiv \mathrm{N}$ distance of $1.099 \AA^{177}$ Trigonal-bipyramidal Ni(II) complexes with terminal $\mathrm{N}_{2}$ ligands have $\mathrm{Ni}-\mathrm{N}=1.905 \AA$, $\mathrm{N} \equiv \mathrm{N}=1.087 \AA$, and $\nu_{\mathrm{NN}}=2223 \mathrm{~cm}^{-1} ;{ }^{178} \mathrm{Ni}-\mathrm{N}=1.891 \AA$, $\mathrm{N} \equiv \mathrm{N}=1.083 \AA$, and $\nu_{\mathrm{NN}}=2234 \mathrm{~cm}^{-1} ;{ }^{178}$ and $\mathrm{Ni}-\mathrm{N}=1.908$ $\AA, \mathrm{N} \equiv \mathrm{N}=0.92 \AA$, and $\nu_{\mathrm{NN}}=2156 \mathrm{~cm}^{-1} \cdot{ }^{179}$ For $\mathrm{Ni}(0)$ complexes with bridging $\mathrm{N}_{2}$ ligands, the $\mathrm{Ni}-\mathrm{N}$ bond length is on the order of $1.84 \AA \AA^{180-183}$ and for $\mathrm{Ni}(\mathrm{I})$ complexes it is $1.830 \AA^{184}$

Therefore, the Ni-N distance of 2.12(3) $\AA$ determined in this work is considerably longer than that found for $\mathrm{Ni}(0), \mathrm{Ni}(\mathrm{I})$, and $\mathrm{Ni}(\mathrm{II})$ complexes, which indicates the relative weakness of the $\mathrm{Ni}-\mathrm{N}$ bond due to limited back-bonding from $\mathrm{Ni}$ (II). The EXAFS data relate to the "as deposited" material with $\nu_{\mathrm{NN}}$ modes in the IR spectrum to high frequency of $\nu_{\mathrm{NN}}$ for "free" $\mathrm{N}_{2}$ (the XAFS experiments were carried out in the dark to avoid any unwanted photochemistry). Although XAFS studies of the $\mathrm{NiBr}_{2}\left(\mathrm{~N}_{2}\right)_{2}$ system after photolysis were seriously considered, they were not undertaken because of the highly reactive nature of the complex and, more importantly, because analysis of the data would be difficult or even impossible as a result of the partial conversion, and it was deemed that the limited amount of beam time could be used more effectively. Therefore, we believe that the best interpretation of the Ni K-edge XAFS and IR data is that the $\nu_{\mathrm{NN}}$ modes observed prior to photolysis are associated with the $\mathrm{Ni}-\mathrm{N} \equiv \mathrm{N}$ units with relatively weak bonding of the $\mathrm{N}_{2}$ to the metal center, akin to physisorption.

Conclusions. Therefore, it is clear from all of the spectroscopic techniques that $\mathrm{NiBr}_{2}$ behaves similarly in $\mathrm{Ne}, \mathrm{Ar}, \mathrm{Kr}$, $\mathrm{Xe}, \mathrm{CH}_{4}$, and $\mathrm{O}_{2}$ matrices but that there is a severe change in structure of $\mathrm{NiBr}_{2}$ in solid $\mathrm{N}_{2}$. The EXAFS data indicate a bond angle of ca. $140^{\circ}$, and both the IR and EXAFS data indicate that this is associated with weak physisorption-type coordination of $\mathrm{N}_{2}$ to Ni. Upon photolysis, more traditional chemisorbed dinitrogen complexes are formed.

Cobalt Dibromide. Cobalt dibromide has received very little attention in the matrix isolation literature, with the emphasis of study residing on $\mathrm{CoCl}_{2}$, although $\mathrm{CoF}_{2}$ has been studied by IR spectroscopy in Ne and Ar matrices. ${ }^{139,185}$ The bias toward $\mathrm{CoCl}_{2}$ is unsurprising from a vibrational spectroscopy viewpoint, with the ${ }^{59} \mathrm{Co}$ isotope being $100 \%$ naturally abundant and the bromine isotopes not easily resolved. $\mathrm{CoCl}_{2}$ has been isolated in $\mathrm{Ar}$ and $\mathrm{N}_{2}$ matrices and examined by $\mathrm{IR}^{17,99,103,151}$ and UV-vis ${ }^{102,103,186}$ spectroscopies, and the fluorescence spectrum has also been obtained in an Ar matrix. ${ }^{186}$ To our knowledge there are no data concerning matrix-isolated $\mathrm{CoBr}_{2}$, although vapor-phase IR spectroscopy ${ }^{187}$ yielded a value of
$396 \mathrm{~cm}^{-1}$ for $\nu_{3}$. Electron diffraction suggested a linear structure for gaseous $\mathrm{CoBr}_{2}$ with a $\mathrm{Co}-\mathrm{Br}$ bond distance of $2.25 \AA^{152,188}$

Infrared Spectroscopy. The IR spectra of $\mathrm{CoBr}_{2}$ in a variety of matrices are shown in Figure 14, and the observed frequencies

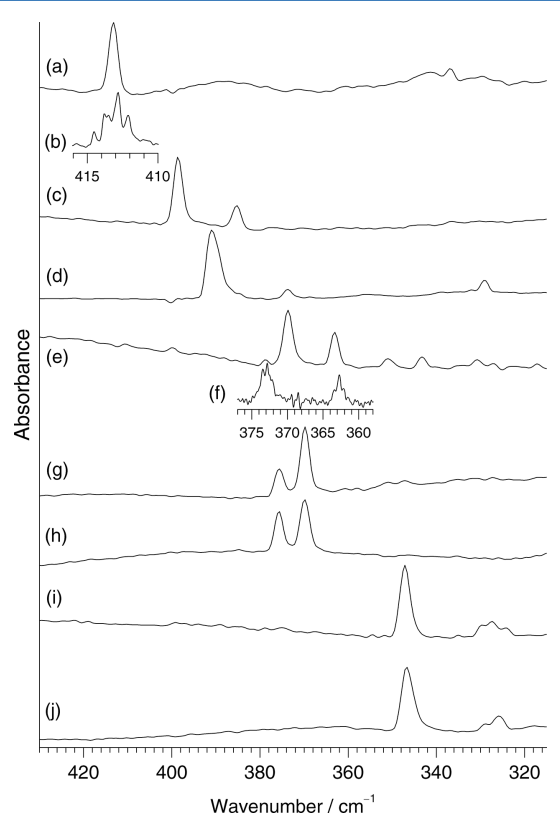

Figure 14. IR spectra of $\mathrm{CoBr}_{2}$ isolated in (a) $\mathrm{Ne},(\mathrm{b}) \mathrm{Ne}$ at higher resolution, (c) $\mathrm{Ar}$, (d) $\mathrm{Kr}$, (e) $\mathrm{Xe}$, (f) Xe at higher resolution, (g) $\mathrm{CH}_{4}$ deposited at ca. $10 \mathrm{~K},(\mathrm{~h}) \mathrm{CH}_{4}$ deposited at ca. $20 \mathrm{~K}$, (i) ${ }^{14} \mathrm{~N}_{2}$, and (j) ${ }^{15} \mathrm{~N}_{2}$ matrices.

of the $\nu_{3}$ asymmetric stretching vibration are given in Table 10 . Two clear differences are observed when the spectra obtained for $\mathrm{CoBr}_{2}$ are compared with those fof $\mathrm{ZnBr}_{2}$ and $\mathrm{NiBr}_{2}$. The first is the number of extra absorption bands (in the form of secondary sites) in addition to the primary band. For $\mathrm{CoCl}_{2}$ in argon, second, weaker features have also been observed $15 \mathrm{~cm}^{-1}$ below the most intense band in previous studies. ${ }^{17,99,103,151}$ The second difference is the range of wavenumbers in which these bands occur. Taking the position of the most intense absorption as the reference, for $\mathrm{ZnBr}_{2}$, the total span of absorption frequencies upon change of matrix for the rare gases from neon to xenon is $16 \mathrm{~cm}^{-1}$. Similarly, for $\mathrm{NiBr}_{2}$, the span in going from neon to xenon matrices is $18 \mathrm{~cm}^{-1}$. For $\mathrm{CoBr}_{2}$, the span is $40 \mathrm{~cm}^{-1}$ in going from neon to xenon matrices.

The shifts in going from $\mathrm{Ne}$ to $\mathrm{N}_{2}$ are 66 and $90 \mathrm{~cm}^{-1}$ for $\mathrm{CoBr}_{2}$ and $\mathrm{NiBr}_{2}$, respectively. It is also clear that there is a gradual change between matrices with no clearly differentiated jumps, which is in stark contrast to $\mathrm{NiBr}_{2}$, where there was a dramatic change in going from a xenon matrix to a nitrogen matrix. A similar span of frequencies for the various matrices was seen previously for the principal $\nu_{3}$ absorptions for ${ }^{59} \mathrm{Co}^{35} \mathrm{Cl}_{2}$, which were observed at 492.2 in $\mathrm{Ar}^{99,103} 484.1$ in $\mathrm{Kr}^{99} 468.3$ in $\mathrm{Xe},{ }^{99}$ and $438.7 \mathrm{~cm}^{-1}$ in ${ }^{14} \mathrm{~N}_{2}{ }^{17}$ Therefore, an intriguing problem is posed as to whether the linearity of the $\mathrm{CoBr}_{2}$ unit is maintained for all of the matrices studied. If this is not the case, at which point in the matrix series does the $\mathrm{CoBr}_{2}$ unit deviate significantly from linearity? Bond angle information for every system in the series would be invaluable in order to solve this problem. Unfortunately, Co is monoisotopic, and therefore, $\mathrm{Br}$ isotopic structure provides the only means of bond angle determination from the IR spectra. Resolving the $\mathrm{Br}$ isotope patterns was very difficult and was possible only in the case of $\mathrm{Ne}$ and 
Table 10. IR Data for $\mathrm{CoBr}_{2}$ Isolated in Different Matrices

\begin{tabular}{|c|c|c|c|}
\hline matrix & $\begin{array}{c}\text { wavenumber } / \mathrm{cm}^{-1} \text { and assignment at medium } \\
\text { resolution }\left(2 \mathrm{~cm}^{-1}\right)\end{array}$ & $\begin{array}{l}\text { wavenumber } / \mathrm{cm}^{-1} \text { and assignment at high resolution } \\
\qquad\left(0.25 \mathrm{~cm}^{-1}\right)\end{array}$ & $\begin{array}{c}\text { calculated wavenumber } / \mathrm{cm}^{-1} \text { for } 180^{\circ} \\
\text { bond angle }\end{array}$ \\
\hline \multirow[t]{6}{*}{$\mathrm{Ne}$} & $413.2-{ }^{59} \mathrm{Co}$ & $414.53-{ }^{59} \mathrm{Co}^{79} \mathrm{Br}_{2}$ & $414.53^{a}$ \\
\hline & $337.0-?$ & $413.82-{ }^{59} \mathrm{Co}^{79} \mathrm{Br}^{81} \mathrm{Br}$ & \\
\hline & & $-\quad-{ }^{59} \mathrm{Co}^{81} \mathrm{Br}_{2}$ & 413.14 \\
\hline & & $413.50-{ }^{59} \mathrm{Co}^{79} \mathrm{Br}_{2}-2^{\text {nd }}$ site & 413.50 \\
\hline & & $412.18-{ }^{59} \mathrm{Co}^{79} \mathrm{Br}^{81} \mathrm{Br}-2^{\text {nd }}$ site & \\
\hline & & $412.11-{ }^{59} \mathrm{Co}^{81} \mathrm{Br}_{2}-2^{\text {nd }}$ site & $412.11^{a}$ \\
\hline \multirow[t]{2}{*}{$\mathrm{Ar}$} & $398.6-{ }^{59} \mathrm{Co}$ & & \\
\hline & 385.3 - 2nd site & & \\
\hline \multirow[t]{3}{*}{$\mathrm{Kr}$} & $390.8-{ }^{59} \mathrm{Co}$ & & \\
\hline & 373.8 - 2nd site & & \\
\hline & $329.1-?$ & & \\
\hline \multirow[t]{2}{*}{$\mathrm{CH}_{4}$} & 375.7 - 2nd site & & \\
\hline & $369.8-{ }^{59} \mathrm{Co}$ & & \\
\hline \multirow[t]{6}{*}{$\mathrm{Xe}$} & $373.6-{ }^{59} \mathrm{Co}$ & $373.45-{ }^{59} \mathrm{Co}^{79} \mathrm{Br}_{2}$ & $373.45^{a}$ \\
\hline & 363.1 - 2nd site & $372.85-{ }^{59} \mathrm{Co}^{79} \mathrm{Br}^{81} \mathrm{Br}$ & \\
\hline & 350.9 - 3rd site & $372.17-{ }^{59} \mathrm{Co}^{81} \mathrm{Br}_{2}$ & 372.19 \\
\hline & 343.2 - 4th site & $363.42-{ }^{59} \mathrm{Co}^{79} \mathrm{Br}_{2}-2^{\text {nd }}$ site & $363.42^{a}$ \\
\hline & & $362.73-{ }^{59} \mathrm{Co}^{79} \mathrm{Br}^{81} \mathrm{Br}-2^{\text {nd }}$ site & \\
\hline & & $362.15-{ }^{59} \mathrm{Co}^{81} \mathrm{Br}_{2}-2^{\text {nd }}$ site & 362.20 \\
\hline \multirow[t]{2}{*}{${ }^{14} \mathrm{~N}_{2}$} & $347.1-{ }^{59} \mathrm{Co}$ & & \\
\hline & 327.4 - 2nd site & & \\
\hline \multirow[t]{2}{*}{${ }^{15} \mathrm{~N}_{2}$} & $346.7-{ }^{59} \mathrm{Co}$ & & \\
\hline & 325.9 - 2nd site & & \\
\hline
\end{tabular}

Xe matrices. Bond angle calculations using the clearest resolved ${ }^{59} \mathrm{Co}^{79} \mathrm{Br}_{2}$ and ${ }^{59} \mathrm{Co}^{81} \mathrm{Br}_{2}$ absorptions (Table 10) produced a $180^{\circ}$ bond angle for $\mathrm{CoBr}_{2}$ isolated in a neon matrix and a $164^{\circ}$ bond angle in a xenon matrix. While a $164^{\circ}$ angle indicates a deviation from a linear structure, an increase in the difference of the two bands of 0.02 to $0.05 \mathrm{~cm}^{-1}$ would result in a linear geometry. Therefore, IR bond angle calculations alone cannot provide conclusive evidence that $\mathrm{CoBr}_{2}$ is bent in a xenon matrix. What perhaps is more important is the actual frequencies and "matrix shifts" of the $\nu_{3}$ mode observed for the dihalide in each matrix and their positions relative to each other in the series. The number of additional site absorptions for each system was consistent despite repeated experiments using different batches of $\mathrm{CoBr}_{2}$.

For $\mathrm{CoBr}_{2}$ isolated in a $\mathrm{CH}_{4}$ matrix, the relative intensities of the two bands at 375.8 and $369.8 \mathrm{~cm}^{-1}$ was dependent on the deposition temperature. The spectra shown in Figure 14g,h show an increase in the $375.8 \mathrm{~cm}^{-1}$ feature compared with that at $369.8 \mathrm{~cm}^{-1}$ when $\mathrm{CoBr}_{2}$ was deposited at $20 \mathrm{~K}$. After deposition, the relative intensities of the absorptions did not change when the sample deposited at $20 \mathrm{~K}$ was cooled to $9 \mathrm{~K}$ or when the sample deposited at $9 \mathrm{~K}$ was annealed to $20 \mathrm{~K}$. Several experiments were conducted on $\mathrm{CoBr}_{2}$ isolated in $\mathrm{Xe}$ matrices, as spectral noise levels were worse than usual and also to discover the nature of the weak bands at 350.9 and $343.2 \mathrm{~cm}^{-1}$. Further purification of the sample and checks on the integrity of the matrix gas led to the assignment of these bands as additional sites, as they were reproducible in each experiment and considered too high in frequency to be bands due to a dimer. ${ }^{99}$

Following the observation of $\nu_{\mathrm{NN}}$ modes to high frequency of the free $\mathrm{N}_{2}$ value and also the photochemical formation of more conventional $\nu_{\mathrm{NN}}$ bands, $\mathrm{CoBr}_{2}$ was isolated in both ${ }^{14} \mathrm{~N}_{2}$ and ${ }^{15} \mathrm{~N}_{2}$ matrices, and photolysis was conducted on both systems. The IR spectra shown in Figure 14i,j show a shift in the principal $\nu_{3}$ absorption band of $0.5 \mathrm{~cm}^{-1}$, which is on the same order as that observed for $\mathrm{NiBr}_{2}\left(0.3 \mathrm{~cm}^{-1}\right)$. Weak bands were observed (Figure 6 and Table 4) upon deposition in the ${ }^{15} \mathrm{~N}_{2}$ matrix at $2261.9 \mathrm{~cm}^{-1}$ (with a shoulder at $2260.2 \mathrm{~cm}^{-1}$ ) and in ${ }^{14} \mathrm{~N}_{2}$ at 2340.0 and $2336.8 \mathrm{~cm}^{-1}$, in addition to the impurityinduced modes $\left({ }^{14} \mathrm{~N}_{2}, 2327.8 \mathrm{~cm}^{-1} ;{ }^{15} \mathrm{~N}_{2}, 2250.0 \mathrm{~cm}^{-1}\right)$. These are similar to (but at different wavenumbers than) the bands observed in the $\mathrm{NiBr}_{2}$ experiments, indicating that they arise from an interaction between the $\mathrm{N}_{2}$ matrix and the metal dibromide. After broadband photolysis of $\mathrm{CoBr}_{2}$ in nitrogen matrices, two new bands were seen at 2235.1 and $2229.7 \mathrm{~cm}^{-1}$ in ${ }^{15} \mathrm{~N}_{2}$ matrices. However, it should be noted that these bands were incredibly weak and were not always reproducibly observed, and therefore, the evidence for chemisorbed $\mathrm{Co}-\mathrm{N}_{2}$ species is not strong. DFT calculations indicate that the reaction enthalpy for the formation of end-on-bonded $\mathrm{CoBr}_{2}\left(\eta^{1}-\mathrm{N}_{2}\right)$ is $-26 \mathrm{~kJ} \mathrm{~mol}^{-1}$ and that for $\mathrm{CoBr}_{2}\left(\eta^{1}-\mathrm{N}_{2}\right)_{2}$ is $-66 \mathrm{~kJ} \mathrm{~mol}^{-1}$.

Electronic Absorption Spectroscopy. The electronic absorption spectra of gaseous $\mathrm{CoCl}_{2}$ have been studied and interpreted using ligand field methodology, with vibrational structure being observed. ${ }^{189-191}$ DeKock and Gruen ${ }^{102}$ proposed a ${ }^{4} \Phi_{\mathrm{g}}$ ground state using the ligand field model, which gives five charge transfer transitions. The argon matrix isolation studies ${ }^{102}$ produced a spectrum with at least eight transitions. Clifton and Gruen ${ }^{186}$ noted that in the $4000-25000 \mathrm{~cm}^{-1}$ region it was only possible to observe a fluorescence spectrum for $\mathrm{CoCl}_{2}$ in $\mathrm{Ar}$ and an absorption spectrum for $\mathrm{CoCl}_{2}$ in $\mathrm{N}_{2}$. The assignment of the ground state by DeKock and Gruen ${ }^{102}$ was contested by Lever and Hollebone, ${ }^{192}$ who predicted it to be ${ }^{4} \Sigma_{\mathrm{g}}^{-}$ on the basis of fitting suitable parameters within the orbital angular overlap model, which led to a predicted spectrum more compatible with the spectroscopic data available. The assignment of the ${ }^{4} \Sigma_{\mathrm{g}}^{-}$ground state for $\mathrm{CoCl}_{2}$ was more recently substantiated by Bridgeman ${ }^{193}$ using density functional theory and a cellular ligand field approach, resulting from the relative 
energies of the $\mathrm{d}$ orbitals being in the order $\mathrm{d}_{\delta}<\mathrm{d}_{\sigma}<\mathrm{d}_{\pi}$ with a $\delta_{\mathrm{g}}{ }^{4} \sigma_{\mathrm{g}}{ }^{1} \pi_{\mathrm{g}}{ }^{2}$ configuration. These results are analogous to those obtained for $\mathrm{NiCl}_{2}{ }^{168}$ Wang and Schwarz ${ }^{129}$ also predicted a ${ }^{4} \Sigma_{\mathrm{g}}^{-}$ ground state, but ${ }^{4} \Delta_{\mathrm{g}}$ was essentially equienergetic. The data in Table 1 show that the DFT-calculated ground state for $\mathrm{CoBr}_{2}$ is ${ }^{4} \Delta_{\mathrm{g}}$ with a d orbital ordering and population of $\delta_{\mathrm{g}}{ }^{3} \sigma_{\mathrm{g}}{ }^{2} \pi_{\mathrm{g}}{ }^{2}$, but this is only $0.33 \mathrm{eV}$ below a ${ }^{4} \Sigma_{\mathrm{g}}^{-}$state with an occupation of $\delta_{\mathrm{g}}{ }^{4} \sigma_{\mathrm{g}}{ }^{1} \pi_{\mathrm{g}}{ }^{2}$, and the ${ }^{4} \Phi_{\mathrm{g}}$ state is $0.48 \mathrm{eV}$ above ${ }^{4} \Delta_{\mathrm{g}}$ with a $\delta_{\mathrm{g}}^{3} \sigma_{\mathrm{g}} \pi_{\mathrm{g}}{ }^{3}$ occupation. Between the ${ }^{4} \Delta_{\mathrm{g}}$ and ${ }^{4} \Sigma_{\mathrm{g}}^{-}$states there are two bent quartet excited states with bond angles of $155^{\circ}$ and $130^{\circ}$. The closeness of the energies of the ${ }^{4} \Delta_{\mathrm{g}}$ and ${ }^{4} \Sigma_{\mathrm{g}}{ }^{-}$states highlights the similarity in energies of the $\mathrm{d}_{\delta}$ and $\mathrm{d}_{\sigma}$ orbitals discussed above for $\mathrm{NiBr}_{2}$.

The UV-vis-NIR spectra of $\mathrm{CoBr}_{2}$ isolated in $\mathrm{Ar}, \mathrm{Kr}, \mathrm{Xe}$, $\mathrm{CH}_{4}$, and ${ }^{14} \mathrm{~N}_{2}$ matrices are shown in Figure 15. The observed

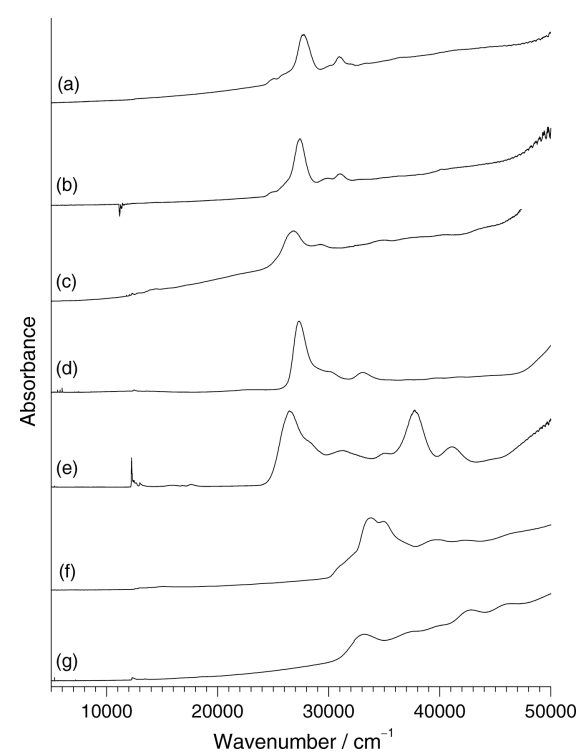

Figure 15. Electronic absorption spectra of $\mathrm{CoBr}_{2}$ in isolated in (a) $\mathrm{Ar}$, (b) $\mathrm{Kr},(\mathrm{c}) \mathrm{Xe}$, (d) $\mathrm{CH}_{4}$, and (e) $\mathrm{N}_{2}$ matrices and $\mathrm{CoCl}_{2}$ in (f) Ar and (g) $\mathrm{N}_{2}$ matrices.

absorption bands are given in Table 7 . DeKock and Gruen ${ }^{102}$ and Jacox and Milligan ${ }^{103}$ observed a complex band for $\mathrm{CoCl}_{2}$ isolated in a $\mathrm{Ar}$ matrix containing at least five transitions between 30000 and $38000 \mathrm{~cm}^{-1}$, with the most intense band at $33700 \mathrm{~cm}^{-1}$ showing a vibrational progression of $233 \pm$ $4 \mathrm{~cm}^{-1}$, which was reported to correspond to the symmetric stretch of the excited state. We have also collected the spectra of $\mathrm{CoCl}_{2}$ in $\mathrm{Ar}$ and $\mathrm{N}_{2}$ matrices using the same protocol and equipment as for $\mathrm{CoBr}_{2}$. Our $\mathrm{CoCl}_{2}$ argon matrix spectra (Figure 15f) are in very good agreement with the literature spectra, with a poorly resolved complex band at ca. $34000 \mathrm{~cm}^{-1}$. For $\mathrm{CoBr}_{2}$ isolated in an $\mathrm{Ar}$ matrix, shown in Figure 15a, the most intense transitions are observed between 23500 and $35000 \mathrm{~cm}^{-1}$. The most intense peaks at 27720 and $30970 \mathrm{~cm}^{-1}$ and weaker shoulders at 25 030, $25840,30100,31960,33280$, and $36540 \mathrm{~cm}^{-1}$ did not exhibit vibrational structure. The spectrum of $\mathrm{CoBr}_{2}$ in $\mathrm{Kr}$ (Figure 15b) is very similar to that of $\mathrm{CoBr}_{2}$ in $\mathrm{Ar}$, with intense peaks at 27380 and $31000 \mathrm{~cm}^{-1}$. However, there are some significant differences in the spectrum of $\mathrm{CoBr}_{2}$ in $\mathrm{Xe}$ (Figure 15c), with some broadening of the main peak at $26800 \mathrm{~cm}^{-1}$ and the appearance of weak features around $12500 \mathrm{~cm}^{-1}$ (Figure 16b) that are not present in the spectrum of $\mathrm{CoBr}_{2}$ in $\mathrm{Ar}$ (Figure 16a).

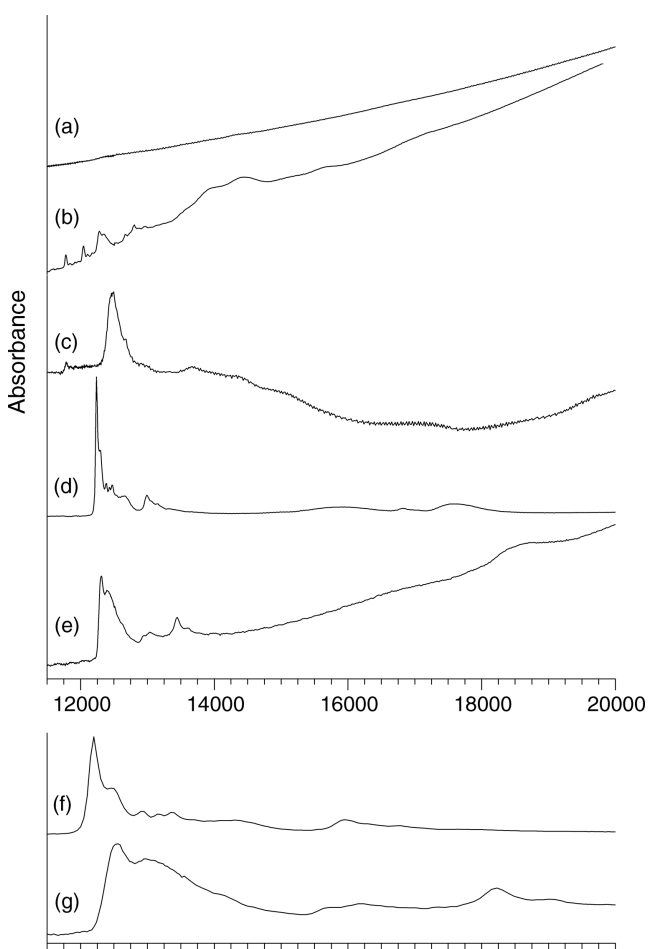

122001240012600128001300013200134001360013800

Wavenumber $/ \mathrm{cm}^{-1}$

Figure 16. Expansion of electronic absorption spectra of $\mathrm{CoBr}_{2}$ in isolated in (a) $\mathrm{Ar},(\mathrm{b}) \mathrm{Xe},(\mathrm{c}) \mathrm{CH}_{4}$, and (d) $\mathrm{N}_{2}$ matrices and (e) $\mathrm{CoCl}_{2}$ in a $\mathrm{N}_{2}$ matrix. The spectra in $(\mathrm{f})$ and $(\mathrm{g})$ are further expansions of those in (d) and (e).

The UV-vis-NIR spectrum of $\mathrm{CoBr}_{2}$ isolated in $\mathrm{CH}_{4}$ is shown in Figure 15d. While it qualitatively looks similar to the argon matrix spectrum, there are some significant differences. Three strong bands are observed, with the most intense band at $27325 \mathrm{~cm}^{-1}$ being very close to the corresponding absorption in an Ar matrix at $27720 \mathrm{~cm}^{-1}$. At higher energy, bands are observed at 30050 and $33070 \mathrm{~cm}^{-1}$. The shape of the main peak is different, and there are also weaker bands at 12475 and $12675 \mathrm{~cm}^{-1}$ that are shown more clearly in Figure $16 \mathrm{c}$.

Figure $15 \mathrm{e}$ shows the very different spectrum obtained for $\mathrm{CoBr}_{2}$ isolated in a $\mathrm{N}_{2}$ matrix, with intense peaks at 26470 and $37750 \mathrm{~cm}^{-1}$ and weaker features at $28260,31250,35070$, and $41100 \mathrm{~cm}^{-1}$. An increase in intensity of the lowerenergy transitions at $12235,12290,15910$, and $17610 \mathrm{~cm}^{-1}$ is shown in Figure 16d,f. Very similar transitions at very similar energies were observed for $\mathrm{CoCl}_{2}$ isolated in a $\mathrm{N}_{2}$ matrix by Clifton and Gruen ${ }^{186}$ and also by us (Figures $15 \mathrm{~g}$ and $16 \mathrm{e}, \mathrm{g}$ ). Clifton and Gruen assigned them to $\mathrm{d}^{7}$ spin-flip transitions. ${ }^{86}$ They based their assignments of the absorption spectrum obtained in a $\mathrm{N}_{2}$ matrix and the fluorescence spectrum obtained in an $\mathrm{Ar}$ matrix on a linear $\mathrm{CoCl}_{2}$ unit. ${ }^{186}$ It was stated, however, that matrix site effects and deviation in the linearity of the molecule would affect their interpretation. Although they recorded the $\mathrm{N}_{2}$ spectrum between 4000 and $50000 \mathrm{~cm}^{-1}$, only the absorption bands between 4000 and $25000 \mathrm{~cm}^{-1}$ were shown and tabulated. ${ }^{186}$ Charge transfer bands in the 25000$30000 \mathrm{~cm}^{-1}$ region were reported to be the same as those observed in an Ar matrix. ${ }^{102}$ Our data for $\mathrm{CoCl}_{2}$ in argon and nitrogen matrices are shown in Figure 15f,g, and while there are some similarities, there are very marked differences, analogous to those for $\mathrm{CoBr}_{2}$ in argon and nitrogen matrices. The spectra 
shown in Figure 15 were obtained from very similar deposition rates and times, so the extra intensity in the $d-d$ transitions compared with the charge transfer bands observed in a $\mathrm{N}_{2}$ matrix are a consequence of a relaxation of the selection rules, which is indicative of a significant change in geometry compared with the linear $\mathrm{CoBr}_{2}$ structure in an Ar matrix.

XAFS Spectroscopy. The Co K-edge XANES spectra of $\mathrm{CoBr}_{2}$ isolated in $\mathrm{Ar}, \mathrm{CH}_{4}$, and $\mathrm{N}_{2}$ matrices are shown in Figure 12 . The spectrum of $\mathrm{CoBr}_{2}$ in argon is very similar to that of $\mathrm{NiBr}_{2}$ in methane and displays the sharp, intense feature on the edge characteristic of transitions from the $1 \mathrm{~s}$ orbital to orbitals with significant $\mathrm{p}$ character in linear molecules. This transition was less well-defined in the $\mathrm{CH}_{4}$ matrix data and was observed only as a shoulder in the $\mathrm{N}_{2}$ data. Conversely, a very weak pre-edge feature at $7709.4 \mathrm{eV}$ in the $\mathrm{Ar}$ matrix data became slightly more intense at $7709.6 \mathrm{eV}$ in a $\mathrm{CH}_{4}$ matrix and grew in intensity and shifted to $7708.8 \mathrm{eV}$ in a $\mathrm{N}_{2}$ matrix. These pre-edge features are due to $1 \mathrm{~s} \rightarrow 3 \mathrm{~d}$ transitions, and their intensities generally increase with a reduction in site symmetry; in the case of $\mathrm{CoBr}_{2}$ in a nitrogen matrix, the position and intensity are very similar to those observed for $\left[\mathrm{CoBr}_{2}\left(\mathrm{PPh}_{3}\right)_{2}\right],{ }^{57,111}$ indicating that the linearity of the $\mathrm{CoBr}_{2}$ unit in argon is being lost in a methane matrix and more markedly so in a nitrogen matrix, which correlates very well with both the IR and UV-vis data. This is further evidence that $\mathrm{CoBr}_{2}$ is nonlinear in $\mathrm{CH}_{4}$ and $\mathrm{N}_{2}$ matrices.

XAFS experiments were carried out at the $\mathrm{Co}$ and $\mathrm{Br}$ K-edges for $\mathrm{CoBr}_{2}$ in $\mathrm{Ar}, \mathrm{CH}_{4}$, and $\mathrm{N}_{2}$ matrices. The results are shown in Figure 17, and the refined parameters are given in
Table 9. What is immediately clear from the Co K-edge data is that the feature at approximately twice the $\mathrm{Co}-\mathrm{Br}$ distance in the argon matrix data is absent in both the methane and nitrogen matrix data. From comparison with Figure 4, this indicates that the bond angle in the $\mathrm{CoBr}_{2}$ cannot be any greater than $155^{\circ}$ in either a $\mathrm{CH}_{4}$ or $\mathrm{N}_{2}$ matrix. In the case of the nitrogen matrix data there is also evidence of additional shells in the Co K-edge data, both under the main peak at $2 \AA$ and at ca. $3 \AA$. In addition, there is significantly enhanced intensity at low $k$ in the EXAFS data, indicating the presence of low- $z$ backscatterers around the $\mathrm{Co}$ in addition to the $\mathrm{Br}$.

The Co K-edge and $\mathrm{Br}$ K-edge data for $\mathrm{CoBr}_{2}$ isolated in an Ar matrix in Figure 17 both gave a $\mathrm{Co}-\mathrm{Br}$ distance of 2.26(3) $\AA$, which is in good agreement with the previous vapor-phase electron diffraction value ${ }^{152,188}$ of $2.241(5) \AA$ and the DFTcalculated value of $2.210 \AA$. The multiple-scattering feature observed at twice the $\mathrm{Co}-\mathrm{Br}$ distance in the Co K-edge data confirms linearity, and the $\mathrm{Br} \cdots \mathrm{Br}$ distance of 4.51(5) $\AA$ from the $\mathrm{Br}$ K-edge data gives a bond angle of $172^{\circ}$.

Therefore, all of the experimental data point to a linear geometry for $\mathrm{CoBr}_{2}$ in an argon matrix. Between the $\mathrm{Br}-\mathrm{Co}$ and $\mathrm{Br} \cdots \mathrm{Br}$ features in the $\mathrm{FT}$ of the $\mathrm{Br}$ K-edge data of $\mathrm{CoBr}_{2}$ in Ar there is a $\mathrm{Br} \cdots A$ Ar interaction at 3.80(4) $\AA$, in excellent agreement with the sum of the van der Waals radii for $\mathrm{Br}$ and $\mathrm{Ar}$ and as observed previously for $\mathrm{CH}_{2} \mathrm{Br}_{2}$ in an argon matrix. ${ }^{105}$ Although the refinement surface is fairly shallow for this shell, the best fit was obtained for an occupation number of nine Ar atoms. Therefore, in combination with the Br..Ar distance, this

\section{Co K-edge}

Br K-edge
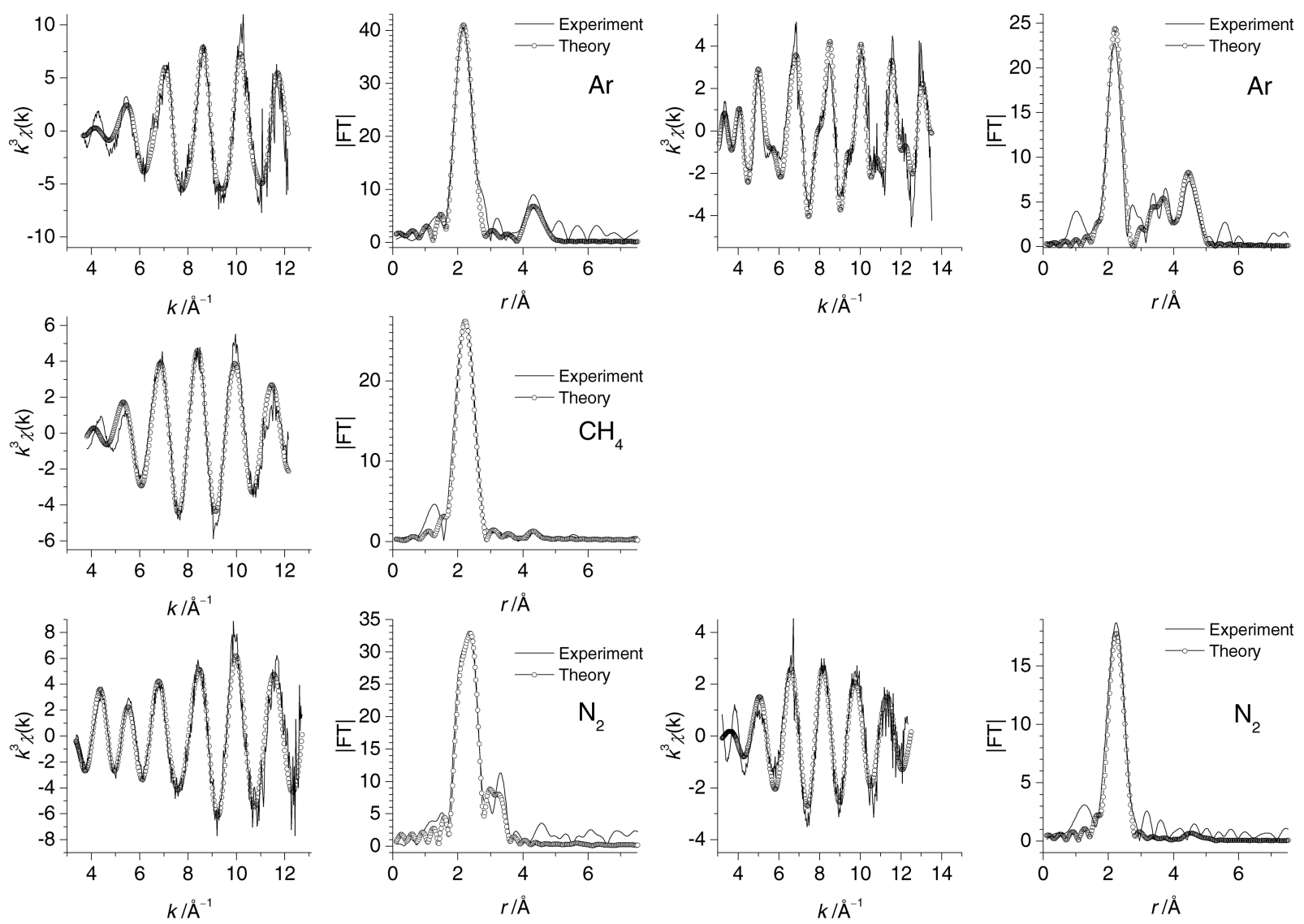

Figure 17. (left) Co K-edge EXAFS and FTs and (right) Br K-edge EXAFS and FTs for $\mathrm{CoBr}_{2}$ isolated in (top) $\mathrm{Ar}$, (middle) $\mathrm{CH}_{4}$, and (bottom) $\mathrm{N}_{2}$ matrices. 
indicates that the $\mathrm{Br}$ atoms of $\mathrm{CoBr}_{2}$ are located within a substitutional site in the argon lattice. There was no evidence for a Co $\cdots$ Ar shell in the Co K-edge EXAFS data, although we have observed $\mathrm{Hg} \cdots$ Ar distances of 3.86 and $3.90 \AA$ for $\mathrm{Hg}$ atoms and $\mathrm{HgF}_{2}$ in argon matrices, respectively. ${ }^{194}$ The Co K-edge XAFS spectrum and FT for $\mathrm{CoBr}_{2}$ isolated in a $\mathrm{CH}_{4}$ matrix are also shown in Figure 17. While $\mathrm{Br}$ K-edge experiments were also performed for this system, unfortunately the data suffered from a large step in the absorption cross section that made fitting of the data impossible, and there was insufficient beam time available to repeat the experiment. The highquality data from the Co K-edge show an increase of $0.05 \AA$ in the $\mathrm{Co}-\mathrm{Br}$ distance from 2.26(3) $\AA$ in an argon matrix to 2.31(3) $\AA$ in a $\mathrm{CH}_{4}$ matrix. The Debye-Waller $2 \sigma^{2}$ term for the $\mathrm{Co}-\mathrm{Br}$ shell is larger than that observed for the other systems, and this reflects the fact that two distinct trapping sites were observed in the IR spectra for $\mathrm{CoBr}_{2}$ in methane, presumably giving rise to two slightly different $\mathrm{Co}-\mathrm{Br}$ distances. The IR spectra of $\mathrm{CoBr}_{2}$ in solid methane recorded simultaneously with the $\mathrm{EXAFS}^{74}$ indicated that there were equal proportions of the two sites in this case. There is no evidence of a multiplescattering feature at approximately twice the $\mathrm{Co}-\mathrm{Br}$ bond distance, and when the bond angle is refined, the maximum value that it would adopt was $158^{\circ}$. This is correlated with a relatively large shift of ca. $25 \mathrm{~cm}^{-1}$ in the $\nu_{3}$ stretching frequencies between the $\mathrm{Ar}$ and $\mathrm{CH}_{4}$ matrices.

Data were obtained at both the Co and $\mathrm{Br}$ K-edges for $\mathrm{CoBr}_{2}$ isolated in $\mathrm{N}_{2}$. The EXAFS spectra and corresponding Fourier transforms are shown in Figure 17, and the refined parameters are collected in Table 9. The Co K-edge data gave a $\mathrm{Co}-\mathrm{Br}$ distance of 2.29(3) $\AA$, while that from the Br K-edge data was 2.31(3) A. The Co-Br bond length is similar in the $\mathrm{CH}_{4}$ and $\mathrm{N}_{2}$ matrices. This degree of bond lengthening is less than that observed for $\mathrm{NiBr}_{2}(0.09 \AA)$ isolated in $\mathrm{N}_{2}$ compared with $\mathrm{NiBr}_{2}$ isolated in $\mathrm{CH}_{4}$, where a change in bond angle from $180^{\circ}$ to $145^{\circ}$ was observed. Taken together with a smaller shift in $\nu_{3}$, this indicates that a smaller perturbation is at work in the $\mathrm{CoBr}_{2} / \mathrm{CH}_{4}$ and $\mathrm{CoBr}_{2} / \mathrm{N}_{2}$ systems than in $\mathrm{NiBr}_{2} / \mathrm{N}_{2}$. While at first glance there does not appear to be a distinguishable feature due to a $\mathrm{Br} \cdots \mathrm{Br}$ interaction in the $\mathrm{Br} \mathrm{K}$-edge $\mathrm{FT}$, it will be recalled from Figure 4 that this in fact is indicative of a bond angle of ca. $160^{\circ}$, and when the model was refined using full multiple scattering, a $\mathrm{Br} \cdots \mathrm{Br}$ distance of $4.55(5) \AA$ was obtained, which gives a bond angle of ca. $160^{\circ}$. The lack of a multiple-scattering feature in the FT of the Co K-edge EXAFS data also indicates that the bond angle must be less than $160^{\circ}$. There were no other shells that could be fit to the Br K-edge data, indicating that there must be a spread of $\mathrm{Br} \cdots \mathrm{N}$ interactions. However, in the Co K-edge data it is clear that there is a low- $z$ backscattering contribution, and this manifests itself in the EXAFS as both enhanced intensity at low $k$ and a shoulder on the main peak and a second peak in the FT. As in the case of $\mathrm{NiBr}_{2}$ in a nitrogen matrix, it was not possible to fit the $3 \AA$ shell without including a shorter $\mathrm{Co}-\mathrm{N}$ interaction, and the only sensible fit was to two dinitrogen ligands attached endon to the Co. These have $\mathrm{Co}-\mathrm{N}$ and $\mathrm{Co} \cdots \mathrm{N}$ distances of 2.13(3) and 3.22(4) $\AA$, respectively, giving a $\mathrm{N} \equiv \mathrm{N}$ distance of $1.09 \AA$ assuming linearity. The corresponding values for $\mathrm{NiBr}_{2}$ were 2.12(3) and 3.19(4) $\AA$ with a $\mathrm{N} \equiv \mathrm{N}$ distance of $1.07 \AA$.

There has been a recent surge in the number of crystallographically characterized cobalt dinitrogen complexes. For example, $S=1 / 2$ complexes with terminal $\mathrm{N}_{2}$ ligands typically have Co-N distances of 1.8-1.9 $\AA^{195,196}$ Upon reduction, the
Co-N distance decreases from 1.865 to $1.792 \AA,{ }^{196}$ whereas upon oxidation it increases from 1.814 to $1.886 \AA^{196}$ These $\mathrm{Co}-\mathrm{N}$ values are all substantially shorter than those observed in our data, indicating the weakness of the bonding of $\mathrm{N}_{2}$ to $\mathrm{CoBr}_{2}$.

Conclusions. When the results produced by all three spectroscopic techniques are collated, a more complex variation in the level of interaction between the matrix hosts and $\mathrm{CoBr}_{2}$ is observed compared with that for $\mathrm{NiBr}_{2}$ and certainly $\mathrm{ZnBr}_{2}$. The IR spectra showed a shift in frequency of $\nu_{3}$ for each matrix gas in the series that was far greater than those observed for $\mathrm{ZnBr}_{2}$ and $\mathrm{NiBr}_{2}$, where a linear geometry was preserved in all cases with the exception of $\mathrm{NiBr}_{2}$ in a $\mathrm{N}_{2}$ matrix. IR isotopic bond angle determinations revealed a linear structure for $\mathrm{CoBr}_{2}$ isolated in $\mathrm{Ne}$ and a $164^{\circ}$ bond angle for $\mathrm{CoBr}_{2}$ isolated in $\mathrm{Xe}$, but the inaccuracy of bond angle determinations close to linearity should be remembered. The electronic absorption data indicate that $\mathrm{Ar}$ and $\mathrm{Kr}$ are similar, but that there are more significant changes in going to $\mathrm{Xe}, \mathrm{CH}_{4}$, and especially $\mathrm{N}_{2}$. Co K-edge XANES data have shown a gradual change in electronic structure and hence geometric structure in going from Ar to $\mathrm{CH}_{4}$ to $\mathrm{N}_{2}$. A combination of Co and $\mathrm{Br}$ K-edge EXAFS has shown that $\mathrm{CoBr}_{2}$ is linear in $\mathrm{Ar}$ and has a bond angle of about $160^{\circ}$ in both $\mathrm{CH}_{4}$ and $\mathrm{N}_{2}$ matrices. As the $\nu_{3}$ stretching frequency for $\mathrm{CoBr}_{2}$ isolated in $\mathrm{CH}_{4}$ is blue-shifted by only $2 \mathrm{~cm}^{-1}$ from that in Xe, a similar bond angle could be assumed. UV-vis-NIR experiments, although difficult to interpret, produced radically different spectra for $\mathrm{CoBr}_{2}$ isolated in $\mathrm{Ar}$ compared with $\mathrm{CoBr}_{2}$ isolated in $\mathrm{N}_{2}$. The spectrum obtained for a $\mathrm{CH}_{4}$ matrix was more similar to that obtained for $\mathrm{Ar}$, which suggested that a less significant deviation from linearity was probable for this system. Co K-edge XANES confirmed these observations. Combined FTIR/XAFS experiments further complemented these results. An average $\mathrm{Co}-\mathrm{Br}$ bond distance of 2.26(1) $\AA$ for $\mathrm{CoBr}_{2}$ isolated in an Ar matrix is in good agreement with the bond length of 2.24(1) $\AA$ obtained by vaporphase electron diffraction. ${ }^{152,188}$ The presence of a multiplescattering feature at twice the $\mathrm{Co}-\mathrm{Br}$ bond length in the $\mathrm{Co}$ K-edge spectrum and a $\mathrm{Br} \cdots \mathrm{Br}$ distance of 4.51(2) $\AA$ obtained from the $\mathrm{Br}$ K-edge spectrum confirmed a linear structure. A lengthening of the $\mathrm{Co}-\mathrm{Br}$ bond distance to 2.31(1) $\AA$ for $\mathrm{CoBr}_{2}$ isolated in a $\mathrm{CH}_{4}$ matrix with no multiple-scattering feature being evident was indicative of a nonlinear structure. Without $\mathrm{Br}$ K-edge data it was difficult to ascertain an accurate bond angle, but from theoretical calculations the absence of multiple scattering had clearly shown that a bond angle of around $155-160^{\circ}$ is reasonable. Co K-edge and $\mathrm{Br} \mathrm{K}$-edge data for $\mathrm{CoBr}_{2}$ isolated in $\mathrm{N}_{2}$, although complicated by matrix interactions, gave bond distance and bond angle information similar to that provided by $\mathrm{CoBr}_{2}$ isolated in $\mathrm{CH}_{4}$. As the $\nu_{3}$ stretching frequency for the $\mathrm{N}_{2}$ system occurred nearly $30 \mathrm{~cm}^{-1}$ below that seen for the $\mathrm{CH}_{4}$ system and a very different UV-vis-NIR spectrum was obtained, a more significant interaction with the $\mathrm{N}_{2}$ matrix and greater perturbation from a linear structure are probable.

Iron Dibromide. In common with $\mathrm{CoBr}_{2}, \mathrm{FeBr}_{2}$ has received little attention in the matrix isolation literature, with nearly all of the iron dihalide studies being concentrated on $\mathrm{FeCl}_{2} . \mathrm{FeBr}_{2}$ has a slight advantage over $\mathrm{CoBr}_{2}$ in determining bond angle information, as the spectral features from the ${ }^{54} \mathrm{Fe}$ isotope, with a natural abundance of $5.8 \%$, in addition to those from the dominant ${ }^{56} \mathrm{Fe}$ isotope can be observed after prolonged deposition. Matrix-isolated $\mathrm{FeCl}_{2}$ has been studied 
as part of several systematic investigations of the $3 \mathrm{~d}$ transition metal dichlorides using IR, ${ }^{17,99,103,142,151,197}$ UV-vis, ${ }^{102,103}$ Raman, ${ }^{198}$ and nuclear $\gamma$ ray (Mössbauer) spectroscopies. ${ }^{199,200,201}$ The $\mathrm{Fe}-\mathrm{Cl}$ bond length in $\mathrm{CH}_{4}$ and $\mathrm{N}_{2}$ matrices was obtained by XAFS spectroscopy, ${ }^{67}$ with the bond length of 2.16(3) $\AA$ in a $\mathrm{CH}_{4}$ matrix being in good agreement with the value of $2.151 \AA$ determined by vapor-phase electron diffraction. ${ }^{152} \mathrm{An}$ increase in the bond length of $0.05 \AA$ was seen in a $\mathrm{N}_{2}$ matrix. There are also reports of ${ }^{57} \mathrm{Fe}$ Mössbauer investigations of $\mathrm{FeBr}_{2}$ matrix-isolated in argon and xenon, ${ }^{200,201}$ together with calculations. ${ }^{199} \mathrm{FeBr}_{2}$ was also studied by vaporphase electron diffraction, which gave an $\mathrm{Fe}-\mathrm{Br} r_{\mathrm{g}}$ value of 2.294(7) $\AA^{152}$ Although experimental data are limited for $\mathrm{FeBr}_{3}$ in matrices, the DFT-calculated value for the IR-active $\mathrm{E}^{\prime}$ mode has been reported as $363.1 \mathrm{~cm}^{-1}$. ${ }^{202}$ For the analogous $\mathrm{FeCl}_{3}$ case, the DFT-calculated value 202 of $473.0 \mathrm{~cm}^{-1}$ was ca. $13 \mathrm{~cm}^{-1}$ higher than the $\mathrm{Kr}$ matrix value 198,203 of $460.2 \mathrm{~cm}^{-1}$ and ca. $8 \mathrm{~cm}^{-1}$ higher than the argon matrix value $\mathrm{c}^{197}$ of $464.8 \mathrm{~cm}^{-1}$. The calculated value for the IR-active terminal $\nu_{\mathrm{Fe}-\mathrm{Br}}$ mode in $\mathrm{Fe}_{2} \mathrm{Br}_{6}$ was found to be $354.4 \mathrm{~cm}^{-1}$. 202

Infrared Spectroscopy. The IR spectra for $\mathrm{FeBr}_{2}$ isolated in a variety of matrices are shown in Figure 18, and the observed

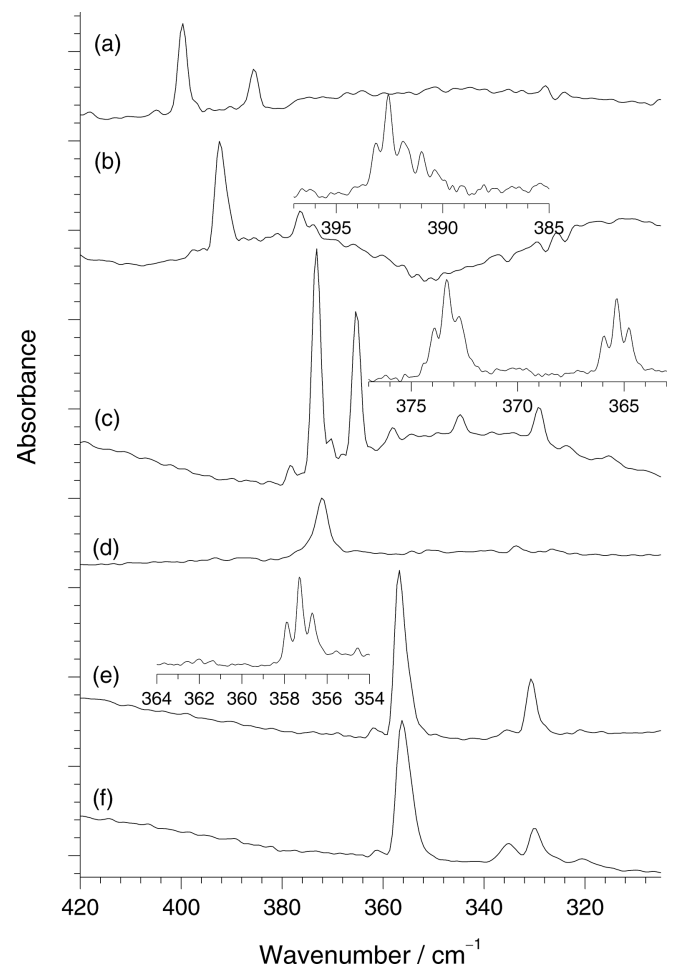

Figure 18. IR spectra of $\mathrm{FeBr}_{2}$ isolated in (a) $\mathrm{Ar}$, (b) $\mathrm{Kr}$, (c) $\mathrm{Xe}$, (d) $\mathrm{CH}_{4}$, (e) ${ }^{14} \mathrm{~N}_{2}$, and (f) ${ }^{15} \mathrm{~N}_{2}$ matrices. The insets show spectra at $0.25 \mathrm{~cm}^{-1}$ resolution.

wavenumbers of the $\nu_{3}$ asymmetric $\mathrm{FeBr}_{2}$ stretching vibration for all of the matrices employed are shown in Table 11. As for $\mathrm{CoBr}_{2}$, a wide range of frequencies was observed, above what would be expected from simple matrix shifts, and these are also more similar to those of $\mathrm{CoBr}_{2}$ than those of $\mathrm{NiBr}_{2}$. The shift in $\nu_{3}$ in going from an Ar matrix to a $\mathrm{N}_{2}$ matrix in this case is $39 \mathrm{~cm}^{-1}$, compared with $51 \mathrm{~cm}^{-1}$ for $\mathrm{CoBr}_{2}$ and $87 \mathrm{~cm}^{-1}$ for $\mathrm{NiBr}_{2}$. The shift of $0.4 \mathrm{~cm}^{-1}$ in $\nu_{3}$ in going from an ${ }^{14} \mathrm{~N}_{2}$ matrix to an ${ }^{15} \mathrm{~N}_{2}$ matrix is similar to that observed for $\mathrm{NiBr}_{2}$ and $\mathrm{CoBr}_{2}$ but larger than that for $\mathrm{ZnBr}_{2}$. The question therefore arises again, for which matrices does the $\mathrm{Br}-\mathrm{Fe}-\mathrm{Br}$ unit suffer significant perturbation from linearity? It has been generally agreed $^{17,99,103,142,151,197}$ that $\mathrm{FeCl}_{2}$ isolated in an Ar matrix is linear, while isolation in ${ }^{14} \mathrm{~N}_{2}$ has previously yielded a bond angle of $150^{\circ} .17$

$\mathrm{FeBr}_{2}$ exhibited extra absorption bands due to matrix effects for all of the matrices except $\mathrm{CH}_{4}$, as shown in Figure 18. The degree of splitting and the intensity of these extra bands varied for each matrix, but as $\mathrm{Br}$ isotopic structure was resolved for $\mathrm{Kr}, \mathrm{Xe}$, and $\mathrm{N}_{2}$ matrices, this indicates that excellent isolation was achieved. In the krypton matrix experiments, the deposition was carried out at $25 \mathrm{~K}$, and upon cooling to $9 \mathrm{~K}$ (Figure 18b), the most intense peak shifted slightly from 391.7 to $392.3 \mathrm{~cm}^{-1}$ with no marked change in intensity, and this was also reflected in the weaker peak at $376.3 \mathrm{~cm}^{-1}$. The inset clearly shows the presence of bromine isotopic structure, and the values are given in Table 11. The xenon matrix experiments were carried out using a deposition temperature of $50 \mathrm{~K}$, and when the sample was cooled to $9 \mathrm{~K}$ (Figure 18c), the band at $365.3 \mathrm{~cm}^{-1}$ grew in intensity slightly, while that at $373.2 \mathrm{~cm}^{-1}$ displayed a much more marked increase in intensity and shifted from to 374.4 to $373.2 \mathrm{~cm}^{-1}$. At higher resolution (see the inset), both of these peaks displayed $\mathrm{Br}$ isotopic structure consistent with the presence of two bromines. In contrast to $\mathrm{CoBr}_{2}$ (Figure 14), only one feature was observed in the $\mathrm{Fe}-\mathrm{Br}$ stretching region for $\mathrm{FeBr}_{2}$ in methane matrices.

In ${ }^{14} \mathrm{~N}_{2}$ matrices (Figure 18e), two peaks were observed at 356.7 and $330.7 \mathrm{~cm}^{-1}$, and upon annealing to $20 \mathrm{~K}$ a feature at $336 \mathrm{~cm}^{-1}$ grew in. In the ${ }^{15} \mathrm{~N}_{2}$ experiments (Figure $18 \mathrm{f}$ ), the deposition was carried out at $15 \mathrm{~K}$, and in this case the additional peak at $336 \mathrm{~cm}^{-1}$ was observed upon deposition before annealing. The $\mathrm{Br}$ isotopic structure on the band at $356.7 \mathrm{~cm}^{-1}$ (shown in the inset) is clearly indicative of a dibromide, and while $\mathrm{Br}$ isotopic structure on the $330.7 \mathrm{~cm}^{-1}$ band was not so well resolved, it is also consistent with the presence of two bromines. ${ }^{57} \mathrm{Fe}$ Mössbauer experiments on $\mathrm{FeCl}_{2}$ indicated two sites in Xe matrices, one of which could be removed by annealing to $42 \mathrm{~K} .{ }^{199}$ Therefore, it is reasonable to assign the second peaks in these data to matrix or site effects.

In addition to confirming the presence of two bromine atoms, the $\mathrm{Br}$ isotopic structure observed for $\mathrm{Kr}, \mathrm{Xe}$, and ${ }^{14} \mathrm{~N}_{2}$ matrices (shown in the insets in Figure 18) can be used for bond angle determination (Table 11). This indicated linear $\mathrm{FeBr}_{2}$ in the case of $\mathrm{Kr}$ and $\mathrm{Xe}$ matrices and a $150^{\circ}$ bond angle for an ${ }^{14} \mathrm{~N}_{2}$ matrix using the higher-quality ${ }^{56} \mathrm{Fe}$ data. An $\mathrm{FeBr}_{2}$ bond angle of $150^{\circ}$ is essentially identical to that previously obtained for $\mathrm{FeCl}_{2}$ in $\mathrm{N}_{2} \cdot{ }^{17}$ The position of the $\nu_{3}$ stretching vibration for $\mathrm{FeBr}_{2}$ isolated in $\mathrm{Xe}$ midway between the $\mathrm{Ar}$ and $\mathrm{N}_{2}$ values might have been expected to indicate some deviation from linearity. However, the insensitivity of bond angle determination using IR data must be highlighted, as the difference between the calculated values of $180^{\circ}$ and $160^{\circ}$ for $\mathrm{FeBr}_{2}$ is only $0.06 \mathrm{~cm}^{-1}$ (Table 11 ). These very small shifts in frequency are clearly within the experimental error, leading to great uncertainty in the true bond angle for each of these systems using this technique alone. While there appears to be isotopic structure associated with ${ }^{54} \mathrm{FeBr}_{2}$ and ${ }^{56} \mathrm{FeBr}_{2}$ in the lower-resolution $\mathrm{Ar}, \mathrm{Xe}$, and $\mathrm{N}_{2}$ matrix spectra, using it is problematic given the large effect on bond angle calculations produced by small errors in the measurement of the positions of weak bands. For example, the separation is too large for linear molecules in the case of $\mathrm{Xe}$ and $\mathrm{N}_{2}$ but indicates a bond angle of ca. $135^{\circ}$ for the argon matrix data. Therefore, other 
Table 11. IR Data for $\mathrm{FeBr}_{2}$ Isolated in Different Matrices ${ }^{a}$

\begin{tabular}{|c|c|c|c|c|}
\hline matrix & $\begin{array}{l}\text { wavenumber } / \mathrm{cm}^{-1} \text { and assignment at } \\
\text { medium resolution }\left(2 \mathrm{~cm}^{-1}\right)\end{array}$ & $\begin{array}{l}\text { calculated wavenumber } / \mathrm{cm}^{-1} \\
\text { for } 180^{\circ} \text { bond angle }\end{array}$ & $\begin{array}{l}\text { wavenumber } / \mathrm{cm}^{-1} \text { and assignment at } \\
\text { high resolution }\left(0.25 \mathrm{~cm}^{-1}\right)\end{array}$ & $\begin{array}{l}\text { calculated wavenumber } / \mathrm{cm}^{-1} \\
\text { for } 180^{\circ} \text { bond angle }\end{array}$ \\
\hline \multirow[t]{2}{*}{$\mathrm{Ne}$} & $414.4-{ }^{56} \mathrm{FeBr}_{2}$ & & & \\
\hline & $404.9-{ }^{54} \mathrm{FeBr}_{2}$ & 405.1 & & \\
\hline \multirow[t]{2}{*}{ Ar } & $399.7-{ }^{56} \mathrm{FeBr}_{2}$ & $399.7^{a}$ & & \\
\hline & 385.5 - 2nd site & & & \\
\hline \multirow[t]{2}{*}{$\mathrm{Kr}$} & $\begin{array}{l}392.3-{ }^{56} \mathrm{FeBr}_{2} \\
376.3-2 \text { 2nd site }\end{array}$ & & $\begin{array}{l}393.14-{ }^{56} \mathrm{Fe}^{79} \mathrm{Br}_{2} \\
392.54-{ }^{56} \mathrm{Fe}^{79} \mathrm{Br}^{81} \mathrm{Br}\end{array}$ & $393.14^{a}$ \\
\hline & & & $\begin{array}{l}391.87-{ }^{56} \mathrm{Fe}^{81} \mathrm{Br}_{2} \\
390.99-{ }^{56} \mathrm{Fe}^{79} \mathrm{Br}^{81} \mathrm{Br} \\
390.39-{ }^{56} \mathrm{Fe}^{81} \mathrm{Br}_{2}\end{array}$ & 391.87 \\
\hline $\mathrm{CH}_{4}$ & $372.0-{ }^{56} \mathrm{Fe}$ & & & \\
\hline \multirow[t]{5}{*}{$\mathrm{Xe}$} & $\begin{array}{l}378.3-{ }^{54} \mathrm{FeBr}_{2} \\
373.2-{ }^{56} \mathrm{FeBr}_{2}\end{array}$ & $\begin{array}{l}378.3 \\
373.2^{a}\end{array}$ & $\begin{array}{l}373.90-{ }^{56} \mathrm{Fe}^{79} \mathrm{Br}_{2} \\
373.33-{ }^{56} \mathrm{Fe}^{79} \mathrm{Br}^{81} \mathrm{Br}\end{array}$ & $373.90^{a}$ \\
\hline & $370.4-{ }^{54} \mathrm{Fe} 2$ nd site & 370.3 & $372.76-{ }^{56} \mathrm{Fe}^{81} \mathrm{Br}_{2}$ & 372.69 \\
\hline & $365.3-{ }^{56} \mathrm{Fe} 2$ nd site & $365.3^{a}$ & $\begin{array}{l}365.95-{ }^{56} \mathrm{Fe}^{79} \mathrm{Br}_{2} 2^{\text {nd }} \text { site } \\
365.34-{ }^{56} \mathrm{Fe}^{79} \mathrm{Br}^{81} \mathrm{Br}^{\text {nd }} \text { site } \\
364.77-{ }^{56} \mathrm{Fe}^{81} \mathrm{Br}_{2} 2^{\text {nd }} \text { site }\end{array}$ & \\
\hline & & & & $365.95^{a}$ \\
\hline & & & & 364.77 \\
\hline \multirow[t]{5}{*}{${ }^{14} \mathrm{~N}_{2}$} & $361.8-{ }^{54} \mathrm{FeBr}_{2}$ & 361.6 & $362.56-{ }^{54} \mathrm{Fe}^{79} \mathrm{Br}_{2}$ & 362.74 \\
\hline & $356.7-{ }^{56} \mathrm{FeBr}_{2}$ & 356.7 & $362.03-{ }^{54} \mathrm{Fe}^{79} \mathrm{Br}^{81} \mathrm{Br}$ & \\
\hline & 330.7 - 2nd site & & $361.42-{ }^{54} \mathrm{Fe}^{81} \mathrm{Br}_{2}$ & 361.60 \\
\hline & & & $\begin{array}{l}357.89-{ }^{56} \mathrm{Fe}^{79} \mathrm{Br}_{2} \\
357.28-{ }^{56} \mathrm{Fe}^{99} \mathrm{Br}^{81} \mathrm{Br}\end{array}$ & $357.89^{a}$ \\
\hline & & & $356.69-{ }^{56} \mathrm{Fe}^{81} \mathrm{Br}_{2}$ & 356.73 \\
\hline \multirow[t]{3}{*}{${ }^{15} \mathrm{~N}_{2}$} & $361.3-{ }^{54} \mathrm{FeBr}_{2}$ & 361.1 & & \\
\hline & $356.2-{ }^{56} \mathrm{FeBr}_{2}$ & $356.2^{a}$ & & \\
\hline & 330.0 - 2nd site & & & \\
\hline
\end{tabular}

techniques are required to identify the geometry of $\mathrm{FeBr}_{2}$ in matrices.

In nitrogen matrices, bands were observed (Figure 6 and Table 4) in the $\nu_{\mathrm{NN}}$ region at $2332.3 \mathrm{~cm}^{-1}\left({ }^{14} \mathrm{~N}_{2}\right)$ and $2254.9 \mathrm{~cm}^{-1}$ $\left({ }^{15} \mathrm{~N}_{2}\right)$ in addition to the impurity-induced modes $\left({ }^{14} \mathrm{~N}_{2}\right.$, $\left.2327.8 \mathrm{~cm}^{-1} ;{ }^{15} \mathrm{~N}_{2}, 2250.0 \mathrm{~cm}^{-1}\right)$. These are closer to the "free" $\mathrm{N}_{2}$ value than for either $\mathrm{NiBr}_{2}$ or $\mathrm{CoBr}_{2}$ and therefore indicate a lower level of interaction between $\mathrm{FeBr}_{2}$ and the $\mathrm{N}_{2}$ host, consistent with the smaller shift of $\nu_{3}$ between $\mathrm{Ar}$ and $\mathrm{N}_{2}$ matrices as well as between ${ }^{14} \mathrm{~N}_{2}$ and ${ }^{15} \mathrm{~N}_{2}$ matrices. Photolysis of $\mathrm{FeBr}_{2}$ in ${ }^{14} \mathrm{~N}_{2}$ and ${ }^{15} \mathrm{~N}_{2}$ matrices yielded no new bands assignable to $\nu_{\mathrm{NN}}$ stretches and no change in the bands close to the impurity-induced modes. The DFT calculations indicated that the reaction enthalpies for the formation of end-on-bonded $\mathrm{FeBr}_{2}\left(\eta^{1}-\mathrm{N}_{2}\right)$ and $\mathrm{FeBr}_{2}\left(\eta^{1}-\mathrm{N}_{2}\right)_{2}$ are -38 and $-72 \mathrm{~kJ} \mathrm{~mol}{ }^{-1}$, respectively, and that the reaction enthalpy for one side-onbonded $\mathrm{N}_{2}$ is $-5 \mathrm{~kJ} \mathrm{~mol}^{-1}$.

Electronic Absorption Spectroscopy. The electronic absorption spectrum of $\mathrm{FeCl}_{2}$ isolated in an Ar matrix was previously studied by DeKock and Gruen ${ }^{102}$ and Jacox and Milligan. ${ }^{103} \mathrm{~A}$ ${ }^{5} \Delta_{\mathrm{g}}$ ground state was proposed, ${ }^{102}$ predicting five charge transfer transitions, all of which were observed. The assignment of the ground state was more recently confirmed by Bridgeman, ${ }^{193}$ although the assignments of the transitions was contested. As in the cases of $\mathrm{NiCl}_{2}$ and $\mathrm{CoCl}_{2}$ the ordering of the $\sigma_{\mathrm{g}}$ and $\pi_{\mathrm{g}}$ orbitals was found to be the reverse of what is predicted by simple ligand field theory arguments. Bridgeman agreed with the assignment of the ground state proposed by previous workers, but only because the ${ }^{5} \Delta_{\mathrm{g}}$ ground state is independent of the order of $\sigma_{\mathrm{g}}$ and $\pi_{\mathrm{g}}$, giving the configuration $\delta_{\mathrm{g}}{ }^{3} \sigma_{\mathrm{g}}{ }^{1} \pi_{\mathrm{g}}{ }^{2}$. Our DFT calculations on $\mathrm{FeBr}_{2}$ also predict a ${ }^{5} \Delta_{\mathrm{g}}$ ground state with a d-orbital configuration of $\delta_{\mathrm{g}}{ }^{3} \sigma_{\mathrm{g}}{ }^{1} \pi_{\mathrm{g}}{ }^{2}$, but it should be noted that there is a second quintet state, ${ }^{5} \Sigma_{\mathrm{g}}^{-}$with a $\delta_{\mathrm{g}}{ }^{2} \sigma_{\mathrm{g}}{ }^{2} \pi_{\mathrm{g}}{ }^{2}$ configuration, at almost the same energy. There are no low-lying bent states.

The UV-vis-NIR spectra of $\mathrm{FeBr}_{2}$ isolated in $\mathrm{Ar}, \mathrm{CH}_{4}$, and ${ }^{14} \mathrm{~N}_{2}$ matrices are shown in Figure 19, and the observed bands are given in Table 7 . The spectrum of $\mathrm{FeBr}_{2}$ in an argon matrix (Figure 19a) is qualitatively similar to that reported previously for Ar-matrix-isolated $\mathrm{FeCl}_{2}$ in the $32000-38000 \mathrm{~cm}^{-1}$ region, ${ }^{102}$ except that the features are ca. $6000 \mathrm{~cm}^{-1}$ lower. In addition to the most intense peak at $35570 \mathrm{~cm}^{-1}$, additional peaks for $\mathrm{FeBr}_{2}$ in argon were seen at 31260,32 950, 33650 , $37060,39615,41180$, and $43850 \mathrm{~cm}^{-1}$. It is not surprising that some of these higher-energy transitions were not seen for $\mathrm{FeCl}_{2}$ in argon, as they would have probably occurred beyond $50000 \mathrm{~cm}^{-1}$, outside the spectral range of the experiment. When $\mathrm{FeBr}_{2}$ was isolated in a $\mathrm{CH}_{4}$ matrix (Figure $19 \mathrm{~b}$ ), a reduction in the number of bands compared with the Ar matrix was observed. The peaks observed in the Ar matrix centered at 31260,32 950, 33650 , and $37060 \mathrm{~cm}^{-1}$ were essentially lost, leaving peaks at 35550,39780, $41930 \mathrm{~cm}^{-1}$, together with a shoulder at $33870 \mathrm{~cm}^{-1}$ and a weak peak at $44130 \mathrm{~cm}^{-1}$.

Relatively little change in energy was seen for the remaining peaks in the $\mathrm{CH}_{4}$ matrix spectrum compared with the Ar matrix spectrum. Even further simplification of the spectrum was seen when $\mathrm{FeBr}_{2}$ was isolated in a $\mathrm{N}_{2}$ matrix (Figure 19c). While the most intense peak was still observed at $35300 \mathrm{~cm}^{-1}$, only 


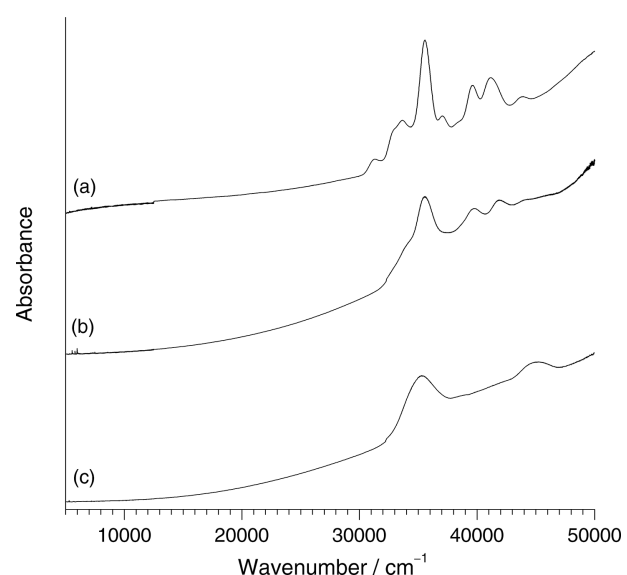

Figure 19. Electronic absorption spectra of $\mathrm{FeBr}_{2}$ isolated in (a) $\mathrm{Ar}$, (b) $\mathrm{CH}_{4}$, and (c) $\mathrm{N}_{2}$ matrices.

one intense band at higher energy remained, at $45190 \mathrm{~cm}^{-1}$, which was blue-shifted in excess of $1000 \mathrm{~cm}^{-1}$ relative to those bands seen in the $\mathrm{Ar}$ and $\mathrm{CH}_{4}$ matrices. This reduction in the number of observed bands upon changing from $\mathrm{Ar}$ to $\mathrm{CH}_{4}$ and $\mathrm{N}_{2}$ matrices was in direct contrast to what was seen for $\mathrm{NiBr}_{2}$ and $\mathrm{CoBr}_{2}$, where the complexity of the spectra increased in going from the Ar matrix to the $\mathrm{N}_{2}$ matrix. All of the observed bands in these spectra are assigned as charge transfer transitions, with no bands occurring at lower energy assignable to $\mathrm{d}-\mathrm{d}$ transitions. The simple observation that the spectra of $\mathrm{FeBr}_{2}$ isolated in $\mathrm{Ar}$ and $\mathrm{N}_{2}$ matrices appear to have little in common is an indication of a significant difference in the electronic and hence geometric structures of $\mathrm{FeBr}_{2}$ in these two matrix environments. Moreover, the spectrum of $\mathrm{FeBr}_{2}$ isolated in a $\mathrm{CH}_{4}$ matrix seems to show an $\mathrm{FeBr}_{2}$ environment intermediate between the extreme cases, which coincides with the evidence provided by the IR studies.

XAFS Spectroscopy. The Fe K-edge XANES of $\mathrm{FeBr}_{2}$ in an argon matrix (Figure 12) is qualitatively similar to that for $\mathrm{CoBr}_{2}$ in argon and $\mathrm{NiBr}_{2}$ in methane and displays an intense edge feature at $7119.3 \mathrm{eV}$ together with a very weak pre-edge feature at $7112.7 \mathrm{eV}$. The feature on the edge is most intense in $\mathrm{FeBr}_{2}$ and decreases as one goes to linear $\mathrm{CoBr}_{2}$ and $\mathrm{NiBr}_{2}$. In a methane matrix, the sharp edge feature at $7119.3 \mathrm{eV}$ has lower relative intensity and the weak pre-edge band at $7112.3 \mathrm{eV}$ has greater intensity, both of which are indicative of a drop in symmetry from linearity. This continued for $\mathrm{FeBr}_{2}$ in a nitrogen matrix, where the edge peak has disappeared into the edge structure and the pre-edge feature at $7112.3 \mathrm{eV}$ is slightly more intense. The behavior of the XANES spectra is consistent with that of the other spectra, indicating a less substantial change in the geometry of $\mathrm{FeBr}_{2}$ in going from the $\mathrm{Ar}$ matrix to the $\mathrm{CH}_{4}$ matrix but a more significant change for $\mathrm{N}_{2}$ matrices.

Fe K-edge XAFS studies were conducted on $\mathrm{FeBr}_{2}$ isolated in $\mathrm{Ar}, \mathrm{CH}_{4}$, and $\mathrm{N}_{2}$ matrices. The results are shown in Table 9 and the spectra in Figure 20. Unfortunately, there was insufficient synchrotron time available to collect the $\mathrm{Br} \mathrm{K}$-edge as well. As for $\mathrm{CoBr}_{2}$, there is a consistent change in the FTs, with the argon data having a multiple-scattering feature at approximately twice the first shell distance, indicating linearity, the methane data containing only the $\mathrm{Fe}-\mathrm{Br}$ shell, indicating a maximum bond angle of ca. $160^{\circ}$, and the $\mathrm{N}_{2}$ data exhibiting a weak feature at ca. $3 \AA$. Although the peak at ca. $4.5 \AA$ in the FT of the $\mathrm{N}_{2}$ data looks like a multiple-scattering feature indicating linearity, it was not possible to fit this using the full multiple-scattering

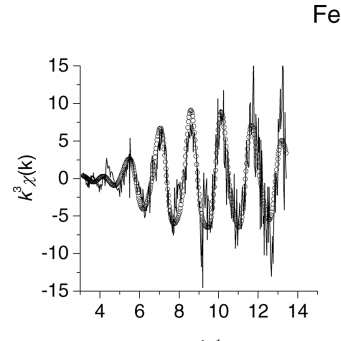

Fe K-edge
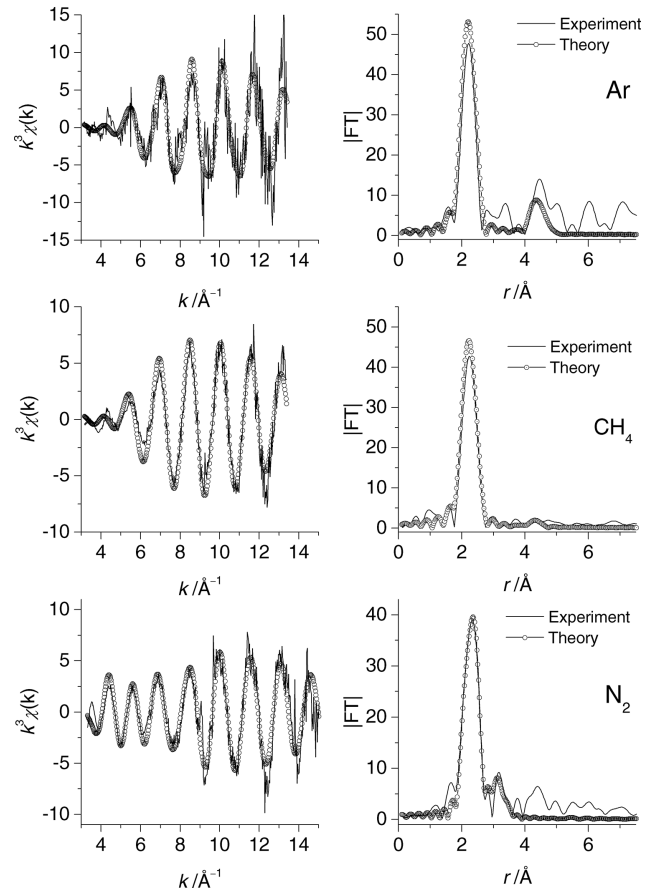

Figure 20. Fe K-edge EXAFS and FTs for $\mathrm{FeBr}_{2}$ in (top) Ar, (middle) $\mathrm{CH}_{4}$, and (bottom) $\mathrm{N}_{2}$ matrices.

approach and is more likely due to some of the high-frequency noise in the spectrum. The argon data are very noisy because of the short X-ray attenuation length $(1 / \mathrm{e})$ of ca. $34 \mu \mathrm{m}$ for $\mathrm{Ar}$ at $7 \mathrm{keV}^{82}$

The $\mathrm{Fe}-\mathrm{Br}$ bond length of 2.27(3) A determined for $\mathrm{FeBr}_{2}$ in solid argon is in good agreement with the electron diffraction $^{152}$ value $\left(r_{\mathrm{g}}\right)$ of 2.294(7) $\AA$. In a methane matrix and a nitrogen matrix, the $\mathrm{Fe}-\mathrm{Br}$ bond length increased by $0.02 \AA$ to 2.29(3) A. Full multiple scattering refinement of the methane data indicated a maximum bond angle of ca. $160^{\circ}$. As was the case for both $\mathrm{NiBr}_{2}$ and $\mathrm{CoBr}_{2}$ in nitrogen matrices, the only sensible model involves a pair of dinitrogen ligands at 2.15(3) $\AA$ with an $\mathrm{Fe} \cdots \mathrm{N}$ distance of 3.19(4) A. This gives a $\mathrm{N} \equiv \mathrm{N}$ distance of $1.04 \AA$, compared with $1.09 \AA$ for the $\mathrm{CoBr}_{2}$ data and $1.07 \AA$ for the $\mathrm{NiBr}_{2}$ case. This might indicate some slight nonlinearity, which would be supported by the slightly larger Debye-Waller $2 \sigma^{2}$ term observed in this case compared with the $\mathrm{CoBr}_{2}$ and $\mathrm{NiBr}_{2}$ examples.

Characteristic $\mathrm{Fe}-\mathrm{N}$ distances for $\mathrm{Fe}(\mathrm{II})$ terminal dinitrogen complexes are $1.833 \AA$, ${ }^{204}$ while those for $\mathrm{Fe}(0)$ are $1.749 \AA$, 205 which upon dimerization increase to $1.85 \AA{ }^{206}$ Calculations carried out on $\mathrm{NeFeBr}_{2}$ at the MP2 level gave an $\mathrm{Fe}-\mathrm{Br}$ distance of $2.290 \AA$, identical to the calculated value for the isolated $\mathrm{FeBr}_{2}$ molecule, as well as an $\mathrm{Fe}-\mathrm{Ne}$ distance of 3.478 $\AA$ and a $\mathrm{Ne}-\mathrm{Fe}-\mathrm{Br}$ bond angle of $90.28^{\circ}$, indicating that the $\mathrm{FeBr}_{2}$ remained essentially linear. ${ }^{131}$

Conclusions. The IR data collected for $\mathrm{FeBr}_{2}$ showed a decrease in the $\nu_{3}$ stretching frequency in going from $\mathrm{Ne}$ to $\mathrm{Xe}$ matrices, but this covered a far greater range than that seen for $\mathrm{ZnBr}_{2}$ and $\mathrm{NiBr}_{2}$ for $\mathrm{Ne}$ to Xe matrices, where a linear geometry was preserved. This was also seen for $\mathrm{CoBr}_{2}$, where there was good evidence that $\mathrm{CoBr}_{2}$ is bent in $\mathrm{CH}_{4}, \mathrm{Xe}$, and $\mathrm{N}_{2}$ matrices. Bond angle information from the IR data suggested that $\mathrm{FeBr}_{2}$ is linear in all of the matrices except $\mathrm{N}_{2}$, where a bond angle of $150^{\circ}$ was obtained. While this angle was 
consistent with that obtained for $\mathrm{FeCl}_{2}$ in $\mathrm{N}_{2},{ }^{17}$ some deviation from linearity might have been expected in a $\mathrm{Xe}$ matrix. The UV-vis-NIR data showed a progression in the number of observed transitions and their frequency in going from Ar to $\mathrm{CH}_{4}$ to $\mathrm{N}_{2}$. This provides good evidence of a steady change in the nature of the $\mathrm{Br}-\mathrm{Fe}-\mathrm{Br}$ unit from linear to increasingly bent when isolated in these matrices, with $\mathrm{FeBr}_{2}$ isolated in $\mathrm{Ar}$ being in reasonable agreement with the comparable spectrum observed for $\mathrm{FeCl}_{2} \cdot{ }^{102}$ The $\mathrm{Fe} \mathrm{K}$-edge XANES data indicate a small change between the $\mathrm{Ar}$ matrix and the $\mathrm{CH}_{4}$ matrix, with a more substantial change for $\mathrm{N}_{2}$. The EXAFS data were consistent with linear $\mathrm{FeBr}_{2}$ in solid argon, but the absence of a feature in the Fourier transform at twice the $\mathrm{Fe}-\mathrm{Br}$ distance combined with a lengthening of the $\mathrm{Fe}-\mathrm{Br}$ bond in solid methane is consistent with a reduction in bond angle. Therefore, it is concluded that the bond angles for $\mathrm{FeBr}_{2}$ isolated in $\mathrm{CH}_{4}$ and $\mathrm{Xe}$ matrices are probably between $150^{\circ}$ and $160^{\circ}$. The Fe K-edge EXAFS data of $\mathrm{FeBr}_{2}$ isolated in solid nitrogen is also consistent with a nonlinear geometry (around $150^{\circ}$ ), together with two weakly bound dinitrogen units in the first coordination sphere.

\section{DISCUSSION}

Figure 21 shows all of the observed $\nu_{3}$ frequencies for different matrix gases plotted against the metal dibromides and also

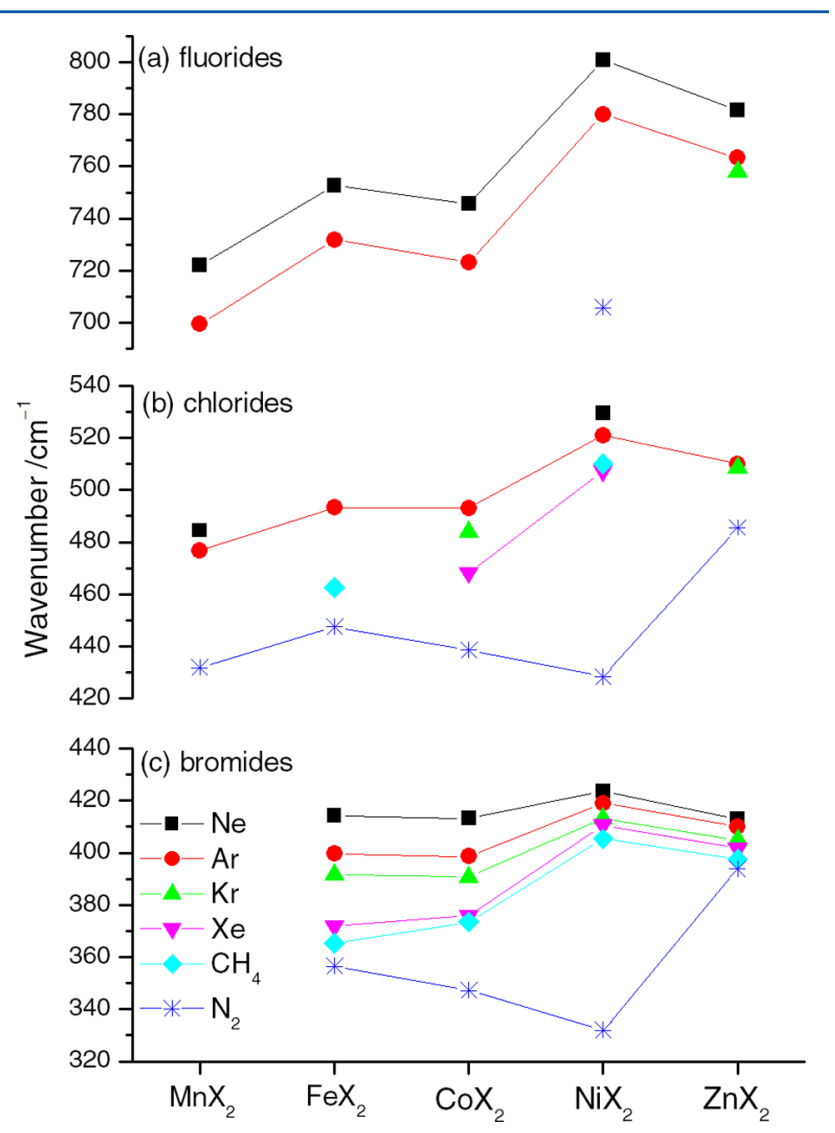

Figure 21. Principal $\nu_{3}$ stretching wavenumbers of the transition metal dihalides in different matrices.

includes all of the related data of which we are aware for the difluorides and dichlorides of $\mathrm{Fe}, \mathrm{Co}, \mathrm{Ni}$, and $\mathrm{Zn}$. (Copper has not been included, as there are only limited matrix data for $\mathrm{CuF}_{2},{ }^{46,207} \mathrm{CuCl}_{2}{ }^{208,209}$ and $\mathrm{CuBr}_{2}{ }^{210}$ ) For the difluorides the only complete sets of data are for Ar and Ne matrices, but the pattern observed is characteristic of a general increase in $Z_{\text {eff }}$ across the row, with a ligand field stabilization energy (LFSE)type effect superimposed on this. For the dichlorides, the only complete sets of data are for argon and nitrogen matrices. As expected, the trends for argon matrices mirror those for the difluorides, but there is a very marked difference in the nitrogen matrix data. The most complete set of data is for the dibromides presented in this work, which in addition to confirming the trend observed for nitrogen matrices highlights some other more subtle effects with $\mathrm{Xe}$ and $\mathrm{CH}_{4}$ matrices. The most dramatic features in Figure 21 are the behavior of the metal halides in nitrogen matrices and the change in the spread of the $\nu_{3}$ modes. For the zinc halides there is very little difference between the values of $\nu_{3}$ in argon and nitrogen matrices. In going from iron to cobalt there is a larger-than-expected drop in the value of $\nu_{3}$ for nitrogen compared with argon, and this is associated with bond angles of ca. $150^{\circ}$ in $\mathrm{FeBr}_{2}$ and $150-160^{\circ}$ in $\mathrm{CoBr}_{2}$. In the case of nickel, the change in going from argon to nitrogen becomes very marked. For $\mathrm{NiF}_{2}$ a drop in $\nu_{3}$ of $9.5 \%$ is observed in going from an argon matrix to a nitrogen matrix. In contrast, reductions of $18 \%$ and $21 \%$ are observed for $\mathrm{NiCl}_{2}$ and $\mathrm{NiBr}_{2}$, respectively, on going from an argon matrix to a nitrogen matrix. These are much larger than usually encountered for "matrix shifts" and are associated with a structural perturbation of the nickel dihalide. For nitrogen matrices the calculated $\mathrm{NiF}_{2}$ bond angle is $152^{\circ}$, which is similar to that in argon matrices, but this decreases much more markedly to ca. $140^{\circ}$ for both $\mathrm{NiCl}_{2}$ and $\mathrm{NiBr}_{2}$, which are essentially linear in argon. This significant structural perturbation is also confirmed by both electronic absorption spectroscopy and X-ray absorption spectroscopy. Therefore, the hardness of the metal center has a profound effect on the propensity for the triatomic molecule to be bent via the interaction with the nitrogen matrix.

While nitrogen may be expected to be a "non-innocent" matrix, the data for the dibromides isolated in noble gas matrices and methane indicate that some more subtle structural perturbation may occur for these molecules in different matrices, although the variation is much less than that observed for the nitrogen matrices. In particular, it is clear from Figure 21c that for $\mathrm{ZnBr}_{2}$ there is very little difference in the value of $\nu_{3}$ among all the matrix gases. A similar position is observed for $\mathrm{NiBr}_{2}$ for all but $\mathrm{N}_{2}$ matrices. In contrast, for both $\mathrm{CoBr}_{2}$ and $\mathrm{FeBr}_{2}$ there is a much greater spread of values observed for $\nu_{3}$, indicating a variation in the extent of interaction of the guest with the host, which is in good agreement with the order proposed by Beattie and Millington ${ }^{15}$ and has also been observed for diatomic molecules. ${ }^{211}$ The electronic absorption spectra for $\mathrm{CoBr}_{2}$ indicate that there is very little difference between argon and krypton matrices but that there are differences between these and xenon and methane matrices, which is mirrored in the value of $\nu_{3}$ for these matrix gases. Likewise, the Co K-edge XANES indicates that there is increasing nonlinearity in going from argon through methane to nitrogen matrices, and both the Co and Br K-edge EXAFS data confirm this. The best estimate is that the bond angle of $\mathrm{CoBr}_{2}$ in a methane matrix cannot be greater than $160^{\circ}$. In view of the similarity of the positions of $\nu_{3}$ and the electronic absorption spectra of $\mathrm{CoBr}_{2}$ in $\mathrm{Xe}$ and $\mathrm{CH}_{4}$, it seems sensible to suggest that $\mathrm{CoBr}_{2}$ is also probably slightly bent in xenon. A similar case exists for $\mathrm{FeBr}_{2}$, but in this case the extent of perturbation is more similar for $\mathrm{CH}_{4}, \mathrm{Xe}$, and $\mathrm{N}_{2}$ matrices. 
There is a subtle interplay of geometric and electronic effects, both intrinsic to the metal dihalide and between the metal dihalide and the matrix host, that are responsible for this complex behavior. For example, the different populations of the metal-based $\sigma_{\mathrm{g}}, \pi_{\mathrm{g}}$ and $\delta_{\mathrm{g}}$ orbitals (Table 1) and the presence of low-lying linear and bent excited states are intrinsic properties of the metal dihalides that affect the way they can interact with the matrix host as well as the relative ease with which the dihalides can bend. The soft-bending modes in $\mathrm{CuCl}_{2}$ have been studied previously. ${ }^{212}$ Hastie et al. ${ }^{139,185}$ estimated the frequencies of $\nu_{2}$ for $\mathrm{CoF}_{2}\left(151 \mathrm{~cm}^{-1}\right), \mathrm{NiF}_{2}\left(142 \mathrm{~cm}^{-1}\right)$, and $\mathrm{ZnF}_{2}\left(157 \mathrm{~cm}^{-1}\right)$ using gas-phase data with an uncertainty of $\pm 30 \mathrm{~cm}^{-1}$. Thompson and Carlson ${ }^{99}$ observed $\nu_{2}$ for $\mathrm{MnCl}_{2}$ $\left(83 \mathrm{~cm}^{-1}\right), \mathrm{FeCl}_{2}\left(88 \mathrm{~cm}^{-1}\right), \mathrm{CoCl}_{2}\left(94.5 \mathrm{~cm}^{-1}\right), \mathrm{NiCl}_{2}\left(85 \mathrm{~cm}^{-1}\right)$, and $\mathrm{NiBr}_{2}\left(69 \mathrm{~cm}^{-1}\right)$. We attempted to determine the values of $\nu_{2}$ for the dibromides using SR-FIR spectroscopy but were unable to identify them in the presence of the various phonon and hindered rotational modes, apart from a possible value of $55 \mathrm{~cm}^{-1}$ for $\mathrm{NiBr}_{2}$ in $\mathrm{CH}_{4}$. The DFT-calculated $\nu_{2}$ bending modes for these molecules are in given in Table 1 and increase from $53 \mathrm{~cm}^{-1}$ for $\mathrm{FeBr}_{2}$ through $63 \mathrm{~cm}^{-1}$ for $\mathrm{CoBr}_{2}$ and $68 \mathrm{~cm}^{-1}$ for $\mathrm{NiBr}_{2}$ to $80 \mathrm{~cm}^{-1}$ for $\mathrm{ZnBr}_{2}$. These data, even with the uncertainty of the difluorides, establish a trend in the frequencies of the $\nu_{2}$ bending modes to be $\mathrm{MF}_{2}>\mathrm{MCl}_{2}>\mathrm{MBr}_{2}$, implying that the dibromides will be easier to bend than the dichlorides and difluorides, and the order of flexibility decreases from $\mathrm{FeX}_{2}$ to $\mathrm{ZnX}_{2}$. It is also reasonable to expect the diiodides to have even lower $\nu_{2}$ bending mode frequencies. The ease of bending is also expected to decrease as the metal-halogen bond length becomes shorter in going from the iron dihalides to the zinc dihalides. This is borne out in the data in Figure 21, where (excluding $\mathrm{N}_{2}$ matrices; see below) the spread of $\nu_{3}$ wavenumbers decreases in going from $\mathrm{FeX}_{2}$ through to $\mathrm{ZnX}_{2}$.

In the previous cases where there was evidence for the metal dihalide being bent in a matrix, the primary interaction between the dihalide and the surrounding host was thought to be electrostatic. ${ }^{17}$ Polarization of the host atom or molecule by the positively charged metal ion leads to an ion-induced-dipole interaction. Therefore, the polarizability of the host is an important consideration. Of those studied in this work, xenon is by far the easiest matrix atom to polarize, followed by methane, which is consistent with the stronger interactions seen with $\mathrm{FeBr}_{2}$ and $\mathrm{CoBr}_{2}$. Neon and argon are the hardest atoms to polarize, and this too was evident, as linear geometries were observed in all cases for the metal dibromides in these matrices. In addition to electrostatic interactions, the physical sizes of the halide and the substitutional sites within the matrix as well as how tightly the metal dihalide is held within in them will also have an effect on the geometry adopted, ${ }^{213}$ especially if the molecule is easily bent and/or there are low-lying excited bent states. Which of these various effects is dominant in any particular case is not straightforward to unravel.

In addition to the structural changes in different matrices, the other key observation is the presence of bands blue-shifted from the impurity-induced $\mathrm{N}_{2}$ modes at $2327.8 \mathrm{~cm}^{-1}\left({ }^{14} \mathrm{~N}_{2}\right)$ and $2250.0 \mathrm{~cm}^{-1}\left({ }^{15} \mathrm{~N}_{2}\right)$ for the metal dihalides in $\mathrm{N}_{2}$ matrices. Table 4 summarizes the observed frequencies of these bands for a variety of metals in both ${ }^{14} \mathrm{~N}_{2}$ and ${ }^{15} \mathrm{~N}_{2}$ matrices, and Figure 6 shows the corresponding spectra in the $\nu_{\mathrm{NN}}$ stretching region, with the $\mathrm{N}_{2}$ impurity-induced modes marked with * labels. The ${ }^{14} \mathrm{~N}_{2}$ data in Figure 6 have been truncated to exclude the $\mathrm{CO}_{2}$ bands, e.g., the band due to $\mathrm{CO}_{2}$ occurred very close to the $2342.8 \mathrm{~cm}^{-1}$ absorption band for $\mathrm{NiBr}_{2}$ in ${ }^{14} \mathrm{~N}_{2}$. It is clear from
Table 4 and Figure 6 that these bands occurred at different frequencies for each metal and also for each halide, clearly indicating that they arise from an interaction between the metal halide and $\mathrm{N}_{2}$. The largest blue shift was observed for nickel, which also had the largest shift in $\nu_{3}$.

For $\mathrm{N}_{2}$ absorbed onto surfaces studied either with highresolution electron energy loss spectroscopy (HREELS) or IR reflection-absorption spectroscopy (IRAS), bands near the gas-phase value are characteristic of physisorbed species, whereas those at lower frequency arise from chemisorbed $\mathrm{N}_{2}$ moieties. ${ }^{214}$ For example from IRAS experiments the $\nu_{\mathrm{NN}}$ mode for $\mathrm{N}_{2}$ physisorbed on $\mathrm{Pt}(111)$ occurs at $2322 \mathrm{~cm}^{-1}$, whereas that for chemisorbed $\mathrm{N}_{2}$ appear at $2265 \mathrm{~cm}^{-1}$ (terrace sites) and $2232 \mathrm{~cm}^{-1}$ (defect/step sites). ${ }^{215,216}$ For physisorbed $\mathrm{N}_{2}$ on $\mathrm{Rh} / \mathrm{Al}_{2} \mathrm{O}_{3}$ and $\mathrm{Al}_{2} \mathrm{O}_{3}, \nu_{\mathrm{NN}}$ was observed at $2331 \mathrm{~cm}^{-1}, 217$ and for chemisorbed ${ }^{14} \mathrm{~N}_{2}$ on $\mathrm{Rh}, \nu_{\mathrm{NN}}$ was measured as $2257 \mathrm{~cm}^{-1} \cdot{ }^{214,217}$ More recently, $\nu_{\mathrm{NN}}$ for physisorbed $\mathrm{N}_{2}$ on $\mathrm{Rh} / \mathrm{Al}_{2} \mathrm{O}_{3}$ and $\mathrm{Rh} / \mathrm{TiO}_{2}$ was observed at $2331 \mathrm{~cm}^{-1}$, with $\nu_{\mathrm{NN}}$ for chemisorbed $\mathrm{N}_{2}$ at $2248 \mathrm{~cm}^{-1} \cdot{ }^{218,219}$ The $2258 \mathrm{~cm}^{-1}$ band observed previously ${ }^{214,217}$ was due to interaction of $\mathrm{N}_{2}$ with a surface treated with $\mathrm{H}_{2}{ }^{218,219}$ On H-ZSM-5, the $\nu_{\mathrm{NN}}$ mode for physisorbed ${ }^{14} \mathrm{~N}_{2}$ was observed at $2332 \mathrm{~cm}^{-1}$ and that for physisorbed ${ }^{15} \mathrm{~N}_{2}$ at $2253 \mathrm{~cm}^{-1}$. ${ }^{220}$ For chemisorbed $\mathrm{N}_{2}$ on $\mathrm{Ni}(110), \nu_{\mathrm{NN}}$ was observed at $2196 \mathrm{~cm}^{-1}$. ${ }^{221}$ From HREELS experiments, $\nu_{\mathrm{NN}}$ for physisorbed $\mathrm{N}_{2}$ on $\mathrm{NbO}(110)$ at $20 \mathrm{~K}$ was observed at $2339 \mathrm{~cm}^{-1}$, whereas for chemisorbed $\mathrm{N}_{2}, \nu_{\mathrm{NN}}$ was observed at $2194 \mathrm{~cm}^{-1}$ at $80 \mathrm{~K}$ and $2162 \mathrm{~cm}^{-1}$ at $20 \mathrm{~K}^{222}$ For $\mathrm{N}_{2}$ on $\mathrm{Ru}(001)$, the physisorbed $\nu_{\mathrm{NN}}$ peak was at $2331 \mathrm{~cm}^{-1}$, while for the chemisorbed species $\nu_{\mathrm{NN}}$ was at $2194 \mathrm{~cm}^{-1}$. 223 $\nu_{\mathrm{NN}}$ for $\mathrm{N}_{2}$ physisorbed on $\mathrm{Al}(111)$ was observed at $2339 \mathrm{~cm}^{-1}$. 224 For $\mathrm{N}_{2}$ on $\operatorname{Pd}(111), \nu_{\mathrm{NN}}$ was observed at $2331 \mathrm{~cm}^{-1}$ for the physisorbed species and at $2258 \mathrm{~cm}^{-1}$ for the chemisorbed species. $^{225}$ Surface EXAFS (SEXAFS) indicates a Ni-N bond length of $1.86 \AA$ for $\mathrm{N}_{2}$ chemisorbed on $\mathrm{Ni}(110) .{ }^{226}$ These $\nu_{\mathrm{NN}}$ modes clearly show the difference in the spectroscopic properties of physisorbed and chemisorbed species.

Kinematic effects will result in an increase in $\nu_{\mathrm{NN}}$ for physisorbed $\mathrm{N}_{2}$ even with the same force constant. As for carbonyl complexes, there is also the possibility that bands to high frequency of the free $\mathrm{N}_{2}$ value may indicate nonclassical bonding, with predominantly $\sigma$ bonding. Lubezky et al. ${ }^{227,228}$ observed bands at 2344 and $2334 \mathrm{~cm}^{-1}$ for ${ }^{14} \mathrm{~N}_{2}$ on $\mathrm{LiCl}$ and at 2341 and $2332 \mathrm{~cm}^{-1}$ for ${ }^{14} \mathrm{~N}_{2}$ on $\mathrm{LiF}$, with calculated adsorption potentials of 18.0 and $6.3 \mathrm{~kJ} \mathrm{~mol}^{-1}$, respectively. Lesiecki and Nibler ${ }^{100}$ observed bands in ${ }^{14} \mathrm{~N}_{2}$ matrices that were blue-shifted from the gas-phase values by $18 \mathrm{~cm}^{-1}$ for $\mathrm{MgF}_{2}$ (Raman) and $14 \mathrm{~cm}^{-1}$ for $\mathrm{MgCl}_{2}$ (Raman and IR). Boganov et al. ${ }^{229}$ calculated that in $\operatorname{SnF}_{2}\left(\mathrm{~N}_{2}\right)$ and $\operatorname{SnF}_{2}\left(\mathrm{~N}_{2}\right)_{2}$ the $\mathrm{Sn}-\mathrm{N}$ bond lengths should be ca. $2.9 \AA$, with the $\nu_{\mathrm{NN}}$ modes 14 and $13 \mathrm{~cm}^{-1}$ higher than "free" $\mathrm{N}_{2}$ value, but they were unable to observe any such features in their spectra. For $\mathrm{NiCl}_{2}$ and $\mathrm{NiF}_{2}$ isolated in solid ${ }^{14} \mathrm{~N}_{2}$ at ca. $14 \mathrm{~K}$, bands at $2327 \mathrm{~cm}^{-1}$ were reported by DeKock and Van Leirsburg ${ }^{140,141}$ that were not assigned with any certainty at the time but are almost certainly due to ${ }^{14} \mathrm{~N}_{2}$-impurity-perturbed $\nu_{\mathrm{NN}}$ modes ${ }^{138}$ rather than $\mathrm{N}_{2}$ complexes.

Therefore, the IR bands to high frequency of the perturbed $\nu_{\mathrm{NN}}$ modes of free $\mathrm{N}_{2}$ in $\mathrm{FeBr}_{2}, \mathrm{CoBr}_{2}$, and $\mathrm{NiBr}_{2}$ are best considered as $\mathrm{X}_{2} \mathrm{M} \cdots\left(\mathrm{N}_{2}\right)_{n}$ species akin to physisorption on a surface, indicative of $\mathrm{N}_{2}$ coordinated to the metal with a relatively weak interaction. The positions of these bands with respect to the perturbed $\nu_{\mathrm{NN}}$ mode are mirrored in the differences of the $\mathrm{MX}_{2} \nu_{3}$ modes between $\mathrm{Ar}$ and $\mathrm{N}_{2}$ matrices. 
The relatively small change $\left(0.3 \mathrm{~cm}^{-1}\right)$ in the position of the $\mathrm{NiBr}_{2} \nu_{3}$ mode between ${ }^{14} \mathrm{~N}_{2}$ and ${ }^{15} \mathrm{~N}_{2}$ matrices indicates a weak level of interaction, as a shift of $7.7 \mathrm{~cm}^{-1}$ has been observed in $\nu_{\mathrm{Cu}-\mathrm{Cl}}$ for $\mathrm{CuCl}\left(\mathrm{N}_{2}\right)$ between ${ }^{14} \mathrm{~N}_{2}$ and ${ }^{15} \mathrm{~N}_{2}$ matrices. ${ }^{70}$ The metal K-edge EXAFS data indicate $\mathrm{M}-\mathrm{N}$ and $\mathrm{M} \cdots \mathrm{N}$ distances of 2.15(3) and 3.19(4) $\AA$ for $\mathrm{FeBr}_{2}, 2.13(3)$ and 3.22(4) $\AA$ for $\mathrm{CoBr}_{2}$, and 2.12(2) and 3.19(4) $\AA$ for $\mathrm{NiBr}_{2}$. All of the $\mathrm{M}-\mathrm{N}$ distances are significantly longer than those observed for complexes or chemisorbed species. The $\nu_{\mathrm{NN}}$ bands observed for $\mathrm{ZnBr}_{2}$ in ${ }^{14} \mathrm{~N}_{2}$ and ${ }^{15} \mathrm{~N}_{2}$ matrices before and after photolysis are very close to the free $\mathrm{N}_{2}$ impurity-induced modes and appear as shouldered absorption bands. This underlines the fact that a minimal interaction between $\mathrm{ZnBr}_{2}$ and $\mathrm{N}_{2}$ was observed, consistent with the molecule retaining its linear structure.

In the case of $\mathrm{NiBr}_{2}$ and $\mathrm{NiCl}_{2}$ in nitrogen matrices, photolysis brings about the appearance of new $\nu_{\mathrm{NN}}$ bands at lower wavenumber than for free $\mathrm{N}_{2}$ that are more consistent with conventional chemisorbed dinitrogen coordinated to the metal center or conventional complexes. For $\mathrm{CoBr}_{2}$ these features were very weak, and none were observed for $\mathrm{FeBr}_{2}$ or $\mathrm{NiF}_{2}$. The isotopic behavior of the $\nu_{\mathrm{NN}}$ bands observed after photolysis clearly indicates the formation of a species containing two geminal $\mathrm{N}_{2}$ units in $\left[\mathrm{NiX}_{2}\left(\eta^{1}-\mathrm{N}_{2}\right)_{2}\right]$. They are at relatively high values compared with those for low-oxidationstate dinitrogen complexes but are similar to those observed for other complexes containing cationic metal centers. Most significantly, they are very similar to those observed for matrix-isolated $\mathrm{Ni}\left(\mathrm{N}_{2}\right)_{2}\left(\mathrm{O}_{2}\right)$, which was shown via isotopic substitution to have a pseudotetrahedral geometry with two end-on-bonded dinitrogen ligands $\left(\eta^{1}-\mathrm{N}_{2}\right)$ in a cis configuration and one side-on-bonded dioxygen ligand $\left(\eta^{2}-\mathrm{O}_{2}\right)$, with the dioxygen unit believed to be between peroxo and superoxo in character. ${ }^{163,164}$ The $\mathrm{NiX}_{2}\left(\eta^{1}-\mathrm{N}_{2}\right)_{2}$ complexes reported in this work are very unstable, even under matrix isolation conditions, and provide an indication of the stability of $\mathrm{Ni}(\mathrm{II})$ dinitrogen complexes as well as being an example of reversible binding of $\mathrm{N}_{2}$ to $\mathrm{Ni}(\mathrm{II})$ centers. This work also indicates a calibration value for $\nu_{\mathrm{NN}}$ attached to a $\mathrm{Ni}$ (II) center, thus confirming that the $\mathrm{Ni}\left(\mathrm{N}_{2}\right)_{2}\left(\mathrm{O}_{2}\right)$ complexes are best considered as containing $\mathrm{Ni}(\mathrm{II})$ and a peroxo ligand. The proportion of $\mathrm{NiX}_{2}\left(\eta^{1}-\mathrm{N}_{2}\right)_{2}$ formed upon photolysis is dependent on the deposition temperature (which needs to be less than $10 \mathrm{~K}$ ) and the photolysis wavelength, but in all cases it appears to remain fairly low. These chemisorbed species dissociate upon warming to $20 \mathrm{~K}$, as found for $\operatorname{Pd}\left(\mathrm{N}_{2}\right)_{2}\left(\mathrm{O}_{2}\right)^{164}$ and $\mathrm{Mo}\left(\mathrm{N}_{2}\right)_{x}$, ${ }^{165}$ indicating their extremely reactive nature. The very low deposition temperatures required to observe the photoproducts may be related to the need for some preorganization of the nitrogen lattice that is only achieved by very rapid quenching of the $\mathrm{NiX}_{2}$ in solid nitrogen below $10 \mathrm{~K}$.

\section{CONCLUSIONS}

The combination of IR, UV-vis-NIR, and XAFS spectroscopies has produced good evidence that there are different and varying interactions between metal dihalides and a wide range of matrix hosts. For zinc there is little perturbation of the spectroscopic signatures, and for nickel this is also the case, except for $\mathrm{N}_{2}$, where there is a significant change associated with a change from a linear geometry to a bent geometry. In the case of cobalt and iron there is a more gradual change, where in addition to $\mathrm{N}_{2}$ matrices the $\mathrm{CH}_{4}$ and Xe matrices also have interactions leading to nonlinear geometries. The extents of interaction between the metal halide and host increased in the order $\mathrm{Ne}<\mathrm{Ar}<\mathrm{O}_{2}<\mathrm{Kr}<\mathrm{CH}_{4}<\mathrm{Xe}$. In $\mathrm{N}_{2}$ matrices there is evidence for the formation of physisorbed-type species, and the extent of the blue shift of the $\nu_{\mathrm{NN}}$ mode correlates strongly with the shift in the $\mathrm{MBr}_{2} \nu_{3}$ mode. Photolysis of $\mathrm{NiBr}_{2}$ and $\mathrm{NiCl}_{2}$ in $\mathrm{N}_{2}$ matrices results in the formation of chemisorbed $\mathrm{NiX}_{2}\left(\eta^{1}-\mathrm{N}_{2}\right)_{2}$-type species, with $\nu_{\mathrm{NN}}$ modes red-shifted from that for free $\mathrm{N}_{2}$.

Therefore, this work has demonstrated that the term "inert" must be viewed with caution when dealing with species that possess geometries that are easily perturbed.

\section{AUTHOR INFORMATION}

\section{Corresponding Author}

*Fax: 441482 466410. Tel: 441482 465442. E-mail: n.a. young@hull.ac.uk.

ORCID *

Nigel A. Young: 0000-0003-4620-5119

Notes

The authors declare no competing financial interest.

\section{ACKNOWLEDGMENTS}

The EPSRC are thanked for financial support of this work through grants for the provision of equipment (GR/H29117, GR/K17513, GR/T09651) and Ph.D. studentships to O.M.W., N.H., E.L.D., and J.F.R. and also for access to the Chemical Database Service at Daresbury Laboratory. ${ }^{230}$ The STFC are acknowledged for access to synchrotron and computing facilities. The staff at Daresbury Laboratory are thanked for their assistance with the X-ray absorption and far-IR experiments.

\section{REFERENCES}

(1) Tremblay, B.; Manceron, L. The Vibrational Spectrum of PdCO Isolated in Solid Argon. Chem. Phys. 1999, 250, 187-197.

(2) Fredin, L.; Nelander, B.; Ribbegård, G. On the Dimerization of Carbon Dioxide in Nitrogen and Argon Matrices. J. Mol. Spectrosc. 1974, 53, 410-416.

(3) Wilde, R. E.; Srinivasan, T. K. K.; Harral, R. W.; Sankar, S. G. Matrix-Isolated Silane. Infrared Spectra. J. Chem. Phys. 1971, 55, $5681-5692$.

(4) Kolomiitsova, T. D.; Savvateev, K. F.; Tokhadze, K. G.; Shchepkin, D. N.; Sennikov, P. G.; Vel'muzhova, I. A.; Bulanov, A. D. Vibrational Spectra of Monoisotopic $\mathrm{SiH}_{4}$ and $\mathrm{GeH}_{4}$ in LowTemperature Matrices. Opt. Spectrosc. 2012, 112, 563-573.

(5) Kolomiitsova, T. D.; Savvateev, K. F.; Shchepkin, D. N.; Tokhadze, I. K.; Tokhadze, K. G. Infrared Spectra and Structures of $\mathrm{SiH}_{4}$ and $\mathrm{GeH}_{4}$ Dimers in Low-Temperature Nitrogen Matrixes. J. Phys. Chem. A 2015, 119, 2553-2561.

(6) Asfin, R. E.; Kolomiitsova, T. D.; Shchepkin, D. N.; Tokhadze, K. G. Infrared Studies of the Symmetry Changes of the ${ }^{28} \mathrm{SiH}_{4}$ Molecule in Low-Temperature Matrixes. Fundamental, Combination, and Overtone Transitions. J. Phys. Chem. A 2017, 121, 5116-5126.

(7) Taketsugu, Y.; Noro, T.; Taketsugu, T. Theoretical study of ArMCO (M = Pd, Pt). Chem. Phys. Lett. 2010, 484, 139-143.

(8) Ono, Y.; Taketsugu, T. Theoretical study of Ng-NiCO ( $\mathrm{Ng}=\mathrm{Ar}$, Ne, He). Chem. Phys. Lett. 2004, 385, 85-91.

(9) Taketsugu, Y.; Noro, T.; Taketsugu, T. Identification of the Matrix Shift: A Fingerprint for Neutral Neon Complex? J. Phys. Chem. A 2008, 112, 1018-1023.

(10) Joly, H. A.; Manceron, L. Complete Vibrational Spectrum of NiCO Isolated in Solid Argon. Chem. Phys. 1998, 226, 61-70.

(11) Tremblay, B.; Manceron, L. Search for the Ar-NiCO complex: A solid neon investigation. Chem. Phys. Lett. 2006, 429, 464-468.

(12) Arthers, S. A.; Beattie, I. R. The Vibrational Spectra of Some Tetrachlorides in Rare-Gas Matrices with Particular Reference to the 
Molecular Shapes of $\mathrm{ThCl}_{4}$ and $\mathrm{UCl}_{4}$. J. Chem. Soc., Dalton Trans. 1984, 819-826.

(13) Beattie, I. R.; Jones, P. J.; Millington, K. R.; Willson, A. D. The Infrared Spectra of Matrix Isolated Thorium and Uranium Tetrachlorides. Change of Shape with Matrix Gas. J. Chem. Soc., Dalton Trans. 1988, 2759-2762.

(14) Arthers, S. A.; Beattie, I. R.; Jones, P. J. The Infrared-Spectra of Alkali-Metal Hexafluorouranates(V). An Example of Dependence of Molecular Geometry on Matrix Gas. J. Chem. Soc., Dalton Trans. 1984, $711-713$.

(15) Beattie, I. R.; Millington, K. R. A Quantitative Approach to Host-Guest Interactions for Matrix-Isolated Alkali-Metal Salts of Hexafluoroanions and Perchlorates. J. Chem. Soc., Dalton Trans. 1987, $1521-1527$.

(16) Beattie, I. R.; Jones, P. J.; Young, N. A. Nickel Dichloride - a Nonlinear Molecule in a Nitrogen Matrix? Implications for Structure Determinations in Cryogenic Matrices. Mol. Phys. 1991, 72, 13091312.

(17) Beattie, I. R.; Jones, P. J.; Young, N. A. The Interaction of Some Metal Dichlorides (Ca, Cr, Mn, Fe, Co, Ni, Zn) with Dinitrogen. Chem. Phys. Lett. 1991, 177, 579-584.

(18) Collier, M. A.; McCaffrey, J. G. The Absorption and Excitation Spectroscopy of Matrix-Isolated Atomic Manganese: Sites of Isolation in the Solid Rare Gases. J. Chem. Phys. 2005, 122, 054503.

(19) Kus, N.; Sharma, A.; Reva, I.; Lapinski, L.; Fausto, R. Using Heavy Atom Rare Gas Matrix to Control the Reactivity of 4Methoxybenzaldehyde: A Comparison with Benzaldehyde. J. Chem. Phys. 2012, 136, 144509.

(20) Kofranek, M.; Karpfen, A.; Lischka, H. Gauche versus s-cisButadiene Revisited - a Molecular Dynamics Simulation of the Ar Matrix Effect. Chem. Phys. Lett. 1992, 189, 281-286.

(21) Khriachtchev, L.; Pettersson, M.; Runeberg, N.; Lundell, J.; Räsänen, M. A Stable Argon Compound. Nature 2000, 406, 874-876.

(22) Khriachtchev, L.; Pettersson, M.; Lignell, A.; Räsänen, M. A More Stable Configuration of HArF in Solid Argon. J. Am. Chem. Soc. 2001, 123, 8610-8611.

(23) Khriachtchev, L.; Räsänen, M.; Gerber, R. B. Noble-Gas Hydrides: New Chemistry at Low Temperatures. Acc. Chem. Res. 2009, 42, 183-191.

(24) Grochala, W.; Khriachtchev, L.; Räsänen, M., Noble Gas Chemistry. In Physics and Chemistry at Low Temperatures; Khriachtchev, L., Ed.; Pan Stanford Publishing: Singapore, 2011; pp 419-446.

(25) Perutz, R. N.; Turner, J. J. Photochemistry of the Group 6 Hexacarbonyls in Low-Temperature Matrices. III. Interaction of the Pentacarbonyls with Noble Gases and Other Matrices. J. Am. Chem. Soc. 1975, 97, 4791-4800.

(26) Turner, J. J.; Burdett, J. K.; Perutz, R. N.; Poliakoff, M. Matrix Photochemistry of Metal Carbonyls. Pure Appl. Chem. 1977, 49, 271285.

(27) Burdett, J. K.; Grzybowski, J. M.; Perutz, R. N.; Poliakoff, M.; Turner, J. J.; Turner, R. F. Photolysis and Spectroscopy with Polarized Light: Key to the Photochemistry of Pentacarbonylchromium and Related Species. Inorg. Chem. 1978, 17, 147-154.

(28) Wells, J. R.; Weitz, E. Rare Gas-Metal Carbonyl Complexes: Bonding of Rare Gas Atoms to the Group VIB Pentacarbonyls. J. Am. Chem. Soc. 1992, 114, 2783-2787.

(29) Grills, D. C.; George, M. W. Transition Metal-Noble Gas Complexes. Adv. Inorg. Chem. 2001, 52, 113-150.

(30) Thompson, C. A.; Andrews, L. Noble Gas Complexes with $\mathrm{BeO}$ : Infrared Spectra of $\mathrm{Ng}-\mathrm{BeO}(\mathrm{Ng}=\mathrm{Ar}, \mathrm{Kr}, \mathrm{Xe})$. J. Am. Chem. Soc. 1994, 116, 423-424.

(31) Wang, Q.; Wang, X. F. Infrared Spectra of $\mathrm{NgBeS}(\mathrm{Ng}=\mathrm{Ne}, \mathrm{Ar}$, $\mathrm{Kr}, \mathrm{Xe})$ and $\mathrm{BeS}_{2}$ in Noble-Gas Matrices. J. Phys. Chem. A 2013, 117, $1508-1513$.

(32) Andrews, L.; Liang, B.; Li, J.; Bursten, B. E. Ground-State Reversal by Matrix Interaction: Electronic States and Vibrational Frequencies of CUO in Solid Argon and Neon. Angew. Chem., Int. Ed. 2000, 39, 4565-4567.
(33) Li, J.; Bursten, B. E.; Liang, B.; Andrews, L. Noble Gas-Actinide Compounds: Complexation of the CUO Molecule by Ar, Kr, and Xe Atoms in Noble Gas Matrices. Science 2002, 295, 2242-2245.

(34) Liang, B.; Andrews, L.; Li, J.; Bursten, B. E. Noble Gas-Actinide Compounds: Evidence for the Formation of Distinct CUO$(\mathrm{Ar})_{4-n}(\mathrm{Xe})_{n}$ and $\mathrm{CUO}(\mathrm{Ar})_{4-n}(\mathrm{Kr})_{n}(n=1,2,3,4)$ Complexes. $J$. Am. Chem. Soc. 2002, 124, 9016-9017.

(35) Andrews, L.; Liang, B.; Li, J.; Bursten, B. E. Noble Gas-Actinide Complexes of the CUO Molecule with Multiple Ar, Kr, and Xe Atoms in Noble-Gas Matrices. J. Am. Chem. Soc. 2003, 125, 3126-3139.

(36) Liang, B.; Andrews, L.; Li, J.; Bursten, B. E. Bonding of Multiple Noble-Gas Atoms to CUO in Solid Neon: $\mathrm{CUO}(\mathrm{Ng})_{n}(\mathrm{Ng}=\mathrm{Ar}, \mathrm{Kr}$, $\mathrm{Xe} ; n=1,2,3,4)$ Complexes and the Singlet-Triplet Crossover Point. Chem. - Eur. J. 2003, 9, 4781-4788.

(37) Andrews, L.; Liang, B.; Li, J.; Bursten, B. E. Noble Gas-Uranium Coordination and Intersystem Crossing for the $\mathrm{CUO}(\mathrm{Ne})_{x}(\mathrm{Ng})_{n}(\mathrm{Ng}$ $=\mathrm{Ar}, \mathrm{Kr}, \mathrm{Xe})$ complexes in solid neon. New J. Chem. 2004, 28, 289294.

(38) Liang, B.; Andrews, L.; Li, J.; Bursten, B. E. On the Noble-GasInduced Intersystem Crossing for the CUO Molecule: Experimental and Theoretical Investigations of $\mathrm{CUO}(\mathrm{Ng})_{n}(\mathrm{Ng}=\mathrm{Ar}, \mathrm{Kr}, \mathrm{Xe} ; n=1$, 2, 3, 4) complexes in solid neon. Inorg. Chem. 2004, 43, 882-894.

(39) Tecmer, P.; van Lingen, H.; Gomes, A. S. P.; Visscher, L. The Electronic Spectrum of $\mathrm{CUONg}_{4}(\mathrm{Ng}=\mathrm{Ne}, \mathrm{Ar}, \mathrm{Kr}, \mathrm{Xe})$ : New Insights in the Interaction of the CUO Molecule with Noble Gas Matrices. J. Chem. Phys. 2012, 137, 084308.

(40) Li, J.; Bursten, B. E.; Andrews, L.; Marsden, C. J. On the Electronic Structure of Molecular $\mathrm{UO}_{2}$ in the Presence of Ar Atoms: Evidence for Direct U-Ar Bonding. J. Am. Chem. Soc. 2004, 126, 3424-3425.

(41) Infante, I.; Andrews, L.; Wang, X. F.; Gagliardi, L. Noble Gas Matrices May Change the Electronic Structure of Trapped Molecules: The $\mathrm{UO}_{2}(\mathrm{Ng})_{4}[\mathrm{Ng}=\mathrm{Ne}, \mathrm{Ar}]$ Case. Chem. - Eur. J. 2010, 16, 1280412807.

(42) Wang, X.; Andrews, L.; Li, J.; Bursten, B. E. Significant Interactions Between Uranium and Noble-Gas Atoms: Coordination of the $\mathrm{UO}_{2}{ }^{+}$Cation by $\mathrm{Ne}, \mathrm{Ar}, \mathrm{Kr}$, and Xe Atoms. Angew. Chem., Int. Ed. 2004, 43, 2554-2557.

(43) Liang, B.; Hunt, R. D.; Kushto, G. P.; Andrews, L.; Li, J.; Bursten, B. E. Reactions of Laser-Ablated Uranium Atoms with $\mathrm{H}_{2} \mathrm{O}$ in Excess Argon: A Matrix Infrared and Relativistic DFT Investigation of Uranium Oxyhydrides. Inorg. Chem. 2005, 44, 2159-2168.

(44) Andrews, L.; Kushto, G. P.; Marsden, C. L. Reactions of Th and $\mathrm{U}$ Atoms with $\mathrm{C}_{2} \mathrm{H}_{2}$ : Infrared Spectra and Relativistic Calculations of the Metallacyclopropene, Actinide Insertion, and Ethynyl products. Chem. - Eur. J. 2006, 12, 8324-8335.

(45) Wang, X. F.; Andrews, L.; Willmann, K.; Brosi, F.; Riedel, S. Investigation of Gold Fluorides and Noble Gas Complexes by MatrixIsolation Spectroscopy and Quantum-Chemical Calculations. Angew. Chem., Int. Ed. 2012, 51, 10628-10632.

(46) Wang, X. F.; Andrews, L.; Brosi, F.; Riedel, S. Matrix Infrared Spectroscopy and Quantum-Chemical Calculations for the CoinageMetal Fluorides: Comparisons of $\mathrm{Ar}-\mathrm{AuF}, \mathrm{Ne}-\mathrm{AuF}$, and Molecules $\mathrm{MF}_{2}$ and $\mathrm{MF}_{3}$. Chem. - Eur. J. 2013, 19, 1397-1409.

(47) Zhao, Y. Y.; Wang, G. J.; Chen, M. H.; Zhou, M. F. Noble GasTransition Metal Complexes: Coordination of $\mathrm{ScO}^{+}$by multiple $\mathrm{Ar}$, $\mathrm{Kr}$, and Xe atoms in noble gas matrixes. J. Phys. Chem. A 2005, 109, $6621-6623$

(48) Zhao, Y. Y.; Gong, Y.; Chen, M. H.; Ding, C. F.; Zhou, M. F. Coordination of $\mathrm{ScO}^{+}$and $\mathrm{YO}^{+}$by Multiple $\mathrm{Ar}, \mathrm{Kr}$, and $\mathrm{Xe}$ Atoms in Noble Gas Matrixes: A Matrix Isolation Infrared Spectroscopic and Theoretical Study. J. Phys. Chem. A 2005, 109, 11765-11770.

(49) Gong, Y.; Ding, C. F.; Zhou, M. F. Formation and Characterization of the Oxygen-Rich Scandium Oxide/Dioxygen Complexes $\mathrm{ScO}_{n}(n=4,6,8)$ in solid argon. J. Phys. Chem. A 2007, $111,11572-11578$.

(50) Zhao, Y. Y.; Gong, Y.; Zhou, M. F. Matrix Isolation Infrared Spectroscopic and Theoretical Study of $\mathrm{NgMO}(\mathrm{Ng}=\mathrm{Ar}, \mathrm{Kr}, \mathrm{Xe} ; \mathrm{M}=$ 
Cr, Mn, Fe, Co, Ni) complexes. J. Phys. Chem. A 2006, 110, 1077710782

(51) Zhao, Y. Y.; Gong, Y.; Chen, M. H.; Zhou, M. F. Noble GasTransition-Metal Complexes: Coordination of $\mathrm{VO}_{2}$ and $\mathrm{VO}_{4}$ by $\mathrm{Ar}$ and Xe atoms in solid noble gas matrixes. J. Phys. Chem. A 2006, 110, $1845-1849$.

(52) Zhao, Y. Y.; Zheng, X. M.; Zhou, M. F. Coordination of Niobium and Tantalum Oxides by $\mathrm{Ar}, \mathrm{Xe}$ and $\mathrm{O}_{2}$ : Matrix Isolation Infrared Spectroscopic and Theoretical Study of $\mathrm{NbO}_{2}(\mathrm{Ng})_{2}(\mathrm{Ng}=$ Ar, $\mathrm{Xe})$ and $\mathrm{MO}_{4}(\mathrm{X})\left(\mathrm{M}=\mathrm{Nb}, \mathrm{Ta} ; \mathrm{X}=\mathrm{Ar}, \mathrm{Xe}, \mathrm{O}_{2}\right)$ in Solid Argon. Chem. Phys. 2008, 351, 13-18.

(53) Zhao, Y. Y.; Su, J.; Gong, Y.; Li, J.; Zhou, M. F. Noble-GasInduced Disproportionation Reactions: Facile Superoxo-to-Peroxo Conversion on Chromium Dioxide. J. Phys. Chem. A 2008, 112, 86068611.

(54) Yang, R.; Gong, Y.; Zhou, M. F. Matrix Isolation Infrared Spectroscopic and Theoretical Study of Noble Gas Coordinated Dipalladium-Dioxygen Complexes. Chem. Phys. 2007, 340, 134-140.

(55) Yang, R.; Gong, Y.; Zhou, H.; Zhou, M. F. Matrix Isolation Infrared Spectroscopic and Theoretical Study of Noble Gas Coordinated Rhodium-Dioxygen Complexes. J. Phys. Chem. A 2007, $111,64-70$.

(56) Zhao, Y. Y.; Zhou, M. F. Are Matrix Isolated Species Really "Isolated"? Infrared Spectroscopic and Theoretical Studies of Noble Gas-Transition Metal Oxide Complexes. Sci. China: Chem. 2010, 53, 327-336.

(57) Young, N. A. The Application of Synchrotron Radiation and in Particular X-ray Absorption Spectroscopy to Matrix Isolated Species. Coord. Chem. Rev. 2014, 277-278, 224-274.

(58) Cooke, S. A.; Gerry, M. C. L. XeAuF. J. Am. Chem. Soc. 2004, 126, 17000-17008.

(59) Seidel, S.; Seppelt, K. Xenon as a Complex Ligand: The Tetra Xenono Gold(II) cation in $\left[\mathrm{AuXe}_{4}\right]^{2+}\left(\mathrm{Sb}_{2} \mathrm{~F}_{11}\right)^{2-}$. Science 2000, 290, $117-118$.

(60) Drews, T.; Seidel, S.; Seppelt, K. Gold - Xenon complexes. Angew. Chem., Int. Ed. 2002, 41, 454-456.

(61) Hwang, I. C.; Seidel, S.; Seppelt, K. Gold(I) and Mercury(II) Xenon Complexes. Angew. Chem., Int. Ed. 2003, 42, 4392-4395.

(62) Seppelt, K. Metal-Xenon Complexes. Z. Anorg. Allg. Chem. 2003, 629, 2427-2430.

(63) Hope, E. G.; Jones, P. J.; Levason, W.; Ogden, J. S.; Tajik, M.; Turff, J. W. Characterization of Chromium(VI) Oxide Tetrafluoride, $\mathrm{CrOF}_{4}$, and Cesium Pentafluoro-oxochromate(VI) $\mathrm{Cs}\left[\mathrm{CrOF}_{5}\right]$. J. Chem. Soc., Dalton Trans. 1985, 529-533.

(64) Ogden, J. S.; Wyatt, R. S. Matrix Isolation and Mass Spectrometric Studies on the Vaporisation of Chromium(III) Chloride. The Characterization of Molecular $\mathrm{CrCl}_{4}$ and $\mathrm{CrCl}_{3}$. J. Chem. Soc., Dalton Trans. 1987, 859-865.

(65) Asfin, R. E.; Melikova, S. M.; Domanskaya, A. V.; Rodziewicz, P.; Rutkowski, K. S. Degeneracy Lifting Effect in the FTIR Spectrum of Fluoroform Trapped in a Nitrogen Matrix. An Experimental and Car-Parrinello Molecular Dynamics Study. J. Phys. Chem. A 2016, 120, 3497-3503.

(66) Bellingham, R. K.; Graham, J. T.; Jones, P. J.; Kirby, J. R.; Levason, W.; Ogden, J. S.; Brisdon, A. K.; Hope, E. G. Matrix Isolation Infrared and Ultraviolet Visible Studies on Some Transition Metal Pentachlorides and Pentabromides. J. Chem. Soc., Dalton Trans. 1991, 3387-3392.

(67) Beattie, I. R.; Spicer, M. D.; Young, N. A. Interatomic Distances for Some First Row Transition Element Dichlorides Isolated in Cryogenic Matrices using X-ray Absorption Fine Structure Spectroscopy. J. Chem. Phys. 1994, 100, 8700-8705.

(68) Young, N. A. Is Nickel Dibromide Bent in a Nitrogen Matrix? A Combined Simultaneous Fourier-Transform Infrared and X-ray Absorption Fine Structure Matrix Isolation Study. J. Chem. Soc., Dalton Trans. 1996, 249-251.

(69) Bridgeman, A. J.; Wilkin, O. M.; Young, N. A. Dinitrogen Bonding Modes to Molecular Nickel(II) Halides: a Matrix Isolation IR and DFT study. Inorg. Chem. Commun. 2000, 3, 681-684.
(70) Plitt, H. S.; Schnöckel, H.; Bar, M.; Ahlrichs, R. MatrixInvestigations on Monomeric Copper(I) Chloride and its Complexes with $\mathrm{N}_{2}$ and PN ligands - IR Spectroscopic Results and ab initio Calculations. Z. Anorg. Allg. Chem. 1992, 607, 45-51.

(71) Huber, H.; Kündig, E. P.; Moskovits, M.; Ozin, G. A. Binary Transition Metal Dinitrogen Complexes. I. Matrix Infrared and Raman Spectra, Structure, and Bonding of $\mathrm{Ni}\left(\mathrm{N}_{2}\right)_{n}$ and $\mathrm{Pd}\left(\mathrm{N}_{2}\right)_{m}(n=1-4$ and $m=1-3)$. J. Am. Chem. Soc. 1973, 95, 332-344.

(72) Klotzbücher, W. E.; Ozin, G. A. Binary Transition Metal Dinitrogen Complexes. III. Metal-Nitrogen Stretching Modes of $\mathrm{Ni}\left(\mathrm{N}_{2}\right)_{n}, \operatorname{Pd}\left(\mathrm{N}_{2}\right)_{m}$, and $\operatorname{Pt}\left(\mathrm{N}_{2}\right)_{m}$ (where $n=1-4$ and $m=1-3$ ). J. Am. Chem. Soc. 1975, 97, 2672-2675.

(73) Chesters, M. A.; Hargreaves, E. C.; Pearson, M.; Hollins, P.; Slater, D. A.; Chalmers, J. M.; Ruzicka, B.; Surman, M.; Tobin, M. J. Infrared Spectroscopy and Microscopy at the Daresbury Synchrotron Light Source. Nuovo Cimento Soc. Ital. Fis., D 1998, 20, 439-448.

(74) Wilkin, O. M.; Young, N. A. The Development of a Combined Simultaneous XAFS/FTIR Facility for the Study of Matrix Species. J. Synchrotron Radiat. 1999, 6, 204-206.

(75) Thompson, A. C.; Vaughan, D.; Attwood, D. T.; Gullikson, E. M.; Howells, M. R.; Kortright, J. B.; Robinson, A. L.; Underwood, J. H.; Kim, K. J.; Kirz, J.; Lindau, I.; Pianetta, P.; Winick, H.; Williams, G. P.; Scofield, J. H. Center for X-ray Optics and Advanced Light Source Xray Data Booklet, 2nd ed.; Lawrence Berkeley National Laboratory, University of California: Berkeley, CA, 2001.

(76) Binsted, N. PAXAS: Program for the Analysis of X-ray Absorption Spectra; University of Southampton: Southampton, U.K., 1988.

(77) O'Grady, W. E.; Qian, X.; Ramaker, D. E. Systematic Chemical Effects Observed in "Atomic" X-ray Absorption Fine Structure. J. Phys. Chem. B 1997, 101, 5624-5626.

(78) Ramaker, D. E.; Qian, X.; O’Grady, W. E. “Atomic” X-ray Absorption Fine Structure: a New Tool for Examining Electronic and Ionic Polarization Effects. Chem. Phys. Lett. 1999, 299, 221-226.

(79) Gurman, S. J.; Binsted, N.; Ross, I. A Rapid, Exact Curved-Wave Theory for EXAFS Calculations. J. Phys. C: Solid State Phys. 1984, 17, $143-151$.

(80) Gurman, S. J.; Binsted, N.; Ross, I. A Rapid, Exact, CurvedWave Theory for EXAFS Calculations 2. The Multiple-Scattering Contributions. J. Phys. C: Solid State Phys. 1986, 19, 1845-1861.

(81) Binsted, N. EXCURV98: CCLRC Daresbury Laboratory Computer Program; CCLRC, Daresbury Laboratory: Daresbury, U.K., 1998.

(82) Henke, B. L.; Gullikson, E. M.; Davis, J. C. X-ray Interactions: Photoabsorption, Scattering, Transmission, and Reflection at $E=50$ 30,000 keV, Z = 1-92. At. Data Nucl. Data Tables 1993, 54, 181-342.

(83) Beattie, I. R.; Cheetham, N.; Gardner, M.; Rogers, D. E. Calculation of the Vibrational Frequencies of Polyatomic Molecules, Including those of Crystals. J. Chem. Soc. A 1971, 2240-2245.

(84) te Velde, G.; Bickelhaupt, F. M.; Baerends, E. J.; Fonseca Guerra, C.; van Gisbergen, S. J. A.; Snijders, J. G.; Ziegler, T. Chemistry with ADF. J. Comput. Chem. 2001, 22, 931-967.

(85) Fonseca Guerra, C.; Snijders, J. G.; te Velde, G.; Baerends, E. J. Towards an order-N DFT method. Theor. Chem. Acc. 1998, 99, 391403.

(86) ADF2010; SCM: Amsterdam, 2010; http://www.scm.com.

(87) van Lenthe, E.; Ehlers, A.; Baerends, E. J. Geometry Optimizations in the Zero Order Regular Approximation for Relativistic Effects. J. Chem. Phys. 1999, 110, 8943-8953.

(88) DeBeer George, S.; Petrenko, T.; Neese, F. Prediction of Iron K-edge Absorption Spectra Using Time-Dependent Density Functional Theory. J. Phys. Chem. A 2008, 112, 12936-12943.

(89) Lee, N.; Petrenko, T.; Bergmann, U.; Neese, F.; DeBeer, S. Probing Valence Orbital Composition with Iron $\mathrm{K}_{\beta} \mathrm{X}$-ray Emission Spectroscopy. J. Am. Chem. Soc. 2010, 132, 9715-9727.

(90) Chandrasekaran, P.; Stieber, S. C. E.; Collins, T. J.; Que, L., Jr.; Neese, F.; DeBeer, S. Prediction of High-Valent Iron K-edge Absorption Spectra by Time-Dependent Density Functional Theory. Dalton Trans. 2011, 40, 11070-11079. 
(91) Beckwith, M. A.; Roemelt, M.; Collomb, M. N.; DuBoc, C.; Weng, T. C.; Bergmann, U.; Glatzel, P.; Neese, F.; DeBeer, S. Manganese $\mathrm{K}_{\beta} \mathrm{X}$-ray Emission Spectroscopy As a Probe of MetalLigand Interactions. Inorg. Chem. 2011, 50, 8397-8409.

(92) Roemelt, M.; Beckwith, M. A.; Duboc, C.; Collomb, M. N.; Neese, F.; DeBeer, S. Manganese K-Edge X-Ray Absorption Spectroscopy as a Probe of the Metal-Ligand Interactions in Coordination Compounds. Inorg. Chem. 2012, 51, 680-687.

(93) Scarborough, C. C.; Sproules, S.; Doonan, C. J.; Hagen, K. S.; Weyhermuller, T.; Wieghardt, K. Scrutinizing Low-Spin Cr(II) Complexes. Inorg. Chem. 2012, 51, 6969-6982.

(94) Scarborough, C. C.; Lancaster, K. M.; DeBeer, S.; Weyhermueller, T.; Sproules, S.; Wieghardt, K. Experimental Fingerprints for Redox-Active Terpyridine in $\left[\mathrm{Cr}(\mathrm{tpy})_{2}\right]\left(\mathrm{PF}_{6}\right)_{n}(n=3-0)$, and the Remarkable Electronic Structure of $\left[\mathrm{Cr}(\mathrm{tpy})_{2}\right]^{1-}$. Inorg. Chem. 2012, 51, 3718-3732.

(95) Ramondo, F.; Bencivenni, L.; Cesaro, S. N.; Hilpert, K. FTIR Matrix Isolation Study on Gaseous Calcium Dihalide Molecules. J. Mol. Struct. 1989, 192, 83-94.

(96) Loewenschuss, A.; Ron, A.; Schnepp, O. Vibrational Spectra and Thermodynamics of the Zinc Halides. J. Chem. Phys. 1968, 49, 272280.

(97) Givan, A.; Loewenschuss, A. Matrix Isolation Infrared and Raman Spectra of Binary and Mixed Zinc Halides, Isotopic Effects, Force Constants, and Thermodynamic Properties. J. Chem. Phys. 1978, 68, 2228-2242.

(98) Gregory, P. D.; Ogden, J. S. Matrix Isolation and Mass Spectrometric Studies on the Vaporization of Chromium(III) Bromide: Characterization of Molecular $\mathrm{CrBr}_{4}, \mathrm{CrBr}_{3}$ and $\mathrm{CrBr}_{2}$. J. Chem. Soc., Dalton Trans. 1995, 1423-1426.

(99) Thompson, K. R.; Carlson, K. D. Bending Frequencies and New Dimer Modes in the Far Infrared (FIR) Spectra of Transition Metal Dihalides. J. Chem. Phys. 1968, 49, 4379-4384.

(100) Lesiecki, M. L.; Nibler, J. W. Infrared and Raman Spectra and Structures of Matrix Isolated Magnesium Dihalides: $\mathrm{MgF}_{2}, \mathrm{MgCl}_{2}$, $\mathrm{MgBr}_{2}$, and $\mathrm{MgI}_{2}$. J. Chem. Phys. 1976, 64, 871-884.

(101) Milligan, D. E.; Jacox, M. E.; McKinley, J. D. Spectra of Matrix Isolated $\mathrm{NiF}_{2}$ and $\mathrm{NiCl}_{2}$. J. Chem. Phys. 1965, 42, 902-905.

(102) DeKock, C. W.; Gruen, D. M. Charge Transfer Spectra of Matrix Isolated 3d Transition Metal Dichlorides. J. Chem. Phys. 1968, 49, 4521-4526.

(103) Jacox, M. E.; Milligan, D. E. Matrix-Isolation Study of the Infrared and Ultraviolet Spectra of Several First-Series TransitionMetal Dichlorides. J. Chem. Phys. 1969, 51, 4143-4155.

(104) Beattie, I. R.; Binsted, N.; Levason, W.; Ogden, J. S.; Spicer, M. D.; Young, N. A. EXAFS, Matrix Isolation, and High-Temperature Chemistry. High Temp. Sci. 1989, 26, 71-86.

(105) Young, N. A.; Spicer, M. D. The 1st Combined in-situ FTIR and EXAFS Study of a Matrix-Isolated Molecule. J. Mol. Struct. 1990, $222,77-86$.

(106) Spicer, M. D.; Young, N. A. Structure of Chromyl Chloride $\left(\mathrm{CrO}_{2} \mathrm{Cl}_{2}\right)$ in a Nitrogen Matrix and in the Solid State as Determined by X-ray Absorption Spectroscopy. J. Chem. Soc., Dalton Trans. 1991, 3133-3135.

(107) Beattie, I. R.; Jones, P. J.; Young, N. A. Characterization of Some Novel 1st row Transition Metal Carbonyl Chlorides by Infrared and EXAFS Spectroscopy of Matrix-Isolated Species. J. Am. Chem. Soc. 1992, 114, 6146-6152.

(108) Young, N. A. Structural Studies of Vapor-Phase Transport Reactions Using X- Ray-Absorption Spectroscopy and MatrixIsolation. Jpn. J. Appl. Phys. 1993, 32, 776-778.

(109) Bridgeman, A. J.; Cavigliasso, G.; Harris, N.; Young, N. A. A Matrix Isolation and DFT Study of the Generation and Characterization of Monomeric Vapour Phase Platinum Chlorides. Chem. Phys. Lett. 2002, 351, 319-326.

(110) Westre, T. E.; Kennepohl, P.; De Witt, J. G.; Hedman, B.; Hodgson, K. O.; Solomon, E. I. A Multiplet Analysis of Fe K-edge 1s to 3d Pre-edge Features of Iron Complexes. J. Am. Chem. Soc. 1997, $119,6297-6314$.
(111) Barnes, A. D. J.; Baikie, T.; Hardy, V.; Lepetit, M. B.; Maignan, A.; Young, N. A.; Francesconi, M. G. Magnetic Coupling and LongRange Order in the Spin-Chain Sulfide $\mathrm{Ba}_{2} \mathrm{CoS}_{3}$. J. Mater. Chem. 2006, 16, 3489-3502.

(112) Colpas, G. J.; Maroney, M. J.; Bagyinka, C.; Kumar, M.; Willis, W. S.; Suib, S. L.; Baidya, N.; Mascharak, P. K. X-Ray Spectroscopic Studies of Nickel-Complexes, with Application to the Structure of Nickel Sites in Hydrogenases. Inorg. Chem. 1991, 30, 920-928.

(113) Kau, L. S.; Spira-Solomon, D. J.; Penner-Hahn, J. E.; Hodgson, K. O.; Solomon, E. I. X-ray Absorption Edge Determination of the Oxidation State and Coordination Number of Copper: Application to the Type 3 Site in Rhus-vernicifera Laccase and its Reaction with Oxygen. J. Am. Chem. Soc. 1987, 109, 6433-6442.

(114) Solomon, E. I.; Szilagyi, R. K.; DeBeer-George, S.; Basumallick, L. Electronic Structures of Metal Sites in Proteins and Models: Contributions to Function in Blue Copper Proteins. Chem. Rev. 2004, 104, 419-458.

(115) Fulton, J. L.; Hoffmann, M. M.; Darab, J. G. An X-ray Absorption Fine Structure Study of Copper(I) Chloride Coordination Structure in Water up to $325^{\circ}$ C. Chem. Phys. Lett. 2000, 330, 300308.

(116) Fulton, J. L.; Hoffmann, M. M.; Darab, J. G.; Palmer, B. J.; Stern, E. A. Copper(I) and Copper(II) Coordination Structure under Hydrothermal Conditions at $325^{\circ} \mathrm{C}$ : An X-ray Absorption Fine Structure and Molecular Dynamics Study. J. Phys. Chem. A 2000, 104, 11651-11663.

(117) Brugger, J.; Etschmann, B.; Liu, W.; Testemale, D.; Hazemann, J. L.; Emerich, H.; van Beek, W.; Proux, O. An XAS Study of the Structure and Thermodynamics of $\mathrm{Cu}(\mathrm{I})$ Chloride Complexes in Brines up to High Temperature $\left(400^{\circ} \mathrm{C}, 600\right.$ bar). Geochim. Cosmochim. Acta 2007, 71, 4920-4941.

(118) Levason, W.; Ogden, J. S.; Spicer, M. D.; Young, N. A. Characterization of Dibromine Monoxide $\left(\mathrm{Br}_{2} \mathrm{O}\right)$ by Bromine K-Edge EXAFS and IR Spectroscopy. J. Am. Chem. Soc. 1990, 112, 1019-1022.

(119) Gilson, T. R.; Levason, W.; Ogden, J. S.; Spicer, M. D.; Young, N. A. Bromine Perbromate - Synthesis and Bromine K-Edge EXAFS Studies. J. Am. Chem. Soc. 1992, 114, 5469-5470.

(120) van der Gaauw, A.; Wilkin, O. M.; Young, N. A. The Importance of Multiple Scattering Pathways Involving the Absorbing Atom in the Interpretation and Analysis of Metal K- edge XAFS Data of Co-ordination Compounds. J. Chem. Soc., Dalton Trans. 1999, 2405-2406.

(121) Binsted, N.; van der Gaauw, A.; Wilkin, O. M.; Young, N. A. The Importance of Multiple Scattering Pathways Through the Central Atom in the Analysis of Metal K-edge XAFS Data of Coordination Complexes. J. Synchrotron Radiat. 1999, 6, 239-241.

(122) Givan, A.; Loewenschuss, A. Evidence for Existence and Vibrational Characterization of Group IIb Mixed Fluorides. J. Chem. Phys. 1978, 68, 5653-5654.

(123) Loewenschuss, A.; Givan, A. Vibrational Spectra, Isotopic Effects, Force Constants and Geometry of Matrix Isolated Binary and Mixed Dihalides. Ber. Bunsenges. Phys. Chem. 1978, 82, 69-71.

(124) Hargittai, M. Molecular Structure of Metal Halides. Chem. Rev. 2000, 100, 2233-2301.

(125) Hargittai, M. The Molecular-Geometry of Gas-Phase MetalHalides. Coord. Chem. Rev. 1988, 91, 35-88.

(126) Porter, R. F.; Schoonmaker, R. C. A Mass Spectrometric Study of the Vaporization of Ferrous Bromide. J. Phys. Chem. 1959, 63, 626628 .

(127) Schoonmaker, R. C.; Friedman, A. H.; Porter, R. F. Mass Spectrometric and Thermodynamic Study of Gaseous Transition Metal(II) Halides. J. Chem. Phys. 1959, 31, 1586-1589.

(128) Keneshea, F. J.; Cubicciotti, D. Vapor Pressures of Zinc Chloride and Zinc Bromide and Their Gaseous Dimerization. J. Chem. Phys. 1964, 40, 191-199.

(129) Wang, S. G.; Schwarz, W. H. E. Density Functional Study of First Row Transition Metal Dihalides. J. Chem. Phys. 1998, 109, 72527262. 
(130) Shao, Y.; Chen, D. H.; Wang, S. G. Density Functional Study of $\mathrm{MnX}_{2}$ (X = F, Cl, Br, I). J. Mol. Struct.: THEOCHEM 2004, 671, $147-152$.

(131) Schwerdtfeger, P.; Söhnel, T.; Pernpointner, M.; Laerdahl, J. K.; Wagner, F. E. Comparison of ab initio and Density Functional Calculations of Electric Field Gradients: The Fe-57 Nuclear Quadrupole Moment from Mössbauer Data. J. Chem. Phys. 2001, 115, 5913-5924.

(132) Sliznev, V. V.; Vogt, N.; Vogt, J. Ab initio Study of the Ground and Lower-Lying Excited Electronic States of $\mathrm{NiX}_{2}$ and $\mathrm{FeX}_{2}(\mathrm{X}=\mathrm{F}$, Cl, Br, I) molecules. J. Mol. Struct. 2006, 780-781, 247-259.

(133) Sliznev, V. V.; Vogt, N.; Vogt, J. Ab initio Study of the Ground and Lower-Lying Excited Electronic States of $\mathrm{CoF}_{2}, \mathrm{CoCl}_{2}, \mathrm{CoBr}_{2}$ and CoI 2 . Mol. Phys. 2004, 102, 1767-1776.

(134) Zhao, J.; Zhang, Y.; Kan, Y.; Zhu, L. Theoretical Studies on Vibrational Spectra of Some Halides of Group IIB Elements. Spectrochim. Acta, Part A 2004, 60, 679-688.

(135) Donald, K. J.; Hargittai, M.; Hoffmann, R. Group 12 Dihalides: Structural Predilections from Gases to Solids. Chem. - Eur. J. 2009, 15, $158-177$.

(136) Riley, K. E.; Merz, K. M. Assessment of Density Functional Theory Methods for the Computation of Heats of Formation and Ionization Potentials of Systems Containing Third Row Transition Metals. J. Phys. Chem. A 2007, 111, 6044-6053.

(137) Hargittai, M.; Tremmel, J.; Hargittai, I. Molecular Structures of Zinc Dichloride, Zinc Dibromide, and Zinc Diiodide from Electron Diffraction Reinvestigation. Inorg. Chem. 1986, 25, 3163-3166.

(138) Thompson, C. A.; Andrews, L.; Davy, R. D. Reactions of Beryllium Species with $\mathrm{N}_{2}$ : Infrared Spectra and Quantum Chemical Calculations of Beryllium Dinitrogen Complexes in Solid Argon and Nitrogen. J. Phys. Chem. 1995, 99, 7913-7924.

(139) Hastie, J. W.; Hauge, R. H.; Margrave, J. L. Infrared Spectra and Geometry of the Difluorides of $\mathrm{Co}, \mathrm{Ni}, \mathrm{Cu}$ and $\mathrm{Zn}$ Isolated in Neon and Argon Matrices. High Temp. Sci. 1969, 1, 76-85.

(140) DeKock, C. W.; Van Leirsburg, D. A. Preparation and Identification of $\mathrm{CO}$ and $\mathrm{N}_{2}$ Complexes of $\mathrm{NiF}_{2}$ and $\mathrm{NiCl}_{2}$ by matrix isolation. J. Am. Chem. Soc. 1972, 94, 3235-3237.

(141) Van Leirsburg, D. A.; DeKock, C. W. Interaction of Matrix -Isolated $\mathrm{NiF}_{2}$ and $\mathrm{NiCl}_{2}$ with $\mathrm{CO}, \mathrm{N}_{2}, \mathrm{NO}$, and $\mathrm{O}_{2}$ and of $\mathrm{CaF}_{2}, \mathrm{CrF}_{2}$, $\mathrm{CuF}_{2}$, and $\mathrm{ZnF}_{2}$ with $\mathrm{CO}$ in Argon Matrices. J. Phys. Chem. 1974, 78, 134-142.

(142) Hastie, J. W.; Hauge, R. H.; Margrave, J. L. Infrared Spectra and Geometries for the Dichlorides of $\mathrm{Ca}, \mathrm{Sc}, \mathrm{Ti}, \mathrm{V}, \mathrm{Cr}, \mathrm{Mn}, \mathrm{Fe}$, and Ni. High Temp. Sci. 1971, 3, 257-274.

(143) Gruen, D. M.; Clifton, J. R.; DeKock, C. W. The Fluorescence Spectrum of Matrix Isolated $\mathrm{NiCl}_{2}$. J. Chem. Phys. 1968, 48, 13941395.

(144) Zink, L. R.; Brown, J. M.; Gilson, T. R.; Beattie, I. R. The Dispersed Fluorescence of Nickel Dichloride under Molecular-Beam Conditions - a Determination of Ground-State Vibrational Intervals. Chem. Phys. Lett. 1988, 146, 501-506.

(145) Ashworth, S. H.; Grieman, F. J.; Brown, J. M. Further Observations Of The $460 \mathrm{Nm}$ Band System Of Nickel Dichloride, Cooled To Lower Temperatures In A Free Jet Expansion. Chem. Phys. Lett. 1990, 175, 660-666.

(146) Grieman, F. J.; Ashworth, S. H.; Brown, J. M.; Beattie, I. R. Vibrational Analysis of the $460 \mathrm{~nm}$ Band System of Nickel Dichloride Produced in a Free Jet Expansion. J. Chem. Phys. 1990, 92, 6365-6375.

(147) Zink, L. R.; Grieman, F. J.; Brown, J. M.; Gilson, T. R.; Beattie, I. R. Vibrational Structure in the Laser Excitation Spectrum of Nickel Dichloride at $360 \mathrm{~nm}$. J. Mol. Spectrosc. 1991, 146, 225-237.

(148) Ashworth, S. H.; Grieman, F. J.; Brown, J. M.; Jones, P. J.; Beattie, I. R. Structure of Nickel Dichloride. J. Am. Chem. Soc. 1993, 115, 2978-2979.

(149) Ashworth, S. H.; Grieman, F. J.; Brown, J. M. Rotational Analysis of Bands in the $460 \mathrm{~nm}$ System of Nickel Dichloride Produced in a Free-Jet Expansion: Determination of the Structure and Electronic Ground State of Nickel Dichloride. J. Chem. Phys. 1996, $104,48-63$.
(150) van den Hoek, G.; Brown, J. M. Rotational Analysis of Bands in the $360-\mathrm{nm}$ System of $\mathrm{NiCl}_{2}$ : Indications of Interacting States. J. Mol. Spectrosc. 1997, 182, 163-177.

(151) Green, D. W.; McDermott, D. P.; Bergman, A. Infrared Spectra of the Matrix-Isolated Chlorides of Iron, Cobalt, and Nickel. J. Mol. Spectrosc. 1983, 98, 111-124.

(152) Hargittai, M.; Subbotina, N. Y.; Kolonits, M.; Gershikov, A. G. Molecular Structure of First-Row Transition-Metal Dihalides from Combined Electron Diffraction and Vibrational Spectroscopic Analysis. J. Chem. Phys. 1991, 94, 7278-7286.

(153) Knözinger, E.; Wittenbeck, R. Intermolecular Motional Degrees of Freedom of $\mathrm{H}_{2} \mathrm{O}$ and $\mathrm{D}_{2} \mathrm{O}$ Isolated in Solid Gas Matrices. J. Am. Chem. Soc. 1983, 105, 2154-2158.

(154) Knözinger, E.; Wittenbeck, R. FIR Matrix Isolation Spectroscopy - a State of the Art Report. Infrared Phys. 1984, 24, 135-142.

(155) Lupinetti, A. J.; Strauss, S. H.; Frenking, G. Nonclassical Metal Carbonyls. Prog. Inorg. Chem. 2001, 49, 1-112.

(156) Ozin, G. A.; Vander Voet, A. "Sideways" Bonded Dinitrogen in Matrix Isolated Cobalt Dinitrogen, $\mathrm{CoN}_{2}$. Can. J. Chem. 1973, 51, 637-640.

(157) Moskovits, M.; Ozin, G. A. Matrix Infrared Spectroscopic Evidence for "End-on" Bonded Dinitrogen in Nickel Monodinitrogen, $\mathrm{NiN}_{2}$, and its Relationship to Dinitrogen Chemisorbed on Nickel. J. Chem. Phys. 1973, 58, 1251-1252.

(158) Andrews, L.; Davis, S. R. FTIR Observation of $\mathrm{N} \equiv \mathrm{N}$ Stretching Fundamentals in Hydrogen-Bonded Complexes in Solid Argon. J. Chem. Phys. 1985, 83, 4983-4989.

(159) Coussan, S.; Loutellier, A.; Perchard, J. P.; Racine, S.; Bouteiller, Y. Matrix Isolation Infrared Spectroscopy and DFT Calculations of Complexes between Water and Nitrogen. J. Mol. Struct. 1998, 471, 37-47.

(160) Miessner, H.; Richter, K. Well-Defined Surface-Bonded Ruthenium Complexes with Molecular Nitrogen. Angew. Chem., Int. Ed. 1998, 37, 117-119.

(161) Miessner, H.; Richter, K. Well-Defined Carbonyl and Dinitrogen Complexes of Ruthenium Supported on Dealuminated Y Zeolite. Analogies and Differences to the Homogeneous Case. J. Mol. Catal. A: Chem. 1999, 146, 107-115.

(162) Miessner, H. Surface-Chemistry in a Zeolite Matrix - WellDefined Dinitrogen Complexes of Rhodium Supported on Dealuminated Y-Zeolite. J. Am. Chem. Soc. 1994, 116, 11522-11530.

(163) Klotzbücher, W. E.; Ozin, G. A. Binary Mixed Dinitrogen Dioxygen Complexes of Nickel $\left(\mathrm{N}_{2}\right) \mathrm{Ni}\left(\mathrm{O}_{2}\right)$ and $\left(\mathrm{N}_{2}\right)_{2} \mathrm{Ni}\left(\mathrm{O}_{2}\right)$. J. Am. Chem. Soc. 1973, 95, 3790-3792.

(164) Ozin, G. A.; Klotzbücher, W. E. Binary Mixed Dioxygen Dinitrogen Complexes of Nickel, Palladium and Platinum, $\left(\mathrm{O}_{2}\right) \mathrm{M}$ $\left(\mathrm{N}_{2}\right)_{n}$ (Where $\mathrm{M}=\mathrm{Ni}, \mathrm{Pd}, \mathrm{Pt}$ and $n=1$ or 2). J. Am. Chem. Soc. 1975, 97, 3965-3974.

(165) Foosnaes, T.; Pellin, M. J.; Gruen, D. M. Photochemical Formation and Dissociation of Molybdenum-Dinitrogen Complexes in Krypton Matrices. J. Chem. Phys. 1983, 78, 2889-2898.

(166) DeKock, C. W.; Gruen, D. M. Electronic Absorption Spectra of Gaseous $\mathrm{NiCl}_{2}, \mathrm{NiBr}_{2}$, and $\mathrm{NiI}_{2}$. Axial Ligand Field Calculations Including Spin-Orbit Coupling. J. Chem. Phys. 1967, 46, 1096-1105.

(167) Deeth, R. J. Impact on Ligand-Field Theory of the Real Ground-State for $\mathrm{CuCl}_{2}$. J. Chem. Soc., Dalton Trans. 1993, 10611064.

(168) Bridgeman, A. J. On the Electronic Structures and Spectra of $\mathrm{NiCl}_{2}$ and $\mathrm{CuCl}_{2}$. J. Chem. Soc., Dalton Trans. 1996, 2601-2607.

(169) Kosugi, N.; Yokoyama, T.; Kuroda, H. Polarization Dependence of XANES of Square-Planar $\left[\mathrm{Ni}(\mathrm{CN})_{4}\right]^{2-}$ Ion - a Comparison with Octahedral $\left[\mathrm{Fe}(\mathrm{CN})_{6}\right]^{4-}$ and $\left[\mathrm{Fe}(\mathrm{CN})_{6}\right]^{3-}$ Ions. Chem. Phys. 1986, 104, 449-453.

(170) Kosugi, N. Molecular Inner-Shell Spectroscopy of Planar Ni Complexes. J. Electron Spectrosc. Relat. Phenom. 1998, 92, 151-157.

(171) Hatsui, T.; Takata, Y.; Kosugi, N. Strong Metal-to-Ligand Charge Transfer Bands Observed in Ni K- and L-edge XANES of Planar Ni Complexes. J. Synchrotron Radiat. 1999, 6, 376-378. 
(172) Hatsui, T.; Takata, Y.; Kosugi, N. Polarized Ni K- and L-edge and $\mathrm{S}$ K-edge XANES Study of $\left[\mathrm{Ni}(\mathrm{III})(\mathrm{mnt})_{2}\right]^{-}$. J. Synchrotron Radiat. 1999, 6, 379-380.

(173) Venables, J. A.; English, C. A. X-ray Structure of $\alpha-\mathrm{N}_{2}$. Acta Crystallogr., Sect. B: Struct. Crystallogr. Cryst. Chem. 1974, 30, 929-935.

(174) Waterman, R.; Hillhouse, G. L. Synthesis and Structure of a Terminal Dinitrogen Complex of Nickel. Can. J. Chem. 2005, 83, 328331.

(175) Cammarota, R. C.; Lu, C. C. Tuning Nickel with Lewis Acidic Group 13 Metalloligands for Catalytic Olefin Hydrogenation. J. Am. Chem. Soc. 2015, 137, 12486-12489.

(176) Harman, W. H.; Lin, T.-P.; Peters, J. C. A d ${ }^{10} \mathrm{Ni}-\left(\mathrm{H}_{2}\right)$ Adduct as an Intermediate in $\mathrm{H}-\mathrm{H}$ Oxidative Addition across a Ni-B Bond. Angew. Chem., Int. Ed. 2014, 53, 1081-1086.

(177) Connelly, S. J.; Zimmerman, A. C.; Kaminsky, W.; Heinekey, D. M. Synthesis, Structure, and Reactivity of a Nickel Dihydrogen Complex. Chem. - Eur. J. 2012, 18, 15932-15934.

(178) Tsay, C.; Peters, J. C. Thermally Stable $\mathrm{N}_{2}$ and $\mathrm{H}_{2}$ Adducts of Cationic Nickel(II). Chem. Sci. 2012, 3, 1313-1318.

(179) Zhu, D.; Thapa, I.; Korobkov, I.; Gambarotta, S.; Budzelaar, P. H. M. Redox-Active Ligands and Organic Radical Chemistry. Inorg. Chem. 2011, 50, 9879-9887.

(180) Cowie, B. E.; Emslie, D. J. H. Nickel and Palladium Complexes of Ferrocene-Backbone Bisphosphine-Borane and Trisphosphine Ligands. Organometallics 2015, 34, 4093-4101.

(181) Kim, Y.-E.; Oh, S.; Kim, S.; Kim, O.; Kim, J.; Han, S. W.; Lee, Y. Phosphinite-Ni(0) Mediated Formation of a Phosphide-Ni(II)OCOOMe Species via Uncommon Metal-Ligand Cooperation. J. Am. Chem. Soc. 2015, 137, 4280-4283.

(182) Charboneau, D. J.; Balcells, D.; Hazari, N.; Lant, H. M. C.; Mayer, J. M.; Melvin, P. R.; Mercado, B. Q.; Morris, W. D.; Repisky, M.; Suh, H.-W. Dinitrogen-Facilitated Reversible Formation of a Si-H Bond in a Pincer-Supported Ni Complex. Organometallics 2016, 35, 3154-3162.

(183) Oh, S.; Kim, S.; Lee, D.; Gwak, J.; Lee, Y. Alkoxide Migration at a Nickel(II) Center Induced by a $\pi$-Acidic Ligand: Migratory Insertion versus Metal-Ligand Cooperation. Inorg. Chem. 2016, 55, 12863-12871.

(184) Pfirrmann, S.; Limberg, C.; Herwig, C.; Stößer, R.; Ziemer, B. A Dinuclear Nickel(I) Dinitrogen Complex and its Reduction in Single-Electron Steps. Angew. Chem., Int. Ed. 2009, 48, 3357-3361.

(185) Hastie, J. W.; Hauge, R. H.; Margrave, J. L. Vibrational Frequencies and Valence Force Constants of First-Row TransitionMetal Di-Fluorides. J. Chem. Soc. D 1969, 1452-1453.

(186) Clifton, J. R.; Gruen, D. M. Electronic Absorption and Fluorescence Spectra of Matrix-Isolated $\mathrm{CoCl}_{2}$ Molecules. Appl. Spectrosc. 1970, 24, 53-59.

(187) Leroi, G. E.; James, T. C.; Hougen, J. T.; Klemperer, W. J. Infrared Spectra of Gaseous Transition Metal Dihalides. J. Chem. Phys. 1962, 36, 2879-2883.

(188) Hargittai, M.; Dorofeeva, O. V.; Tremmel, J. Molecular Structure of Monomeric Cobalt Dibromide with Some Information on the Structure of the Dimer from Electron Diffraction. Inorg. Chem. $1985,24,245-246$.

(189) Hougen, J. T.; Leroi, G. E.; James, T. C. Application of Ligand Field Theory to the Electronic Spectra of Gaseous $\mathrm{CuCl}_{2}, \mathrm{NiCl}_{2}$, and $\mathrm{CoCl}_{2}$. J. Chem. Phys. 1961, 34, 1670-1677.

(190) Gruen, D. M.; DeKock, C. W. Electronic Absorption Spectrum of $\mathrm{CsCoCl}_{3}$ Vapor. J. Chem. Phys. 1965, 43, 3395-3396.

(191) DeKock, C. W.; Gruen, D. M. Electronic Absorption Spectra of the Gaseous 3d Transition-Metal Dichlorides. J. Chem. Phys. 1966, 44, 4387-4398.

(192) Lever, A. B. P.; Hollebone, B. R. Electronic Spectra of Linear Transition Metal Dihalides. Theoretical Approach Involving GroundState-Energy Space Diagrams. Inorg. Chem. 1972, 11, 2183-2189.

(193) Bridgeman, A. J. Bonding in the Monochlorides and Dichlorides of Iron and Cobalt. J. Chem. Soc., Dalton Trans. 1997, 4765-4771.
(194) Rooms, J. F.; Wilson, A. V.; Harvey, I.; Bridgeman, A. J.; Young, N. A. Mercury-Fluorine Interactions: a Matrix Isolation Investigation of $\mathrm{Hg} \cdots \mathrm{F}_{2}, \mathrm{HgF}_{2}$ and $\mathrm{HgF}_{4}$ in Argon Matrices. Phys. Chem. Chem. Phys. 2008, 10, 4594-4605.

(195) Suess, D. L. M.; Tsay, C.; Peters, J. C. Dihydrogen Binding to Isostructural $S=1 / 2$ and $S=0$ Cobalt Complexes. J. Am. Chem. Soc. 2012, 134, 14158-14164.

(196) Del Castillo, T. J.; Thompson, N. B.; Suess, D. L. M.; Ung, G.; Peters, J. C. Evaluating Molecular Cobalt Complexes for the Conversion of $\mathrm{N}_{2}$ to $\mathrm{NH}_{3}$. Inorg. Chem. 2015, 54, 9256-9262.

(197) Frey, R. A.; Werder, R. D.; Günthard, H. H. Far Infrared Matrix Spectra of Iron Chlorides $\mathrm{Fe}_{2} \mathrm{Cl}_{6}, \mathrm{FeCl}_{3}, \mathrm{Fe}_{2} \mathrm{Cl}_{4}$, and $\mathrm{FeCl}_{2}$. J. Mol. Spectrosc. 1970, 35, 260-284.

(198) Loewenschuss, A.; Givan, A. Matrix-Isolation Raman-Spectra of $\mathrm{FeCl}_{3}$ And $\mathrm{Fe}_{2} \mathrm{Cl}_{6}$. Ber. Bunsenges. Phys. Chem. 1978, 82, 75-76.

(199) McNab, T. K.; Carstens, D. H. W.; Gruen, D. M.; McBeth, R. L. Nuclear Gamma Resonance Studies on Matrix Isolated $\mathrm{FeCl}_{2}$ Molecules at $4.2 \mathrm{~K}$. Chem. Phys. Lett. 1972, 13, 600-601.

(200) Litterst, F. J.; Schichl, A.; Kalvius, G. M. Mossbauer $\left({ }^{57} \mathrm{Fe}\right)$ Study Of Rare-Gas Matrix-Isolated $\mathrm{FeCl}_{2}, \mathrm{FeBr}_{2}$, and $\mathrm{Fe}_{2} \mathrm{Cl}_{6}$. Chem. Phys. 1978, 28, 89-95.

(201) Litterst, F. J.; Schichl, A.; Baggio-Saitovitch, E.; Micklitz, H.; Friedt, J. M. Mossbauer Studies Of Rare-Gas Matrix-Isolated Halide Molecules Containing Fe-57, Sn-119, And Eu-151. Ber. Bunsenges. Phys. Chem. 1978, 82, 73-75.

(202) Varga, Z.; Kolonits, M.; Hargittai, M. Gas-Phase Structures of Iron Trihalides: A Computational Study of all Iron Trihalides and an Electron Diffraction Study of Iron Trichloride. Inorg. Chem. 2010, 49, $1039-1045$

(203) Givan, A.; Loewenschuss, A. Matrix Isolation Raman Spectra of Iron Trichloride and Diiron Hexachloride. J. Raman Spectrosc. 1977, 6, $84-88$.

(204) Zhang, F.; Xu, X.; Zhao, Y.; Jia, J.; Tung, C.-H.; Wang, W. Solvent Effects on Hydride Transfer from $\mathrm{Cp} *(\mathrm{P}-\mathrm{P}) \mathrm{FeH}$ to $\mathrm{BNA}^{+}$ Cation. Organometallics 2017, 36, 1238-1244.

(205) Komiya, S.; Akita, M.; Yoza, A.; Kasuga, N.; Fukuoka, A.; Kai, Y. Isolation of a zerovalent iron dinitrogen complex with 1,2bis(diethylphosphino)ethane ligands. J. Chem. Soc., Chem. Commun. 1993, 787-788.

(206) Doyle, L. R.; Hill, P. J.; Wildgoose, G. G.; Ashley, A. E. Teaching Old Compounds New Tricks: Efficient $\mathrm{N}_{2}$ Fixation by Simple $\mathrm{Fe}\left(\mathrm{N}_{2}\right)$ (diphosphine) ${ }_{2}$ Complexes. Dalton Trans. 2016, 45, $7550-7554$

(207) Kasai, P. H.; Whipple, E. B.; Weltner, W. ESR of $\mathrm{Cu}\left(\mathrm{NO}_{3}\right)_{2}$ and $\mathrm{CuF}_{2}$ Oriented in Neon and Argon Matrices at $4 \mathrm{~K}$. J. Chem. Phys. 1966, 44, 2581-2591.

(208) Lorenz, M.; Caspary, N.; Foeller, W.; Agreiter, J.; Smith, A. M.; Bondybey, V. E. Electronic Structure of Triatomic Copper(II) Chloride. Mol. Phys. 1997, 91, 483-493.

(209) Lorenz, M.; Smith, A. M.; Bondybey, V. E. Electronic Structure and Spectroscopy of Copper Dichloride. J. Chem. Phys. 2001, 115, $8251-8252$.

(210) Lorenz, M.; Bondybey, V. E. Electronic and Vibrational Structure of Copper Dibromide. J. Phys. Chem. A 2002, 106, 54295436.

(211) Jacox, M. E. Comparison of the Ground-State Vibrational Fundamentals of Diatomic Molecules in the Gas Phase and in Inert Solid Matrices. J. Mol. Spectrosc. 1985, 113, 286-301.

(212) Ystenes, B. K.; Jensen, V. R. Soft Bending Modes of Terminal Chlorides in Gaseous Two and Three-coordinate $\mathrm{Cu}(\mathrm{II})-\mathrm{Cl}$ species. Inorg. Chem. 1999, 38, 3985-3993.

(213) Pimentel, G. C.; Charles, S. W. Infrared Spectral Perturbations in Matrix Experiments. Pure Appl. Chem. 1963, 7, 111-123.

(214) Yates, J. T.; Haller, G. L. Interaction of Physisorbed Species with Chemisorbed Species as Studied by Infrared-Spectroscopy. J. Phys. Chem. 1984, 88, 4660-4664.

(215) Gustafsson, K.; Karlberg, G. S.; Andersson, S. Infrared Spectroscopy of Physisorbed and Chemisorbed $\mathrm{N}_{2}$ in the Pt(111)(3 $\times 3) \mathrm{N}_{2}$ structure. J. Chem. Phys. 2007, 127, 194708. 
(216) Brubaker, M. E.; Trenary, M. Adsorbate Ordering Processes and Infrared-Spectroscopy - an FT- IRAS Study of $\mathrm{N}_{2}$ Chemisorbed on the Ni (110) Surface. J. Chem. Phys. 1986, 85, 6100-6109.

(217) Wang, H. P.; Yates, J. T. Infrared Spectroscopic Study of $\mathrm{N}_{2}$ Chemisorption on Rhodium Surfaces. J. Phys. Chem. 1984, 88, 852856.

(218) Pei, Z.; Fang, T. H.; Worley, S. D. An Infrared Study of the Interaction of Dinitrogen with Dihydrogen over Supported Rhodium Films. J. Phys. Chem. 1995, 99, 3663-3670.

(219) Pei, Z.; Fang, T. H.; Worley, S. D. An Infrared Study of Support Effects on the Interaction of Dihydrogen and Dinitrogen with Supported Rhodium Films. Colloids Surf., A 1995, 105, 79-86.

(220) Neyman, K. M.; Strodel, P.; Ruzankin, S. P.; Schlensog, N.; Knözinger, $\mathrm{H}_{\text {.; }}$ Rösch, N. $\mathrm{N}_{2}$ and CO Molecules as Probes of Zeolite Acidity: an Infrared Spectroscopy and Density Functional Investigation. Catal. Lett. 1995, 31, 273-285.

(221) Brubaker, M. E.; Malik, I. J.; Trenary, M. Time-Dependence of the Infrared Spectrum of $\mathrm{N}_{2}$ Adsorbed at Low Coverage on the Ni(110) Surface. J. Vac. Sci. Technol., A 1987, 5, 427-430.

(222) Franchy, R.; Bartke, T. U. The Adsorption of $\mathrm{N}_{2}$ on $\mathrm{Nb}(110)$ at 80 and 20 K. Surf. Sci. 1995, 322, 95-102.

(223) Shi, H.; Jacobi, K. Evidence for Physisorbed $\mathrm{N}_{2}$ in the Monolayer on $\mathrm{Ru}(001)$ at $40 \mathrm{~K}$. Surf. Sci. 1992, 278, 281-285.

(224) Jacobi, K.; Bertolo, M. Physisorption of $\mathrm{CO}$ and $\mathrm{N}_{2}$ on $\mathrm{Al}(111)$ : Observation of surface-molecule vibrations in electron resonance scattering. Phys. Rev. B: Condens. Matter Mater. Phys. 1990, 42, 3733-3736.

(225) Bertolo, M.; Jacobi, K. Adsorption of $\mathrm{N}_{2}$ on the $\operatorname{Pd}(111)$ Surface at $20 \mathrm{~K} 0.1$. Chemisorption and Physisorption in the Monolayer. Surf. Sci. 1992, 265, 1-11.

(226) Wilde, L.; Pangher, N.; Haase, J. Structure Determination of $\mathrm{Ni}(110)-(2 \times 3)-\mathrm{N}$ by Use of SEXAFS Measurements on Surface and Subsurface Sites on a Pseudo-(100) Reconstructed Surface. Surf. Sci. 1994, 316, L1093-L1098.

(227) Lubezky, A.; Kozirovski, Y.; Folman, M. Induced IR-Spectra of $\mathrm{N}_{2}$ and $\mathrm{O}_{2}$ Adsorbed on Evaporated-Films of Ionic-Crystals. J. Phys. Chem. 1993, 97, 1050-1054.

(228) Lubezky, A.; Kozirovski, Y.; Folman, M. IR Spectral Shifts and Adsorption Potentials of $\mathrm{CO}$ and $\mathrm{N}_{2}$ adsorbed on LiF and LiCl. J. Electron Spectrosc. Relat. Phenom. 1998, 95, 37-44.

(229) Boganov, S. E.; Faustov, V. I.; Egorov, M. P.; Nefedov, O. M. Matrix IR-Spectroscopic and Quantum-Chemical Study of Difluorostannylene Complexation with Dinitrogen. Russ. Chem. Bull. 1998, 47, 1054-1060.

(230) Fletcher, D. A.; McMeeking, R. F.; Parkin, D. The United Kingdom Chemical Database Service. J. Chem. Inf. Comput. Sci. 1996, 36, 746-749. 